\title{
FACULDADE DE MEDICINA DA UNIVERSIDADE DE SÃO PAULO
} FISIOPATOLOGIA EXPERIMENTAL

\author{
FERNANDO DOS SANTOS
}

Curso temporal das alterações autonômicas e metabólicas da hipertensão por sobrecarga de frutose: papel do barorreflexo 



\section{FERNANDO DOS SANTOS}

Curso temporal das alterações autonômicas e metabólicas da hipertensão por sobrecarga de frutose: papel do barorreflexo

Tese apresentada à Faculdade de Medicina da Universidade de São Paulo para obtenção do título de Doutor em Ciências

Programa de Fisiopatologia Experimental

Orientadora: Prof. ${ }^{a}$ Dr. ${ }^{-}$Maria Claudia Costa Irigoyen 
Autorizo a reprodução e divulgação total ou parcial deste trabalho, por qualquer meio convencional ou eletrônico, para fins de estudo e pesquisa, desde que citada a fonte.

\section{Dados Internacionais de Catalogação na Publicação (CIP)}

Preparada pela Biblioteca da

Faculdade de Medicina da Universidade de São Paulo

Creprodução autorizada pelo autor

Santos, Fernando dos

Curso temporal das alterações autonômicas e metabólicas da hipertensão por sobrecarga de frutose: papel do barorreflexo / Fernando dos Santos. -São Paulo, 2015.

Tese(doutorado)--Faculdade de Medicina da Universidade de São Paulo.

Programa de Fisiopatologia Experimental.

Orientadora: Maria Claudia Costa Irigoyen. 
Nome: SANTOS, Fernando dos

Título: Curso temporal das alterações autonômicas e metabólicas da hipertensão por sobrecarga de frutose: papel do barorreflexo

Tese apresentada à Faculdade de Medicina da Universidade de São Paulo para obtenção do título de Doutor em Ciências

Aprovado em:

Banca Examinadora

Prof. Dr. Instituição:

Julgamento: Assinatura:

Prof. Dr. Instituição:

Julgamento: Assinatura:

Prof. Dr. Instituição: Julgamento: Assinatura: 

Este trabalho é Dedico este trabalho à minha família, em especial aos meus pais, Marcos e Ivone, e meu irmão Vinicius, que me ensinaram todo o necessário para que chegasse até aqui, fizeram de mim a pessoa que sou hoje e que sem eles nada seria possível. 

Agradeço à Faculdade de Medicina da Universidade de São Paulo pela oportunidade de aprendizado quem me proporcionou.

Obrigado ao laboratório de fisiologia de Hipertensão experimental do Instituto do Coração, por contribuir com meu crescimento profissional.

À professora Dr. ․ Maria Claudia Irigoyen por todas as horas de discussões e ensinamentos ao longo destes últimos oito anos da minha vida, o meu muito obrigado.

Agradeço à Cynthia Rodrigues Muller por estar ao meu lado sempre apoiando nos momentos mais difíceis e sendo o motivo de eu sempre seguir em frente.

Em especial aos professores, alunos, amigos e companheiros de trabalho por estarmos sempre aprendendo e caminhando juntos em busca da evolução pessoal, obrigado! 

"O mais competente não discute, domina a sua ciência e cala-se." Voltaire 



\section{Resumo}

Santos F. Curso temporal das alterações autonômicas e metabólicas da hipertensão por sobrecarga de frutose: papel do barorreflexo [Tese]. São Paulo: Faculdade de Medicina, Universidade de São Paulo; 2015.

O aumento do consumo de frutose nas últimas décadas está intimamente associado à maior incidência de obesidade e síndrome metabólica e co-morbidades associadas, como, a dislipidemia, a disautonomia e o diabetes. No entanto, a literatura não apresenta caracterização temporal dos eventos que ocorrem até o estabelecimento das doenças. Com base nisso, este trabalho tem como objetivo avaliar as alterações temporais autônomicas e metabólicas em modelo de síndrome metabólica induzida por sobrecarga de frutose, com ênfase no papel do barorreflexo, aqui testado pelo uso da desnervação sinoaórtica. Adicionalmente, pretende-se identificar neste modelo, se as alterações autonômicas precedem ou se seguem às alterações metabólicas. Foram utilizados quatro grupos experimentais (ratos), seguidos por 90 dias: controle $(C)$, tratados com frutose $(F)$, controle desnervado (D) e desnervados tratados com frutose (DF). A sobrecarga de frutose foi feita através de solução em água de beber (10\%). A avaliação dos parâmetros cardiovasculares ocorreu pelo registro da pressão arterial via radiotelemetria durante 13 semanas. A frutose foi capaz de promover desenvolvimento de síndrome metabólica, causando aumento da pressão arterial, glicemia de jejum, gordura abdominal e do perfil lipídico em média a partir da sétima semana de tratamento. As alterações autonômicas, principalmente aumento da modulação cardíaca e periférica simpática, ocorreram já na segunda semana de protocolo. Este grupo apresentou ainda alterações de função renal e inflamação. O barorreflexo parece participar das alterações induzidas 
pela frutose durante o desenvolvimento da síndrome metabólica, uma vez que sua ausência determina mudanças em vários dos parâmetros metabólicos além dos hemodinâmicos já esperados. Adicionalmente, no grupo frutose, o prejuízo funcional do controle reflexo da circulação se estabelece mais tardiamente. Com base em nossos resultados podemos concluir que as alterações no controle autonômico são anteriores e provavelmente contribuem para as alterações metabólicas causadas pelo consumo excessivo de frutose.

Descritores: doenças do sistema nervoso autônomo; síndrome X metabólica; inflamação; pressão sanguínea; frutose; sistema nervoso simpático; barorreflexo. 


\section{Abstract}

Santos F. Temporal development of autonomic and metabolic alterations of hypertension by fructose overload [Thesis]. São Paulo: "Faculdade de Medicina, Universidade de São Paulo"; 2015.

The increased consumption of fructose in recent decades is closely associated with the higher incidence of obesity, metabolic syndrome and associated comorbidities, such as Dyslipidemia, Dysautonomia, and diabetes. However, the literature does not present temporal characterization of the events that occur until the establishment of the diseases. On this basis, this work aims to evaluate the temporal autonomic and metabolic changes in metabolic syndrome model induced by fructose overload, with emphasis on the role of the baroreflex, here tested using sinoaortic denervation. Additionally, we intend to identify in this model, if autonomic changes precede or follow the metabolic changes. Four experimental groups were used (rats), followed by 90 days: control $(C)$, treated with fructose $(F)$, sinoaortic denervated (D) and denervated treated with fructose (DF). Fructose overload was performed using drinking water solution (10\%). Blood pressure recording was performed via radio telemetry for 13 weeks. Fructose was able to promote development of metabolic syndrome, causing blood pressure, fasting blood glucose and abdominal fat increase and changing lipid profile (from the seventh week to thirteenth week of treatment). Autonomic changes, characterized by increased cardiac and peripheral sympathetic modulation, occurred in the second week of Protocol. Fructose group presented changes of renal function and inflammation. The baroreflex seems to participate in the changes induced by fructose during the development of the metabolic syndrome, 
since his absence determines changes in various metabolic parameters in addition to the expected hemodynamic. Additionally, fructose treatment induced late functional impairment of blood pressure reflex control. Based on our results we can conclude that the changes in autonomic control precede and probably contribute to the metabolic changes induced by the excessive consumption of fructose.

Descriptors: autonomic nervous system diseases; metabolic syndrome X; inflammation; blood pressure; fructose; sympathetic nervous system; baroreflex. 


\section{Relação de figuras}

Figura 1: Modelo de desnervação sino-aórtica............................................... 30

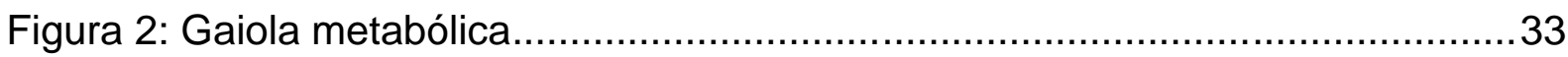

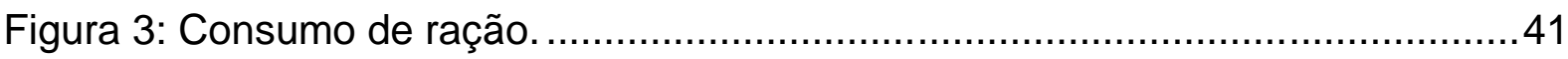

Figura 4: Consumo médio de ração ao longo de 13 semanas. ............................42

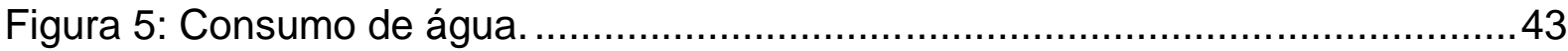

Figura 6: Consumo médio de água ao longo de 13 semanas. ............................43

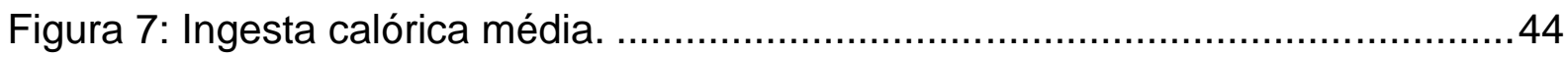

Figura 8: Peso corporal ao longo de 13 semanas de protocolo. .............................45

Figura 9: Ganho total de peso corporal. ................................................ 46

Figura 10: Ganho de peso semanal. ..................................................... 47

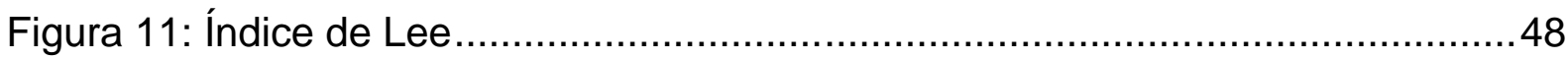

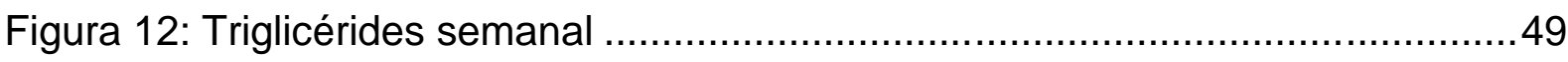

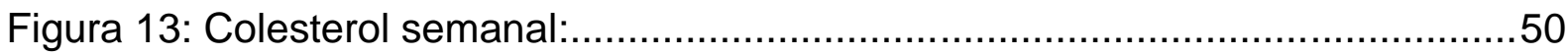

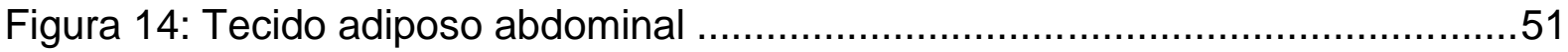

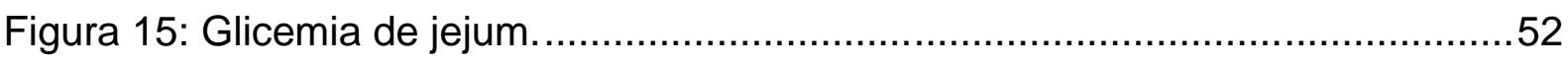

Figura 16: Índice de sensibilidade à insulina............................................53

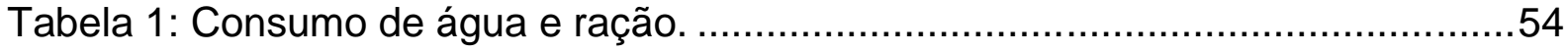

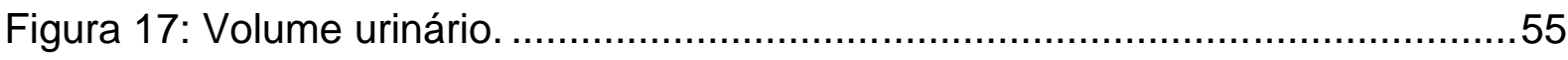

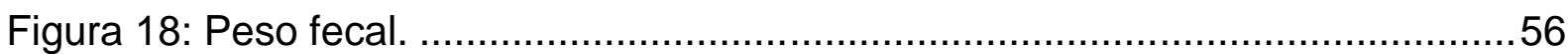

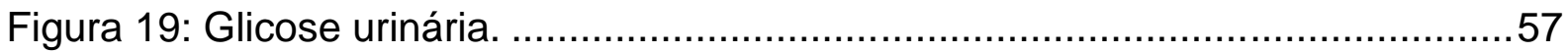


Figura 20: Lactato urinário .58

Figura 21: Osmolaridade urinária. Dosagem da osmolaridade ...............................59

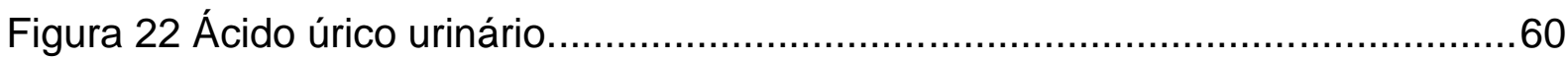

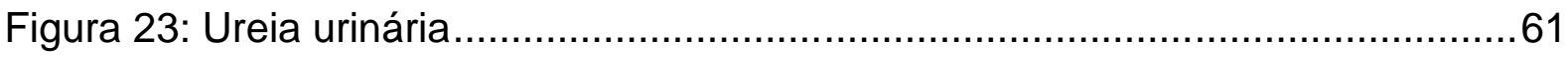

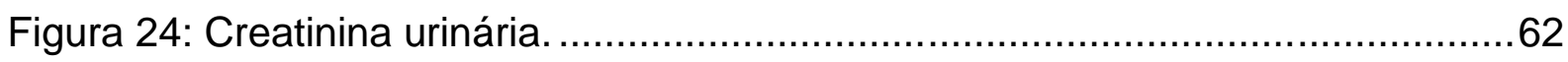

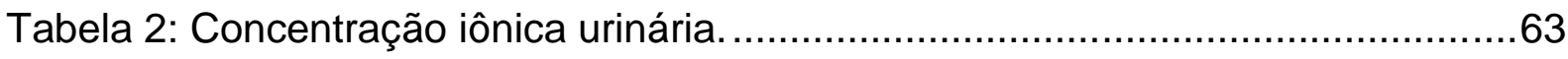

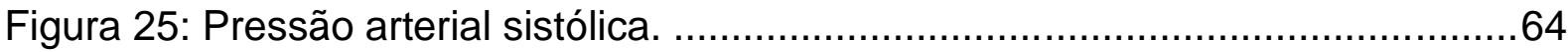

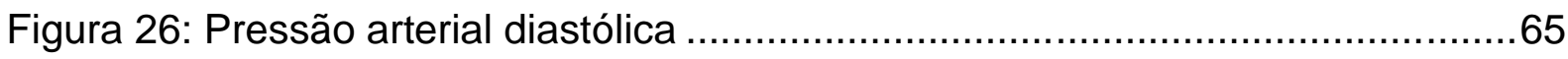

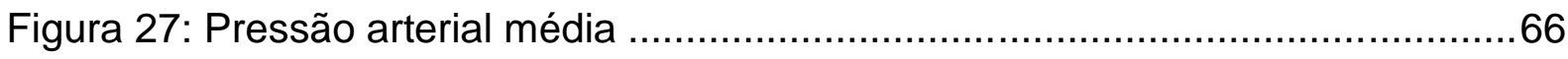

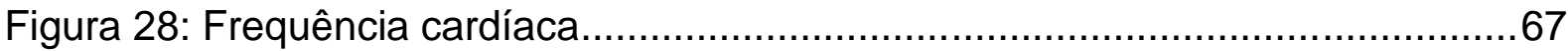

Figura 29: Variância do intervalo de pulso .......................................................6

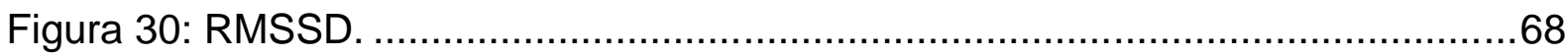

Figura 31: Modulação simpática cardíaca absoluta ...................................................69

Figura 32: Modulação parassimpática cardíaca absoluta .....................................70

Figura 33: Modulação simpática cardíaca percentual ..............................................71

Figura 34: Modulação parassimpática cardíaca percentual ...................................71

Figura 35: Modulação simpática cardíaca relativa …............................................72

Figura 36: Modulação parassimpática cardíaca relativa ...........................................73

Figura 37: Balanço simpato-vagal ......................................................................

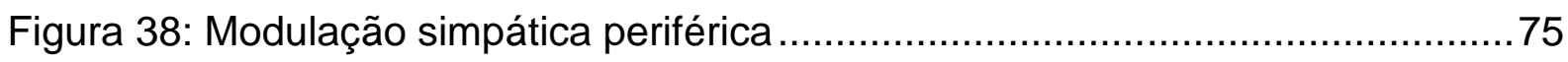

Figura 39: Variância da pressão arterial sistólica .................................................76

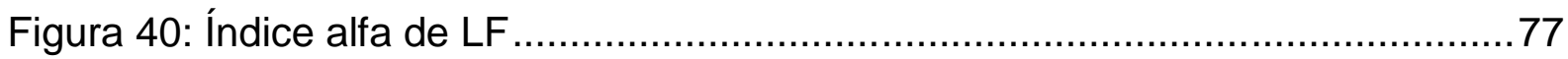




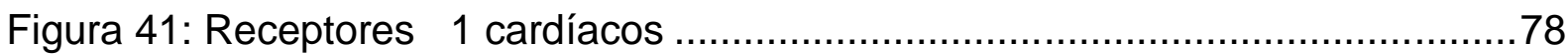

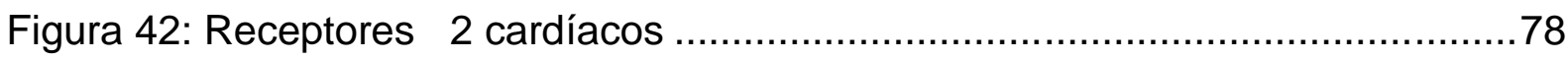

Figura 43: Receptor AT1 em medula renal........................................................79

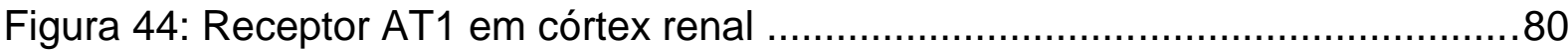

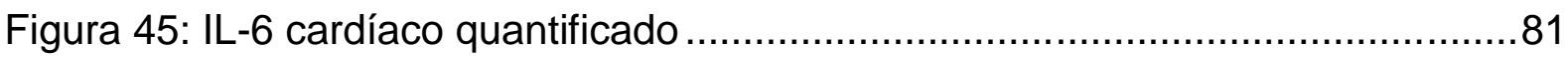

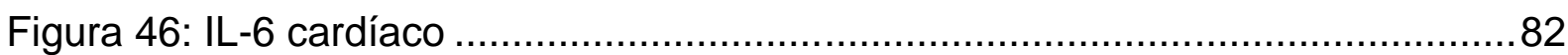

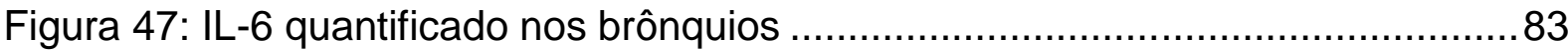

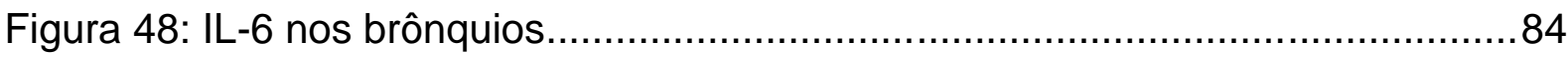

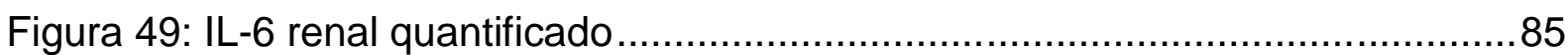

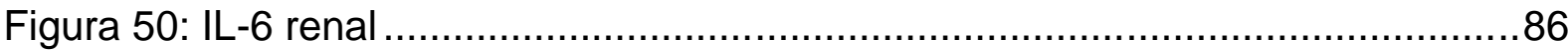

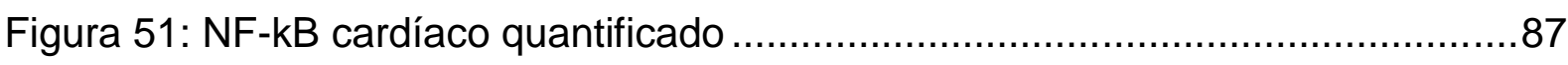

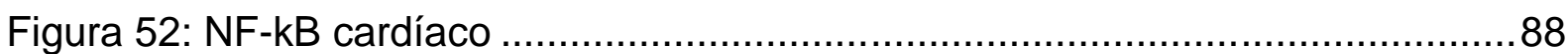

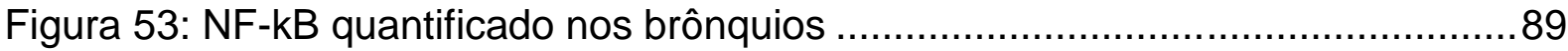

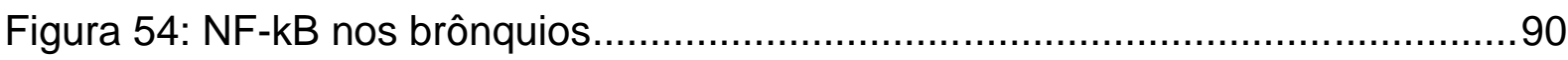

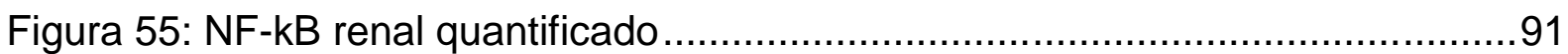

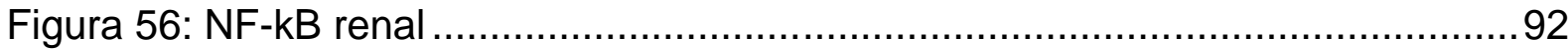

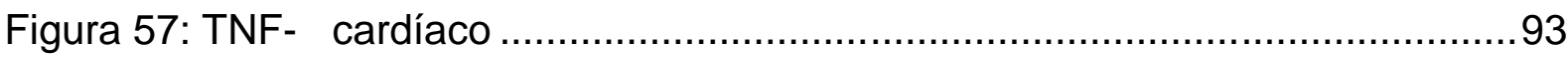

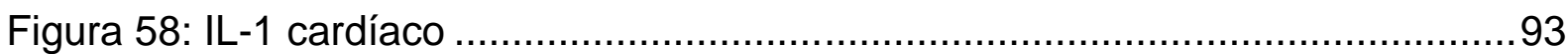

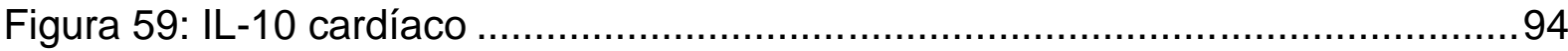

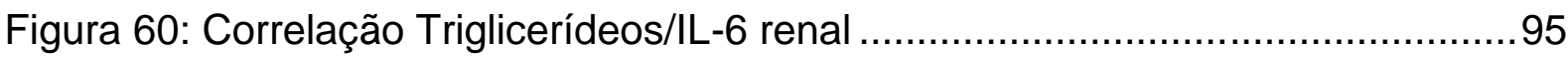

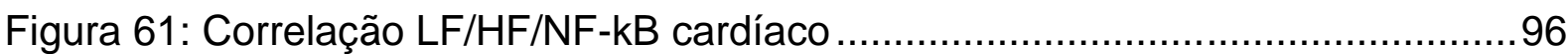

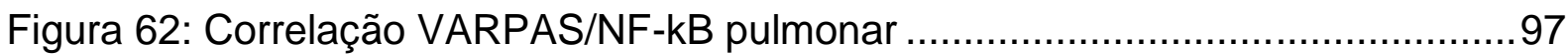





\section{Relação de tabelas}

Tabela 1: Consumo de água e ração. ..............................................................54

Tabela 2: Concentração iônica urinária.............................................................63

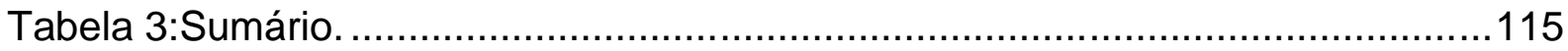





\section{Relação de abreviaturas}

\begin{tabular}{|c|c|}
\hline ANF & Fator Natriurético Atrial \\
\hline ANOVA & Análise de Variância \\
\hline AT1 & Receptor de Angiotensina II \\
\hline C & Grupo Controle \\
\hline $\mathrm{D}$ & Grupo Desnervado \\
\hline DF & Grupo Desnervado Frutose \\
\hline DSA & Desnervação sino-aórtica \\
\hline ELISA & Ensaio Imunoenzimático \\
\hline $\mathrm{F}$ & Grupo Frutose \\
\hline FC & Frequência Cardíaca \\
\hline FFT & Transformada Rápida de Fourier \\
\hline HF & Alta Frequência \\
\hline $\mathrm{IHQ}$ & Imunohistoquímica \\
\hline $\mathrm{IL}-1$ & Interleucina 1 \\
\hline IL-6 & Interleucina 6 \\
\hline IL-10 & Interleucina 10 \\
\hline Kitt & Constante do Teste de Tolerância à Insulina \\
\hline LF & Baixa Frequência \\
\hline MCP-1 & Proteína Quimiotática de Monócitos \\
\hline NF-kB & Fator Nuclear kappa B \\
\hline PA & Pressão Arterial \\
\hline PAD & Pressão Arterial Diastólica \\
\hline PAM & Pressão Arterial Média \\
\hline PAS & Pressão Arterial Sistólica \\
\hline RMSSD & $\begin{array}{l}\text { Raiz Quadrada da Soma das Diferenças Sucessivas entre Intervalos } \\
\text { RR }\end{array}$ \\
\hline SM & Síndrome Metabólica \\
\hline TNF- $\alpha$ & Fator de Necrose Tumoral alfa \\
\hline un & Unidades Normalizadas \\
\hline USP & Universidade de São Paulo \\
\hline VARIP & Variância do Intervalo de pulso \\
\hline VARPA & Variância da Pressão Arterial \\
\hline
\end{tabular}




$\begin{array}{ll}\text { VD } & \text { Ventrículo Direito } \\ \text { VE } & \text { Ventrículo Esquerdo } \\ \text { VFC } & \text { Variabilidade da Frequência Cardíaca } \\ \text { VIP } & \text { Variabilidade do Intervalo de Pulso } \\ \text { VLF } & \text { Muito Baixa Frequência } \\ \text { VPA } & \text { Variabilidade da Pressão Arterial }\end{array}$




\section{Conteúdo}

Resumo

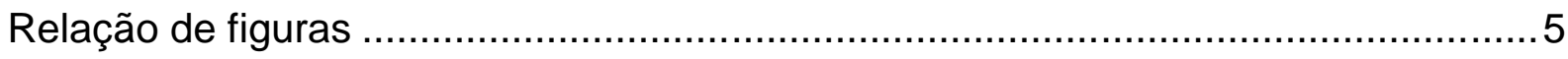

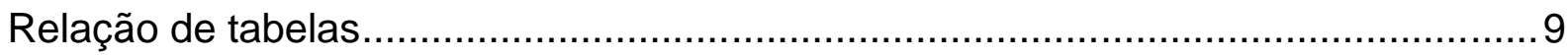

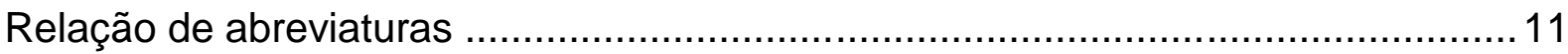

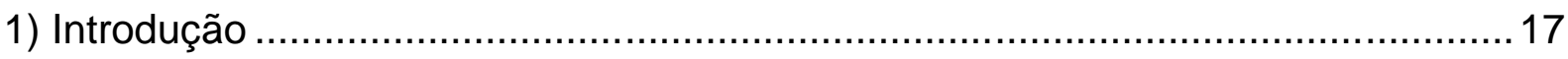

1.1) Consumo inadequado de frutose e risco cardiovascular ..........................17

1.2) Sistema nervoso autônomo e regulação cardiovascular .............................19

1.3) Interação entre alterações autonômicas e metabólicas diante do consumo

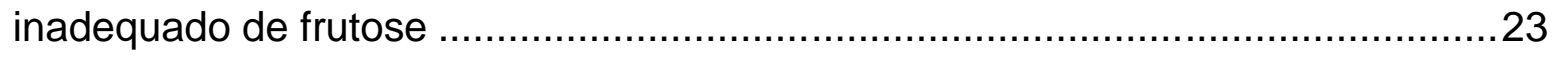

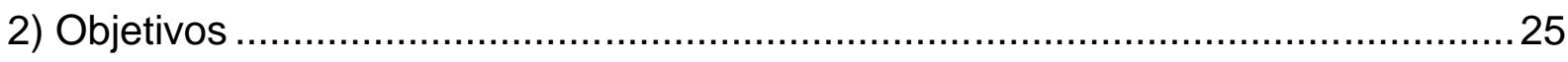

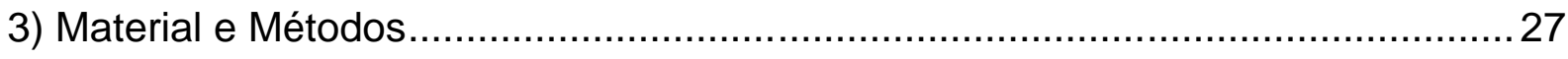

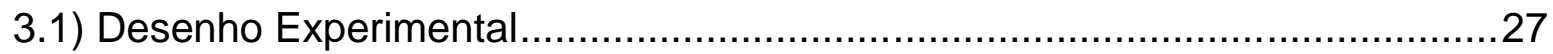

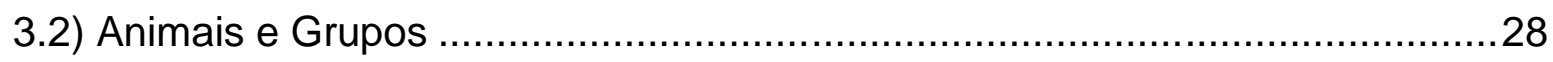

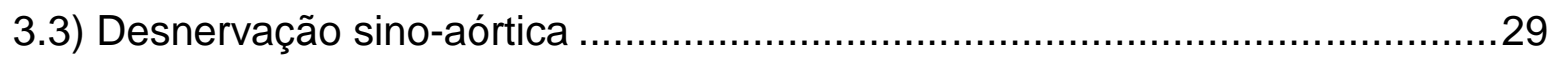

3.4) Indução do modelo experimental de síndrome metabólica ............................30

3.5) Monitoramento dos parâmetros cardiovasculares …...................................30

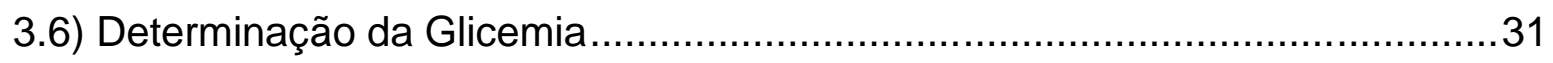

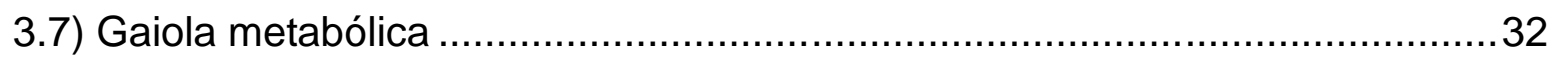


3.8) Variabilidade do intervalo de pulso e pressão arterial nos domínios do tempo e frequência.

3.9) Avaliações celulares e moleculares

3.9.1) Preparação Histológica .35

3.9.2) Imunohistoquímica (IHQ) .35

3.9.3) Avaliação de marcadores inflamatórios. 36

3.9.4) Western Blot. 36

3.9.5) Reação qRT-PCR

3.10) Análise estatística 39

4) Resultados 41

4.1) Consumo calórico e ganho de peso corporal.

4.2) Perfil lipídico e gordura corporal 48

4.3) Glicemia e resistência à insulina. 51

4.4) Gaiola metabólica .53

4.5) Avaliações hemodinâmicas .63

4.6) Análise de variabilidade da FC e da PAS 67

4.7) Receptores $\beta$-adrenérgicos. 77

4.8) Receptores AT1 renais 79

4.9) Avaliação de imunohistoquímica. .80 


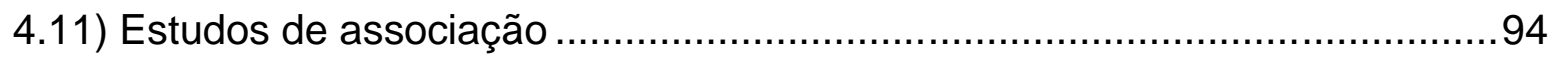

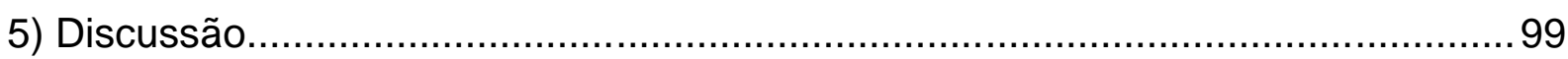

5.1) Barorreflexo e desenvolvimento de síndrome metabólica..........................99

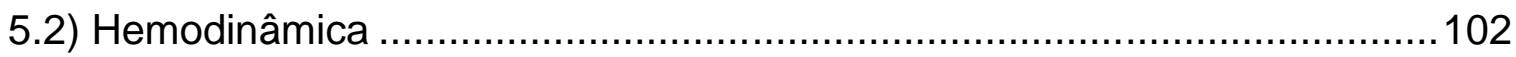

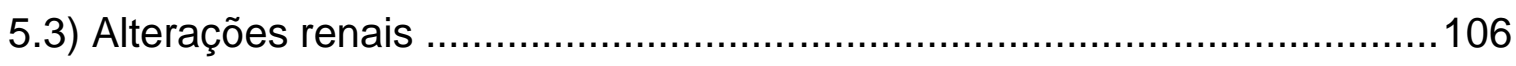

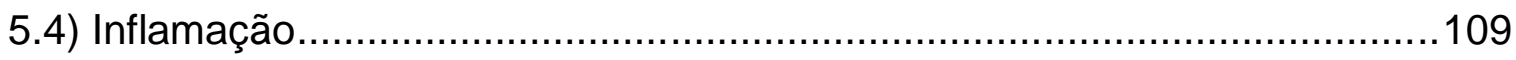

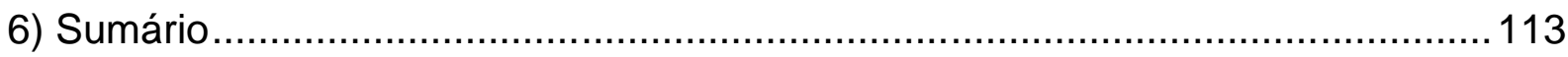

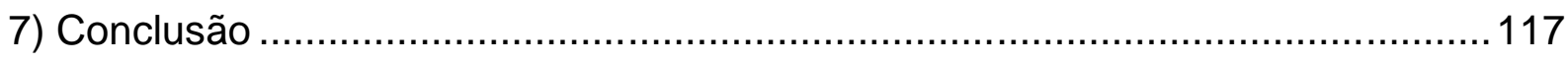

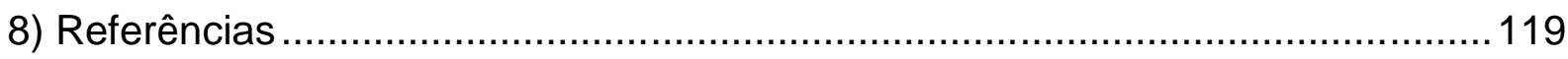




\section{1) Introdução}

\section{1) Consumo inadequado de frutose e risco cardiovascular}

Atualmente, uma das maiores causas de morte no mundo são as doenças cardiovasculares (OMS, 2013), cujos principais fatores de risco são: fumo, obesidade, hipertensão arterial, disposição hereditária, processos inflamatórios, inatividade física, má alimentação e diabetes (GUIMARAES \& CIOLAC, 2004). A associação desses fatores de risco geralmente está relacionada com alterações fisiológicas como deposição central de gordura, resistência à insulina, hipertensão arterial, dislipidemia, podendo caracterizar um quadro de Síndrome Metabólica (SM). Segundo Lopes (2006) e de acordo com a I Diretriz Brasileira de Diagnóstico e Tratamento da Síndrome Metabólica (2005) a obesidade central, a pressão arterial aumentada, o aumento de triglicérides, a glicemia de jejum alterada e baixos níveis de HDL- colesterol são os principais componentes para definir a SM. Adicionalmente, vários estudos correlacionaram a hiperinsulinemia e resistência à insulina com risco aumentado para aterosclerose (MCAULEY et al., 2013), hipertensão arterial, dislipidemias, cardiopatia isquêmica (BANERJEE et al., 2013), intolerância à glicose, obesidade abdominal e Diabetes Mellitus tipo 2 (ROCCHINI et al., 1989; DALY \& LANDSBERG, 1991). Dessa forma, observa-se que a SM engloba variáveis que aumentam o risco para as doenças cardiovasculares (LOPES \& EGAN, 2006).

A presença desta síndrome pode aumentar relativamente à mortalidade geral em 1,5 vezes e a cardiovascular em cerca de 2,5 vezes (I Diretriz Brasileira de 
Diagnóstico e Tratamento da Síndrome Metabólica, 2005) (LAKKA et al., 2002; GIRMAN et al., 2004).

Dentre os fatores que podem contribuir para o estabelecimento da SM estão os maus hábitos alimentares (CHANG et al., 2013), evidenciados pela maior popularização do fast-food, e maior consumo de calorias, especialmente de açúcar refinado e de frutose (RICHELSEN, 2013). A frutose é um importante carboidrato para os seres humanos e é encontrada em frutas, hortaliças, vegetais e no mel. Por ser 1,7 vezes mais doce do que a sacarose, ela vem sendo empregada pela indústria alimentícia para adoçar e dar gosto aos alimentos (BARREIROS et al., 2005).

Estudos em humanos verificaram que o consumo de frutose pode induzir ganho de peso, redução da sensibilidade à insulina, dislipidemia e aumento da pressão arterial (PA) (ELLIOTT et al., 2002; STANHOPE et al., 2015). Experimentalmente, um modelo simples para indução de SM é através de ração comercial rica em frutose (60\%) (HWANG et al., 1987) ou adicionando frutose na água de beber (10 a 20\%) (DAI \& MCNEILL, 1995). Animais que são tratados com frutose, independentemente da via de administração, apresentam distúrbios semelhantes aqueles encontrados na SM, como resistência à insulina, aumento dos triglicerídeos e da insulina plasmática e hipertensão (YOSHIDA et al., 2003; BRITO et al., 2008; ARAUJO et al., 2015).

Nesse contexto, nosso grupo tem trabalhado com animais tratados com frutose, demonstrando diversas alterações autonômicas, como menor atividade vagal e menor controle reflexo da pressão arterial (BRITO et al., 2008), aumento na concentração de catecolaminas e expressão de receptores adrenérgicos (MILLER et 
al., 1999; KAMIDE et al., 2002), metabólicas, bem como alterações na variabilidade da pressão arterial (VPA) e da frequência cardíaca (VFC) (FARAH, V. et al., 2006).

\section{2) Sistema nervoso autônomo e regulação cardiovascular}

Os mecanismos de regulação da PA estão intimamente integrados à principal finalidade da circulação, que é a de manter um fluxo sanguíneo adequado às necessidades do organismo (KRIEGER, 1976). A manutenção (componente tônico), e a variação momento a momento da PA (componente fásico) dependem desses mecanismos que determinam ajustes apropriados da frequência e contratilidade cardíacas, do estado contrátil dos vasos de resistência e de capacitância e da distribuição de fluído dentro e fora dos vasos (MICHELINI, 1999). O aumento da atividade simpática periférica na hipertensão tem sido atribuído a um aumento central do tônus simpático, mas também a um controle barorreflexo prejudicado e menos eficiente na inibição tônica da atividade simpática. De fato, tanto na hipertensão espontânea em ratos (THOREN, 1987), como na hipertensão humana (WALLIN, 1989), foi demonstrado um aumento da atividade simpática renal e muscular, respectivamente.

Sabe- se que a disfunção autonômica, também contribui de forma indireta com o aumento da PA, uma vez que o aumento da atividade simpática, através do receptor $\beta$-adrenérgico, no aparelho justaglomerular renal, medeia a liberação de 
renina que, por sua vez, atua de forma tecidual e sistêmica aumentando a angiotensina II (Ang II) (KALIL \& HAYNES, 2012).

A grande maioria das ações da Ang II nos sistemas cardiovascular e renal é mediada pelo receptor AT1 promovendo contração de músculo liso, secreção de aldosterona, reabsorção renal de sódio resultando no aumento da pressão arterial (CAREY \& SIRAGY, 2003). A Ang II também pode estar associada à inibição da sinalização intracelular de insulina (MORI et al., 2007), aumento do estresse oxidativo e, indução da inflamação via ativação do TNF- $\alpha$, NF-kB e IL-6 (MARCUS et al., 2013). Além disso, Navar (2000) cita a importância da ANG II na regulação da hemodinâmica renal, e descreve que a diminuição da função e suas alterações estruturais estão associadas com modificações importantes na concentração de Ang II intra-renal (NAVAR et al., 2000).

A influência mais rápida sobre esta regulação é dada pelo sistema nervoso, mais especificamente pelo sistema nervoso autônomo, agindo em diferentes níveis do sistema cardiovascular por atuações das eferências nervosas simpáticas e parassimpáticas, que por sua vez respondem a estímulos de receptores, mais especificamente os pressorreceptores arteriais, os quimiorreceptores arteriais e os receptores cardiopulmonares (ABBOUD; \& THAMES; 1983).

Os barorreceptores são mecanorreceptores constituídos por terminações livres sensíveis às deformações da parede vascular, localizados principalmente na crossa da aorta e no sino carotídeo (KRIEGER, 1964). Eles também exercem controle tônico, inibindo a atividade simpática e estimulando a parassimpática, sendo capazes de se adaptarem a novos valores de PA, seja na hipertensão ou hipotensão (MCCUBBIN et al., 1956; KRIEGER, 1970). Portanto, o comprometimento da função 
dos pressorreceptores, resultando em uma inadequada modulação da atividade simpática e parassimpática, poderia possibilitar alterações primárias de outros mecanismos de controle da função cardiovascular (IRIGOYEN et al., 1995).

A ação e a importância dos pressorreceptores podem ser evidenciadas através da desnervação sino-aórtica (DSA), descrita em ratos por Krieger (1964), e que consiste na remoção cirúrgica das fibras aferentes dos pressorreceptores aórticos e carotídeos. Este procedimento resulta em uma acentuada labilidade da PA, com aumento pressórico na fase aguda e volta aos valores de normalidade na fase crônica. A desnervação aórtica isolada, mantendo intactos os aferentes carotídeos, pode produzir aumento sustentado da PA em ratos (KRIEGER, 1970; FRANCHINI \& KRIEGER, 1992) acompanhado de aumento da VPA, taquicardia e hiperatividade simpática (IRIGOYEN et al., 1988). Em contraste, a desnervação carotídea isolada leva a uma redução dos níveis pressóricos (Franchini and Krieger 1992) e da atividade simpática renal (IRIGOYEN et al., 1991), sendo a DSA um excelente modelo de prejuízo barorreflexo.

Como descrito anteriormente, observa-se na DSA um quadro agudo de hipertensão e retorno aos níveis pressóricos normais na fase crônica (IRIGOYEN et al., 1995), sendo que a hiperatividade simpática parece ser o maior determinante do aumento da pressão arterial após a desnervação sino-aórtica (ALEXANDER et al., 1980; VASQUEZ \& KRIEGER, 1980). Observa-se que as variações temporais detectadas em animais normotensos coincidem em ambas as fases com um aumento na variabilidade da PA, que parece ser menor na condição de hipertonia simpática. Portanto, quando a atividade simpática volta aos valores de controle (cronicamente), a VPA tem mantem-se elevada (FRANCHINI \& KRIEGER, 1992; 
IRIGOYEN et al., 1995). Essa variabilidade, independentemente dos valores da PA tem sido associada com lesão de órgão alvo (MIAO et al., 2006) já que existem relatos de que a DSA pode, de fato, induzir a resposta de hipertrofia cardíaca nesses animais. Além disso, existem estudos demonstrando que a DSA praticamente abole as respostas favoráveis ao treinamento físico (CERONI et al., 2009; MORAESSILVA, I. C. et al., 2010). Todas as evidências apontando para o papel homeostático do barorreflexo.

O aumento da VPA encontrado após a DSA tem sido de grande interesse na medida em que, em modelos experimentais, pode-se estudar as causas e consequências dessas alterações. De fato, indivíduos hipertensos apresentam maior variabilidade da pressão (PARATI et al., 2013) e, consequentemente, menor capacidade de tamponar flutuações de PA em comparação com normotensos, evidenciando maior risco cardiovascular nesta população (MORTON et al., 1993). Isto tem sido demonstrado por estudos clínicos, onde o aumento da variabilidade da pressão arterial está associado à morbimortalidade cardiovascular (KIKUYA et al., 2000) e maior risco para lesão de órgãos alvo (FRATTOLA et al., 1993).

A DSA tem sido utilizada como um modelo experimental para estudar o papel do barorreflexo em diferentes situações fisiológicas e patológicas (ALEXANDER et al., 1990; OSBORN \& ENGLAND, 1990; SHADE et al., 1990). A DSA crônica está associada à maior lesão de órgãos-alvo na hipertensão arterial (MIAO et al., 2006; MORAES-SILVA, I. et al., 2010), à disfunção diastólica (MOSTARDA et al., 2011) e diminuição do consumo máximo de oxigênio (MORAES-SILVA, I. C. et al., 2010). 


\section{3) Interação entre alterações autonômicas e metabólicas diante do consumo inadequado de frutose}

A ligação entre o sistema nervoso autônomo e as alterações associadas à SM permanecem controversas. Embora se reconheça que na SM existam mudanças no controle neural (TRAN et al., 2009), não se conhece bem se elas ocorreriam antes, durante ou após o estabelecimento das alterações metabólicas. Existem evidências favoráveis à disfunção autonômica como consequência desta síndrome (DA SILVA et al., 2009), como por exemplo, o aumento do consumo energético e do sobrepeso levando à aumento do sistema nervoso simpático afim de estabilizar o ganho de peso e regular a termogênese (LANDSBERG, 2001). Além disso, já foi demonstrado que o aumento do tecido adiposo branco é capaz de elevar a atividade simpática muscular em 55\% em humanos (ALVAREZ et al., 2002).

No entanto, também existem evidências de que a disautonomia poderia ser anterior e causadora das alterações metabólicas (ROCCHINI et al., 1999). Há evidencias que em jovens adultos o aumento da atividade simpática está diretamente relacionado com ganho de peso e resistência à insulina (JULIUS et al., 2000). De qualquer forma, está muito bem descrito na literatura que a hiperatividade simpática está fortemente relacionada com o risco cardiovascular durante o desenvolvimento da SM (GRASSI, 2006), assim como no aumento em marcadores metabólicos de risco, como colesterol, triglicérides, insulina, leptina e glicose (DE ANGELIS et al., 2012). Isto fica evidente quando observado que em um modelo de

simpatectomia os animais tratados com frutose não desenvolvem hipertensão e hiperinsulinemia (VERMA et al., 1999). 
Hellstrom (2007) apresentou uma série de evidências que lhe permitiram formular a hipótese de que o desenvolvimento de diversas doenças, incluindo a hipertensão arterial e diabetes, seria resultado de uma disfunção autonômica, especialmente do sistema nervoso simpático, gerando disfunção endotelial, dislipidemia, inflamação e resistência à insulina.

No entanto, a gênese e desenvolvimento dessa disfunção simpática permanecem pouco elucidados. Embora se reconheça que a sobrecarga crônica de frutose esteja associada com aumento da PA e redução da sensibilidade do barorreflexo, não existem dados mostrando os efeitos da frutose em animais normotensos com déficit completo do barorreflexo induzido por DSA. De fato, em associação com uma dieta rica em frutose, não há trabalhos evidenciando o quanto a perda do barorreflexo e o aumento da labilidade da PA podem comprometer a evolução natural das alterações metabólicas esperadas.

Diante do exposto, neste projeto, testaremos a hipótese de que as alterações da modulação simpática e parassimpática (avaliadas por telemetria e análise espectral dos sinais de pressão arterial obtidos) estão temporalmente associadas com o desenvolvimento da SM induzida pela sobrecarga de frutose em ratos, podendo ocorrer até mesmo antes do estabelecimento das mesmas. Além disso, sendo o barorreflexo um mecanismo de controle cujo prejuízo tem sido associado com o risco cardiovascular (ROVERE et al., 1998), inclusive como preditor prognóstico, é possível que a desnervação sino-aórtica nesses animais potencialize o aparecimento das mudanças metabólicas e hemodinâmicas neste modelo. 


\section{2) Objetivos}

Este trabalho tem por objetivos gerais: Avaliar o curso temporal das alterações autonômicas e metabólicas em um modelo de síndrome metabólica induzida por sobrecarga de frutose, bem como identificar os efeitos do prejuízo barorreflexo nessas alterações.

Como objetivos específicos, investigaremos a modulação autonômica aguda e cronicamente, estabelecendo um padrão de comportamento para os grupos estudados, assim como a análise das alterações metabólicas e inflamatórias no sistema cardiovascular promovidas pela sobrecarga de frutose. 


\section{3) Material e Métodos}

Todos os experimentos descritos a seguir foram realizados mediante aprovação do Comissão de Ética em Uso de Animais da Faculdade de Medicina da Universidade de São Paulo (USP) (protocolo 274/11). Os animais submetidos a procedimentos cirúrgicos tiveram tratamento pós-operatório com antibiótico (Benzetacil, 30.000U/Kg) e analgésico (Dipirona Sódica, 0,35g/Kg) visando o menor sofrimento possível para o animal.

\section{1) Desenho Experimental}

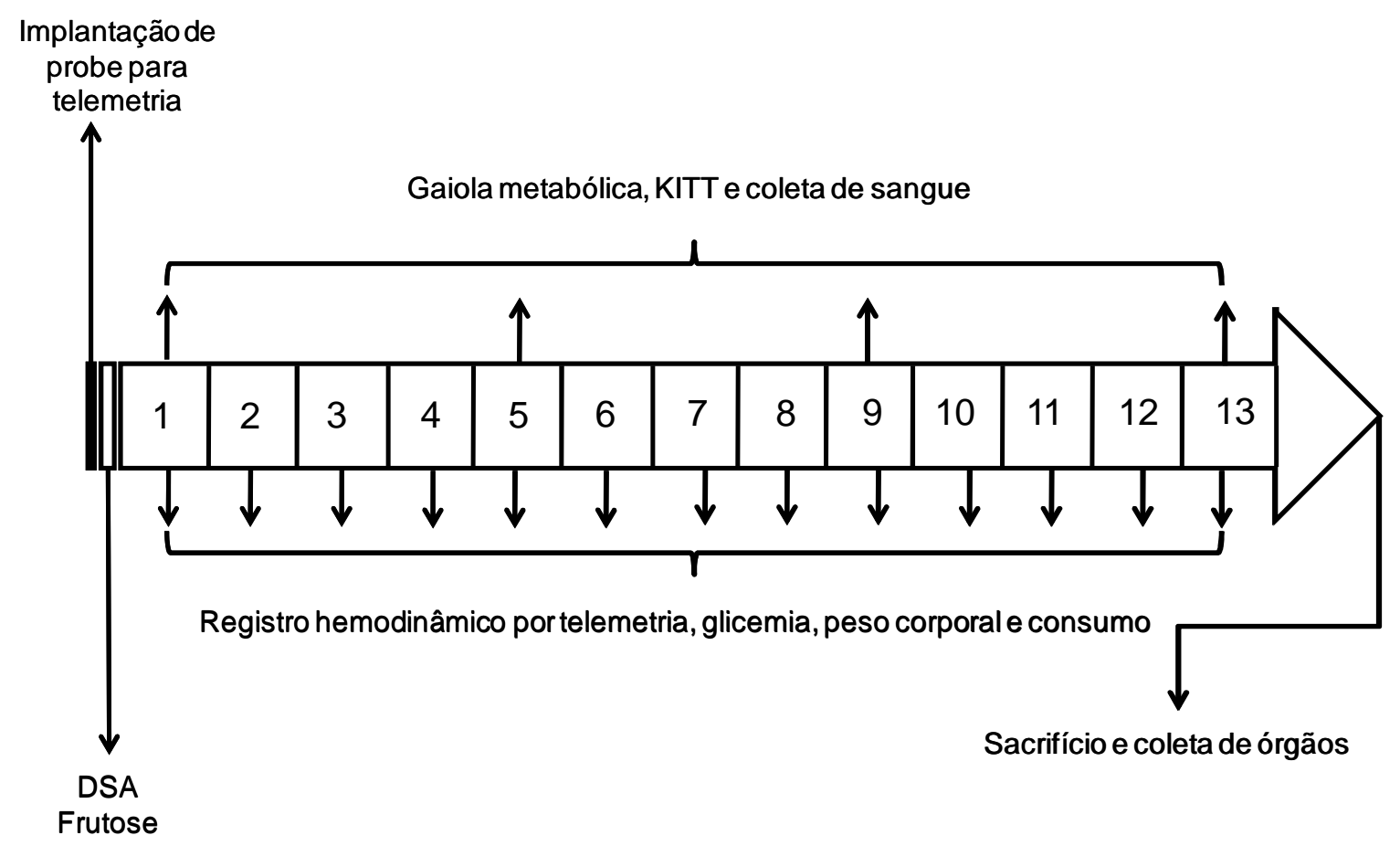


Modelo do desenho experimental desenvolvido durante o projeto. Inicialmente realizou-se implantação de probe de telemetria nos animais submetidos à este sistema. O início de tempo de protocolo ocorreu simultaneamente com a cirurgia de DSA e administração de frutose na água de beber.

\section{2) Animais e Grupos}

Foram utilizados ratos (Rattus novergicus) Wistar machos, de 2 meses de idade, provenientes do biotério central da Faculdade de Medicina da USP. Os animais eram mantidos em caixas individuais, alocados no Biotério do Laboratório de Hipertensão Experimental do Instituto do Coração (Hospital das Clínicas, Faculdade de Medicina/USP), em ambiente com temperatura $\left(22^{0}-24^{\circ} \mathrm{C}\right)$ e luz controladas, em ciclo de 12 horas (claro-escuro). Água e comida foram oferecidas de modo irrestrito, sendo que a dieta foi normoproteica (12\% de proteínas). Os animais foram divididos em 4 grupos experimentais a seguir relacionados:

GRUPO I - Grupo Controle (C)- composto por 8 animais Wistar monitorados via radiotelemetria durante 90 dias;

GRUPO II - Grupo Frutose (F)- composto por 8 animais Wistar tratados com solução de frutose na água de beber e monitorados via radiotelemetria durante 90 dias;

GRUPO III - Grupo Desnervado (D)- composto por 8 animais Wistar submetidos à Desnervação sino-aórtica e monitorados via radiotelemetria durante 90 dias;

GRUPO IV - Grupo Frutose Desnervado (FD)- composto por 8 animais Wistar submetidos à Desnervação sino-aórtica e subsequentemente tratados com frutose na água de beber, enquanto monitorados via radiotelemetria durante 90 dias. 


\section{3) Desnervação sino-aórtica}

Os animais foram anestesiados com isoflurano sob dose inalatória (1,5 a 2\% em $\mathrm{O}_{2}$ ) suficiente para sedação completa do animal sem prejuízo autonômico observável. Para o procedimento cirúrgico os animais foram colocados em decúbito dorsal. O método de desnervação sino-aórtica foi feito de acordo com o descrito por Krieger (1964).

O procedimento consistiu de uma incisão mediana na região cervical anterior, separação dos músculos pré-traqueais e localização bilateral do feixe vásculo nervoso, constituído pela artéria carótida, jugular, nervo vago e tronco simpático. As fibras pressorreceptoras aórticas localizadas junto ao tronco simpático ou como nervo isolado foram seccionadas. A seguir, a bifurcação da carótida comum foi localizada, exposta e dissecada completamente nos dois lados, seccionando-se as fibras carotídeas e do corpúsculo carotídeo. Finalmente, o outro contingente de fibras pressorreceptoras aórticas que podem situar-se junto ao laríngeo inferior, foi

interrompido quando seccionado o laríngeo superior (KRIEGER \& MARSEILLAN, 1963). 

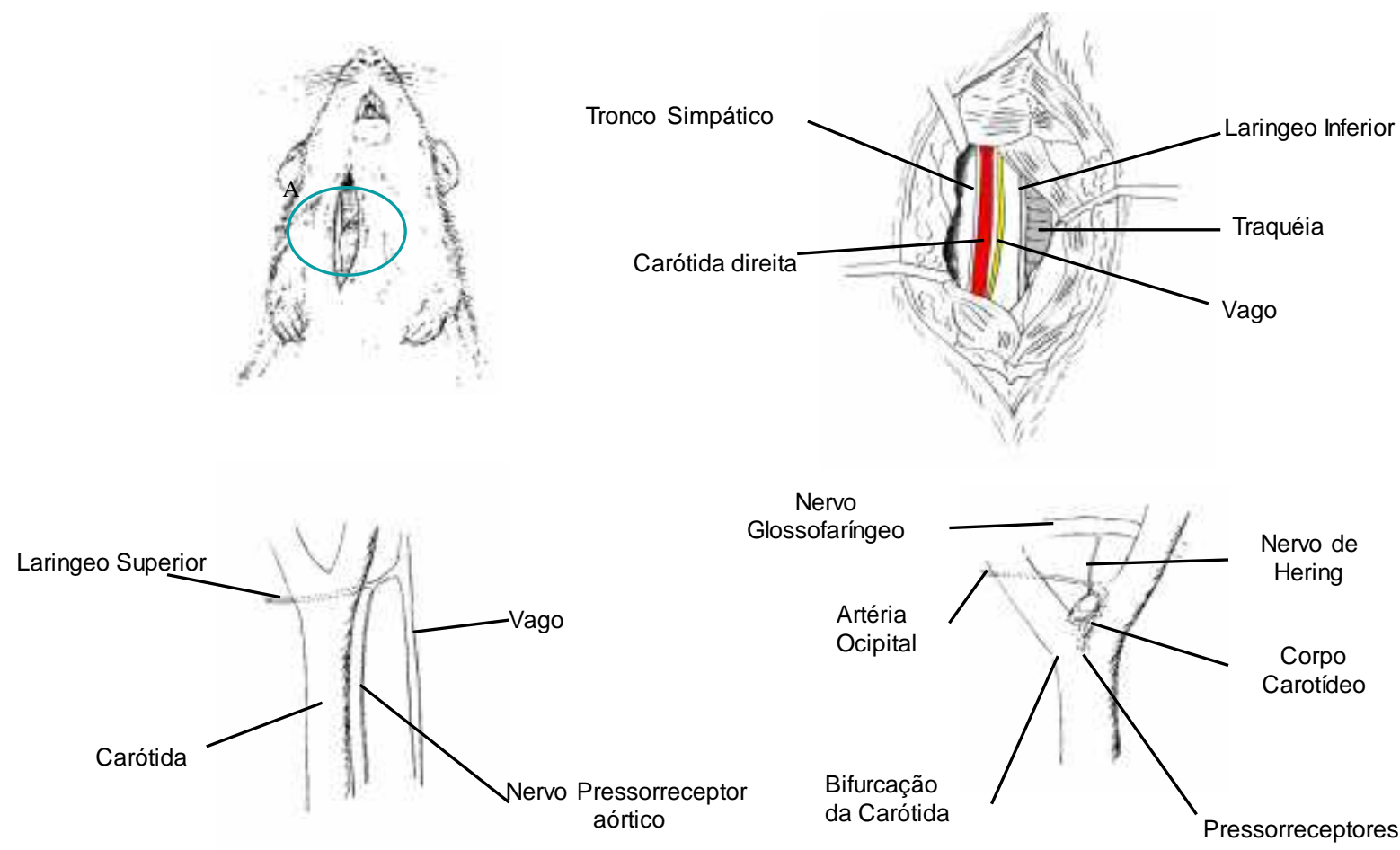

Figura 1: Modelo de desnervação sino-aórtica. Adaptado de Lacchini, S.

\section{4) Indução do modelo experimental de síndrome metabólica}

O modelo de síndrome metabólica foi induzido com sobrecarga de frutose na água de beber (D-frutose, 100g/L) (SUZUKI et al., 1997; SILVA et al., 2011; SENADOR et al., 2012). O tratamento com frutose foi durante 90 dias em todos os estudos realizados, onde observou-se o consumo de ração e água, assim como o ingesta calórica através da multiplicação do valor energético em cada grama de ração e/ou frutose pelo volume ingerido.

\section{5) Monitoramento dos parâmetros cardiovasculares}

A medida direta de PA e frequência cardíaca $(F C)$, utilizada nos protocolos experimentais foram obtidas por radiotelemetria (Dataquest A.R.T. Versão 4.2, Data 
Sciences International, St. Paul, MN). Este método permite um monitoramento crônico e preciso destes parâmetros em mínimas condições de estresse ao animal e interferência humana. Sendo particularmente útil para registro de PA e FC em forma contínua e também sob perspectiva do ciclo claro/escuro (FARAH, V. et al., 2006).

Sob efeito de isoflurano ( 1,5 a $2 \%$ em O2), novamente os animais foram colocados em decúbito dorsal sobre a mesa cirúrgica e foi feita uma incisura $(1 \mathrm{~cm})$ na região anterior da coxa. Foi localizado o ramo vascular femoral e feita uma pequena secção parcial na artéria para inserção do sensor. Os cateteres dos sensores de radiotelemetria (modelo TA11PA-C40 ou TA11PA-C10, Data Sciences International, St. Paul, $\mathrm{MN})$ foram inseridos $(5 \mathrm{~cm})$ até região abdominal da aorta e o transmissor associado ao sensor foi posicionado subcutaneamente no abdômen.

O protocolo foi iniciado após a completa recuperação dos animais (6 a 7 dias). Após cirurgia de DAS e com simultâneo oferecimento de frutose, a PA e FC foram aquisitados $(500 \mathrm{~Hz}) 10$ segundos por minuto durante 24 horas, uma vez por semana. Ao final de cada registro, uma nova aquisição foi realizada de forma continua por 30 minutos à $5000 \mathrm{~Hz}$ (DE ANGELIS et al., 2012).

\section{6) Determinação da Glicemia}

Semanalmente todos os animais foram submetidos à 4 horas de jejum para retirada de uma gota de sangue retirado da cauda e subsequente análise da glicose plasmática por glicosímetro comercial (Accucheck, Roche). Em intervalos de 4 semanas os animais permaneceram em jejum por 2 horas para o teste de determinação de resistência à insulina. Após serem anestesiados com pentobarbital sódico $(40 \mathrm{mg} / \mathrm{kg})$, receberam uma injeção endovenosa de insulina $(0,75 \mathrm{U} / \mathrm{kg})$. A 
glicose plasmática foi medida a partir de amostras de sangue obtidas da cauda utilizando-se de um glicosímetro (Accucheck, Roche) nos tempos 0, 4, 8, 12 e 16 min. após a injeção de insulina. Os valores de glicemia dos minutos 4 a 16 foram usados para calcular a constante de queda da glicose plasmática através do teste de tolerância à insulina (Kitt) (BONORA et al., 1989).

\section{7) Gaiola metabólica}

Durante o protocolo, a cada 4 semanas, todos os animais foram colocados em gaiolas metabólicas individuais, nas quais permaneceram por 24 horas para adaptação ao ambiente. As coletas obtidas nas 24 horas seguintes foram utilizadas para mensurar o volume urinário e o peso das fezes, bem como o consumo de água e ração. Foram realizadas dosagens nas urinas afim de determinar osmolaridade, eletrólitos, lactato, ureia, ácido úrico e glicose via kit comercial no aparelho (ABL 800 Flex - Radiometer®). Os resultados quantitativos serão apresentados como valor absoluto de 24 horas normalizado pelo volume urinário. 

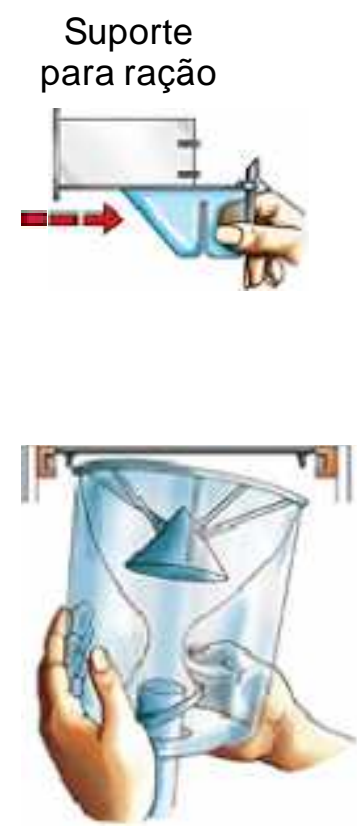

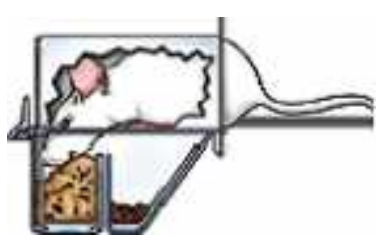

Coleta individual de fezes e urina

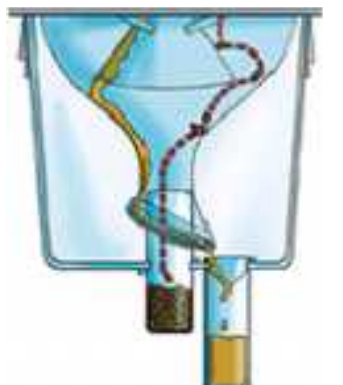

Bebedouro com coletor

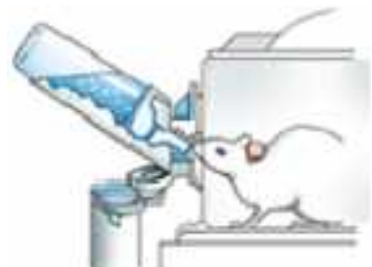

Urina utilizada

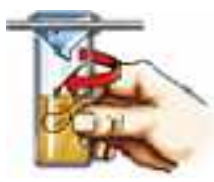

Figura 2: Gaiola metabólica. Modelo de gaiola utilizada para coleta de urina.

\section{8) Variabilidade do intervalo de pulso e pressão arterial nos domínios do tempo e frequência.}

Cada ciclo cardíaco obtido previamente através da aquisição da onda de pressão pelo programa Dataquest A.R.T. 4.2, resultou nas medidas de frequência cardíaca, intervalo de pulso, pressão arterial diastólica, sistólica e média. A variabilidade do intervalo de pulso (VIP) no domínio do tempo foi quantificada pela variância total (VARIP) e pela raiz quadrada da soma das diferenças sucessivas entre intervalos RR (RMSSD). Já a variabilidade da pressão arterial (VPA) no domínio do tempo foi representada pela variância (VARPA)

Para análise da VIP e VPA no domínio da frequência, as séries temporais foram armazenadas em forma de texto para posterior análise pelo programa 
Cardioseries 2.4 utilizando-se da transformada rápida de Fourier (FFT) para decomposição dos sinais de onda em espectros de potência. O sinal sofreu interpolação de $10 \mathrm{~Hz}$ e os espectros foram gerados a partir de trechos contendo 512 pontos com sobreposição de $50 \%$. Os resultados apresentados são referentes à média de todos os trechos presentes em 30min de registro.

As potências para as bandas de muito baixa frequência (VLF) foram definidas como inferiores à $0,20 \mathrm{~Hz}$, as de baixa frequência $(\mathrm{LF})$, representando a modulação simpática, foi fixada entre $0,20-0,75 \mathrm{~Hz}$ e alta frequência (HF), correspondente com modulação parassimpática, em $0,75-4,0 \mathrm{~Hz}$. Cada uma foi calculada pela integração da potência nas bandas de interesse e apresentadas como valores absolutos e normalizados. Para normalização as potências das bandas de LF e HF foram subtraídas da potência na banda VLF e sua soma foi considerada a totalidade (PAGANI et al., 1986; PAGANI et al., 1988).

\section{9) Avaliações celulares e moleculares}

Depois de efetuados os tratamentos os animais foram sacrificados por sobrecarga de anestésico (pentobarbital sódico) seguido de perfusão com solução fisiológica e Cloreto de Potássio (14 mmol/L). A seguir, os tecidos foram perfundidos com formol (10\%). Ao final foram coletados coração, rins e pulmões para análise histológica. Os animais destinados à avaliação de marcadores inflamatórios, dosagem de proteína ou RNAm foram sacrificados por decapitação de forma rápida sem gerar sofrimento aos animais. 


\subsection{1) Preparação Histológica}

A fixação dos órgãos foi realizada em formol a $4 \%$ tamponado (tampão fosfato, $\mathrm{pH} 6,8-7,2 ; 0.1 \mathrm{M})$ por 24 horas. Após este período os órgãos foram dispostos em cassete plástico, processados em histotécnico com ciclo total de 8 horas onde se realizou a desidratação, diafanização e parafinização dos tecidos. A seguir, estes tecidos foram emblocados em parafina e foi feita a microtomia obtendose cortes de 4-5um nos tecidos que foram fixados em lâminas histológicas.

\subsection{2) Imunohistoquímica (IHQ)}

Os cortes obtidos foram submetidos à desidratação, clareamento e incluídos em parafina. Em seguida, foram desparafinados e hidratados, caso necessário, foi feita a recuperação antigênica usando-se tripsina como primeira opção. O método de Imunohistoquímica (IHQ) a ser utilizado é o tipo A-B-C (Estreptoavidina - Biotina - Peroxidase).

O estudo para identificação das proteínas de interesse foi feito usando-se os seguintes anticorpos: NFk-B tecidual para comprovação de sua presença e efeito, IL-6 tendo-se como marcadores PLC e IP3, e NF-kB, usando-se como alvos plasmina, PAI-1 e LTBP.

As análises foram realizadas através de fotos tiradas na mesma ocasião sob os mesmos parâmetros de luminosidade, abertura de diafragma, tempo de exposição, contraste, entre outros. Para cada marcador em cada tecido, foi gerado uma padrão de coloração tecidual no software Image-Pro Plus. Os resultados são apresentados em média do percentual de área marcada por área total de tecido (descontando-se as regiões em branco) de 20 fotos por lâmina. As regiões avaliadas são: cardiomiócito, brônquios e tecido renal. 


\subsection{3) Avaliação de marcadores inflamatórios}

A avaliação bioquímica foi realizada com intuito de localizar presença de IL-1, IL-10 e TNF- $\alpha$ no coração. Esta avaliação foi feita pelo método de ensaio imunoenzimático (ELISA), em todos os animais para que se tenha uma ideia melhor dos efeitos inflamatórios para estes órgãos.

O método de ELISA se baseia no uso de placas preparadas com anticorpo para a proteína de interesse onde é feita incubação das amostras experimentais seguida de uma nova incubação contendo anticorpo conjugado com enzima e posterior reação com cromógeno. Desta forma, quanto mais proteína de interesse estiver contida na amostra mais forte será a coloração obtida.

\subsection{4) Western Blot}

Para esse ensaio, amostras de córtex e medula renal foram homogeneizadas em tampão de extração na proporção $1 \mathrm{ml}$ para cada $50 \mathrm{mg}$ de rim. $O$ tampão de lise utilizado foi RIPA (Radio Immuno Precipitation Assay Buffer) contendo: cloreto de Sódio a 150nM, 1,0\% de Triton X-100, 0,5\% de Deoxicolato de Sódio, 0,1 \% de SDS (Dodecil Sulfato de Sódio) e 50mM de Tris $(\mathrm{pH} 8,0)$ e coquetel de inibidor de protease (Roche EUA). O homogeneizado foi centrifugado por $10 \mathrm{~min}$ a $4^{\circ} \mathrm{C} \mathrm{com}$ $12.000 \mathrm{rpm}$. Parte do sobrenadante foi utilizado para determinar a concentração de proteína pelo kit de ensaio proteico BCA (PIERCE Biotechnology) e parte foi armazenada a $-80^{\circ} \mathrm{C}$ para posteriores análises por Western Blot. Foi padronizada a quantidade de $50 \mathrm{~g}$ de proteína para cada sujeito da amostra, e com ele foi realizada eletroforese em gel de poliacrilamida (Gel em gradiente 4-12\% (Bolt@ 4- 
12\% Bis-Tris Plus Gel), no aparelho para minigel (Thermo Fisher Scientific, EUA). Posteriormente, as proteínas foram transferidas para uma membrana de nitrocelulose pelo sistema de transferência Iblot 2 Dry Blot System (Thermo Fisher Scientific EUA). A membrana foi submetida a bloqueio com solução BSA (bovine serum albumin $5 \%$ ), posteriormente incubada por $1 \mathrm{~h}$ com 0 anticorpos primários (rabbit anti-AT1R, 1:500 (sc1173), rabbit anti- $\beta$-actina 1:1000, Sigma (PA1-183), lavada com solução de lavagem com BSA a 5\%, e seguidamente incubadas por $1 \mathrm{~h}$ com os anticorpos secundários Goat anti rabbit 1:300000 da Abcam (AB6721). O sinal de membrana foi detectado através de reação da peroxidase na solução de ECL durante exposição no equipamento American Imager 600 (GE Healthcare Life Sciences, EUA). A intensidade de banda foi quantificada no programa Image $\mathrm{J}$ (versão 1.49 para Windows).

\subsection{5) Reação qRT-PCR}

Para extração do ácido ribonucleico (RNA) das amostras de tecido do coração foi utilizado de 50-100 mg de tecido em 1,0 ml de TRIzol@ Reagent (Invitrogen TM). O material foi triturado no TRIzo|® Reagent, até sua completa homogeneização, e mantido em temperatura ambiente por 5 minutos. Em seguida, seguiu-se o protocolo descrito na bula do reagente. As concentrações das amostras foram determinadas por meio da leitura em espectrofotômetro no comprimento de onda 260/280 nm, utilizando-se o aparelho nanodrop (Thermo Scientific). A qualidade das mesmas foi verificada por meio de corrida de eletroforese em gel de agarose. Uma alíquota com $3 \mu \mathrm{g}$ de RNA de cada amostra foi separada, para a realização do tratamento e transcrição reversa e o restante das amostras foi armazenado em freezer $-80^{\circ} \mathrm{C}$. 
O RNA foi submetido ao tratamento com a enzima Turbo DNA-Free ${ }^{\mathrm{TM}}$ da empresa Ambion (The RNA Company). O protocolo do fabricante foi seguido rigorosamente. Após término da incubação, seguiu-se a centrifugação da amostra a $10.000 \times \mathrm{g}$ por 1 minuto e meio e o sobrenadante foi transferido para um novo tubo livre de RNase. Para transcrição reversa foi utilizada a enzima SuperScriptTM II Reverse Transcriptase (InvitrogenTM). Foram utilizadas duas misturas: Mix 1 contendo: $\quad 10 \mu \mathrm{l}$ de RNA tratado $(3,0 \mu \mathrm{g}) ; 0,5 \mu \mathrm{L}$ de Oligo-(dT)12-18 Primer(InvitrogenTM) $(0,5 \mu \mathrm{g} / \mu \mathrm{L}) ; 0,5 \mu \mathrm{L}$ de random primers (InvitrogenTM) $(3,0$ $\mu \mathrm{g} / \mu \mathrm{L}$ ) e 1,0 $\mu \mathrm{L}$ de dNTP (InvitrogenTM) (10 mM); e Mix 2 contendo: 4,0 $\mu \mathrm{L}$ de tampão da enzima $(5 \mathrm{X}) ; 2,0 \mu \mathrm{L}$ de DTT $(0,1 \mathrm{M}) ; 1,0 \mu \mathrm{L}$ de RNase Out TM (Recombinant Ribonuclease Inhibitor-InvitrogenTM) 1,0 $\mu \mathrm{L}$ de SuperScript II.

$\mathrm{O}$ Mix 1 (12 $\mu \mathrm{L}$ de volume) foi levado ao termociclador à temperatura de $65^{\circ} \mathrm{C}$ por 5 minutos. O programa foi pausado, e então, o Mix $2(8,0 \mu \mathrm{L}$ por amostra) foi acrescentado. $\mathrm{O}$ programa foi continuado com as seguintes ciclagens: $42^{\circ} \mathrm{C}$ por 2 minutos, $42^{\circ} \mathrm{C}$ por 50 minutos, $70^{\circ} \mathrm{C}$ por 15 minutos e $4^{\circ} \mathrm{C}$. Os cDNAs foram posteriormente armazenados à temperatura de $-20^{\circ} \mathrm{C}$.

As reações semi-quantitativas de PCR em tempo real (qRT-PCR) foram feitas em placas de 96 poços, usando reagente Power SYBR Green Master Mix (Applied Biosystems - EUA), conforme descrito pelo fabricante e o equipamento utilizado foi o Step One Plus Real-Time PCR Systems - Applied Biosystems.

A reação foi preparada com $6 \mu \mathrm{L}$ de Sybr Green; 3,0 $\mu \mathrm{L}$ de cDNA diluído 1:40 e 3,0 $\mu \mathrm{L}$ de primer (forward e reverse), já diluídos na concentração determinada previamente na reação de otimização dos primers, necessária para uma eficiência 
de $100 \%$. Essas quantidades foram utilizadas para elaboração da reação de qRTPCR em duplicata. O programa para a amplificação das amostras consiste em uma desnaturação inicial de 95ํㅡ por 10 minutos, seguidos de 40 ciclos de 95ํ $\mathrm{C}$ por 15 segundos e $60^{\circ} \mathrm{C}$ por 1 minuto (anelamento dos primers e extensão).

No final de todas as reações, as curvas de dissociação com temperaturas crescentes foram analisadas, a fim de verificar a amplificação de um único produto. As condições da reação foram idênticas às utilizadas para a construção das curvas de calibração e otimização dos primers. As amostras foram estudadas em duplicata, e para cada gene do estudo, foram amplificadas em paralelo as amostras controles cDNA. Todas as reações de PCR consideradas para análise apresentaram eficiência igual ou superior a $95 \%$.

A expressão dos genes escolhidos para este estudo foi normalizada em relação ao mRNA dos gene endógenos, GAPDH e Beta Actina, conforme descrito anteriormente por (LIVAK \& SCHMITTGEN, 2001)

\subsection{0) Análise estatística}

Por se tratar de um experimento com animais, utilizando um " $\mathrm{n}$ " relativamente baixo, todos os parâmetros passaram no teste de normalidade de D'Agostino e Pearson. Sendo assim, os resultados são apresentados como média e erro padrão. As médias foram comparadas por testes estatísticos utilizando-se o programa GraphPad Prism 5.0 (GraphPad Software, Inc) através da análise de variância (ANOVA) de uma via para as análises no tempo de 90 dias e ANOVA de duas vias para os parâmetros temporais. Quando se mostrou necessário, foi utilizada análise 
complementar de Bonferroni. Diferenças que apresentaram probabilidade de acaso menores que $5 \%(p<0,05)$ foram consideradas significativas. 


\section{4) Resultados}

\section{1) Consumo calórico e ganho de peso corporal.}

O acompanhamento dos grupos experimentas durante 90 dias possibilitou uma análise refinada do consumo de ração, água, frutose e ganho calórico, assim como ganho de peso corporal durante o curso temporal de 13 semanas, como se pode evidenciar nas figuras a seguir.

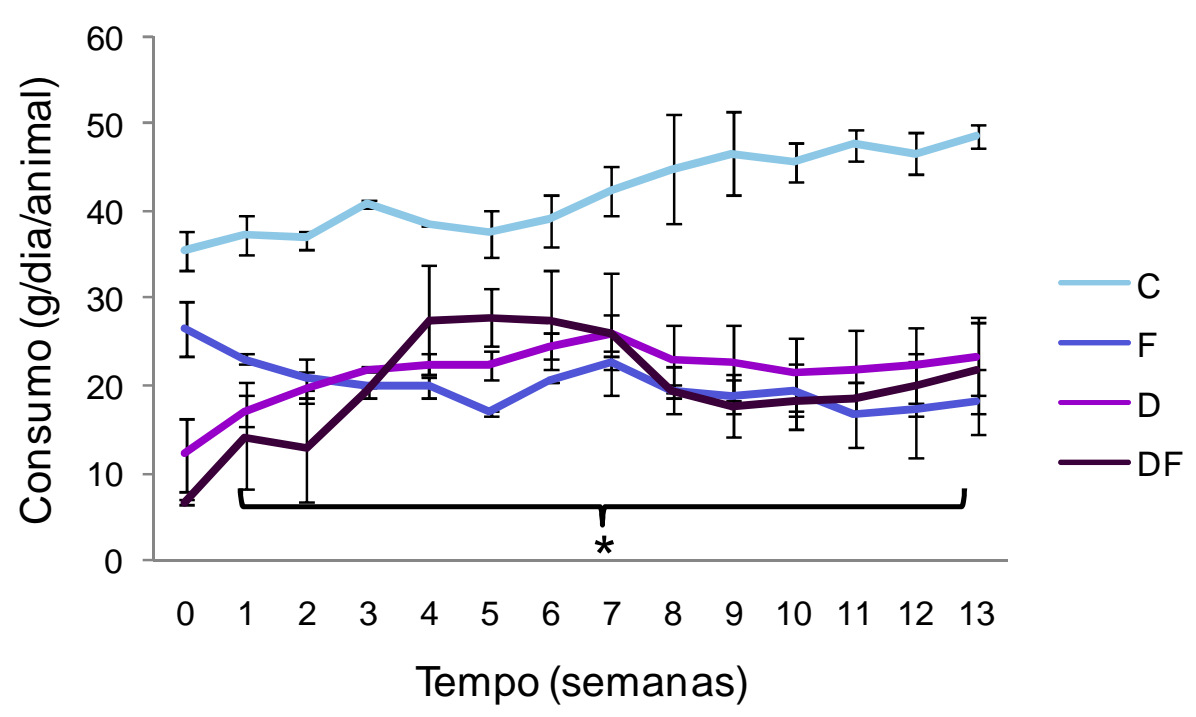

Figura 3: Consumo de ração. Acompanhamento temporal no consumo de ração pelos grupos $(n=8)$ : controle $(C)$, frutose $(F)$, desnervado (D) e desnervado frutose (DF). ${ }^{*} p<0,05$ vs. $C$.

Observa-se na Figura 3 que os três grupos experimentais apresentam menor consumo de ração em relação ao controle, evidenciado na Figura 4 pelo consumo médio de cada grupo ao longo das 13 semanas. 


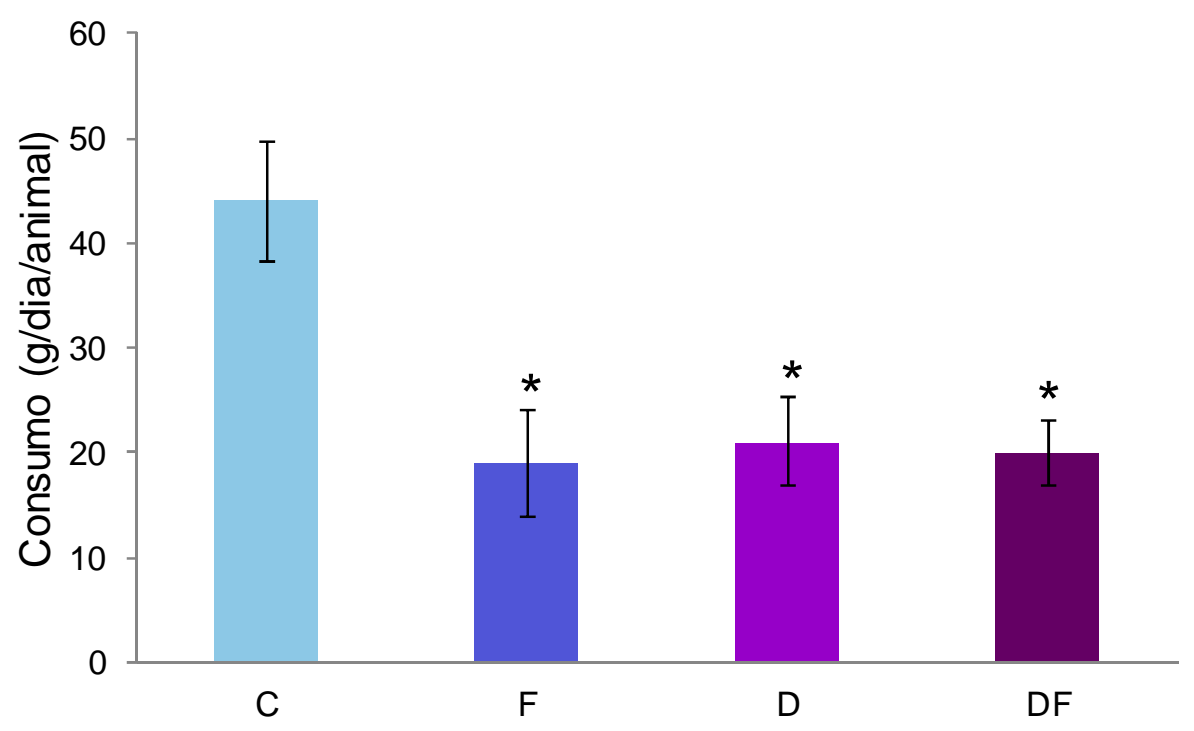

Figura 4: Consumo médio de ração ao longo de 13 semanas. Valor médio e erro padrão do consumo de ração durante o protocolo nos grupos $(n=8)$ : controle $(C)$, frutose $(F)$, desnervado $(D)$ e desnervado frutose (DF). ${ }^{*} p<0,05$ vs. C.

Avaliando o consumo de água (Figura 5), parece haver um aumento no volume ingerido pelo grupo $\mathrm{F}$ em comparação aos demais grupos, assim como uma tendência a aumento do volume de água ingerido pelo grupo DF no curso temporal do protocolo. Essa situação pode ser melhor compreendida observando-se a Figura 6, onde apresenta-se média diária de consumo de água e/ou água com frutose das 13 semanas de protocolo. 


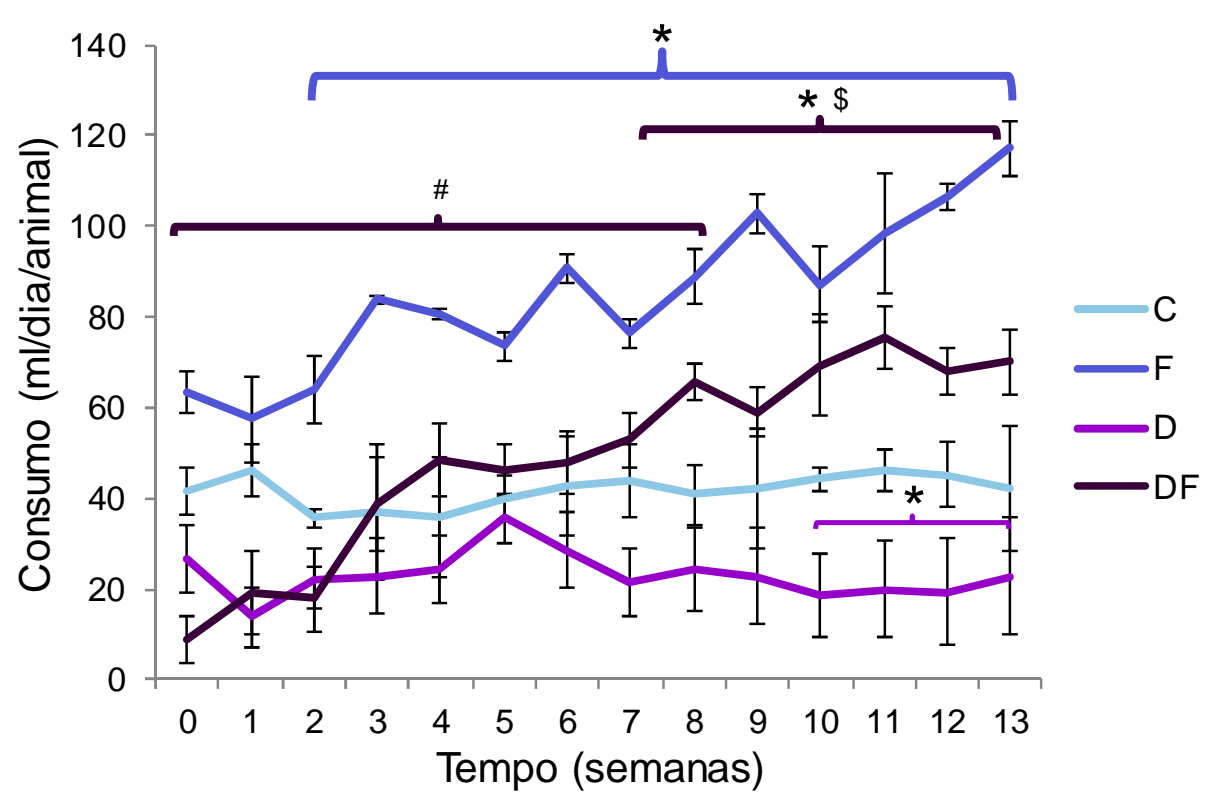

Figura 5: Consumo de água. Acompanhamento temporal no consumo de água pelos grupos $(n=8)$ : controle (C), frutose $(F)$, desnervado (D) e desnervado frutose (DF). * $p<0,05$ vs. $C, \# p<0,05$ vs. $F, \$$ $\mathrm{p}<0,05$ vs. $D$.

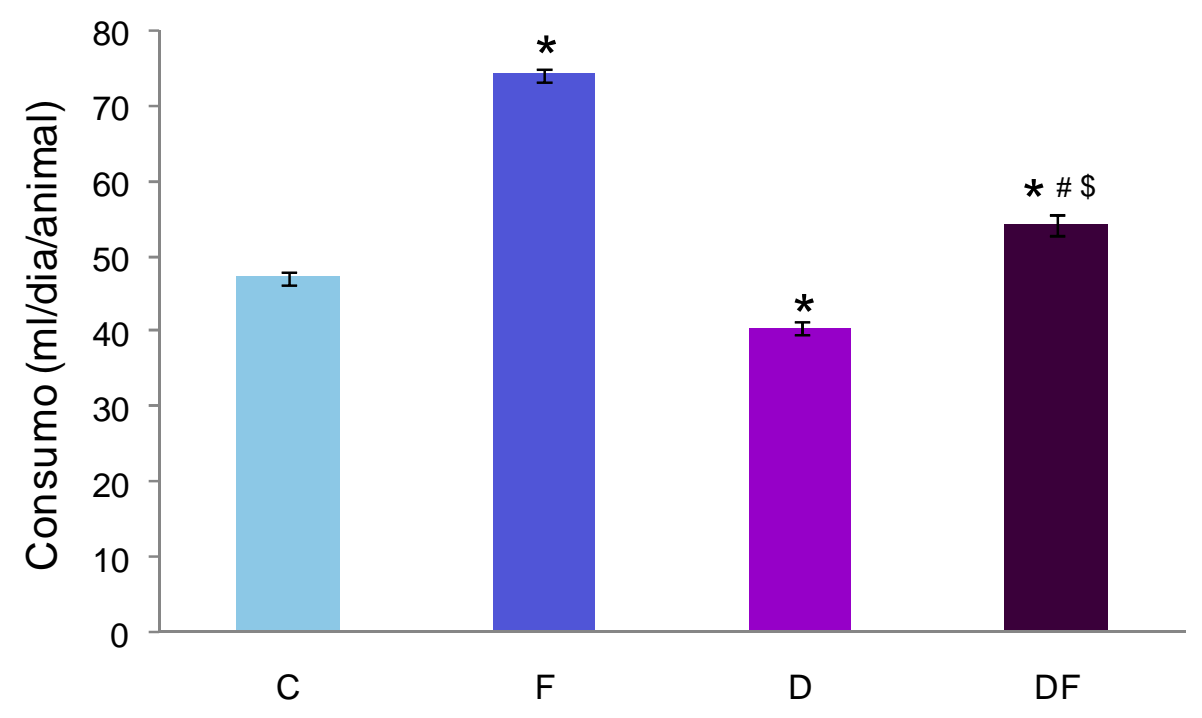

Figura 6: Consumo médio de água ao longo de 13 semanas. Valor médio e erro padrão do consumo de água durante o protocolo nos grupos $(n=8)$ : controle $(C)$, frutose $(F)$, desnervado $(D)$ e desnervado frutose (DF). * $p<0,05$ vs. $C, \# p<0,05$ vs. $F, \$ p<0,05$ vs. $D$. 
Dessa forma, pode-se notar que os grupos com secção das fibras pressorreceptoras apresentam menor consumo de ração e água que seus controles, e os submetidos ao consumo de frutose bebem mais água com frutose do que o grupo desnervado exposto somente à água. Quando converte-se estes valores em ingesta calórica obtém-se o seguinte resultado.

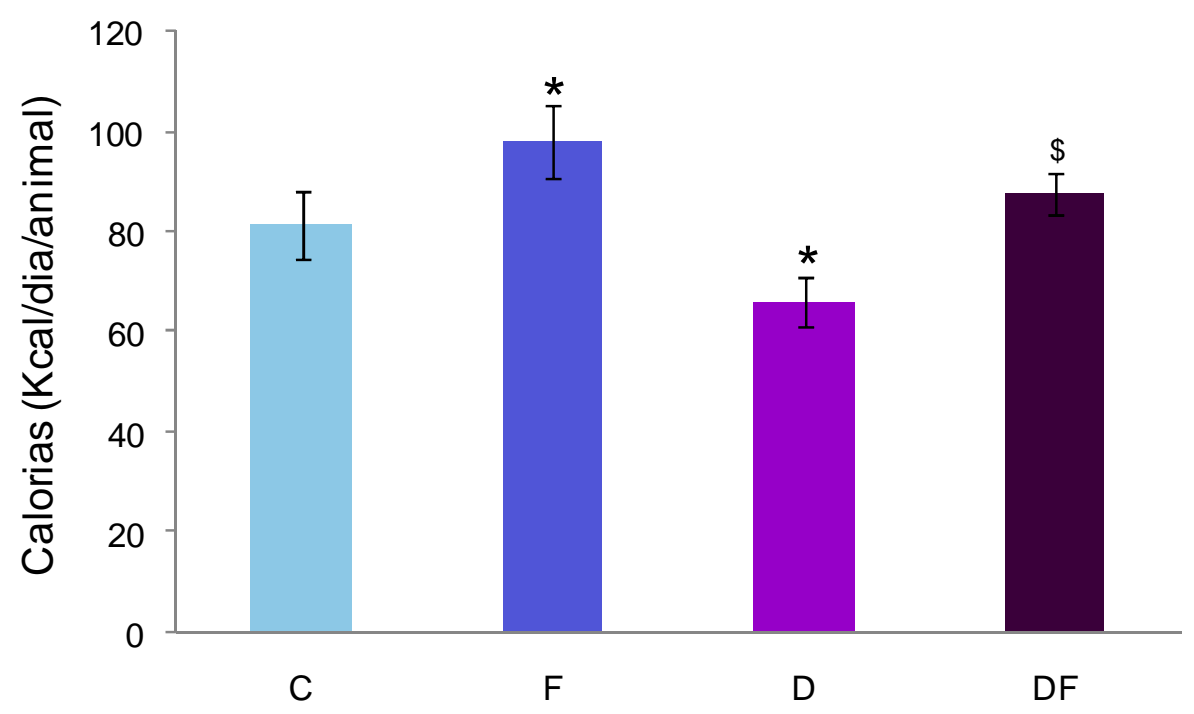

Figura 7: Ingesta calórica média. Valor médio e erro padrão do consumo calórico de 13 semanas de protocolo nos grupos $(n=8)$ : controle $(C)$, frutose $(F)$, desnervado (D) e desnervado frutose (DF). * $p<0,05$ vs. $C, \$ p<0,05$ vs. $D$. 
Na Figura 7 temos a representação média das calorias ingeridas diariamente pelos animais, indicando que o grupo desnervado apresenta uma redução na ingesta energética diária, enquanto os grupos frutose têm sua ingesta calórica aumentada em relação à seus respectivos controles. Estes achados se refletem no ganho de peso corporal ao longo das 13 semanas de protocolo, conforme pode-se observar na Figura 8.

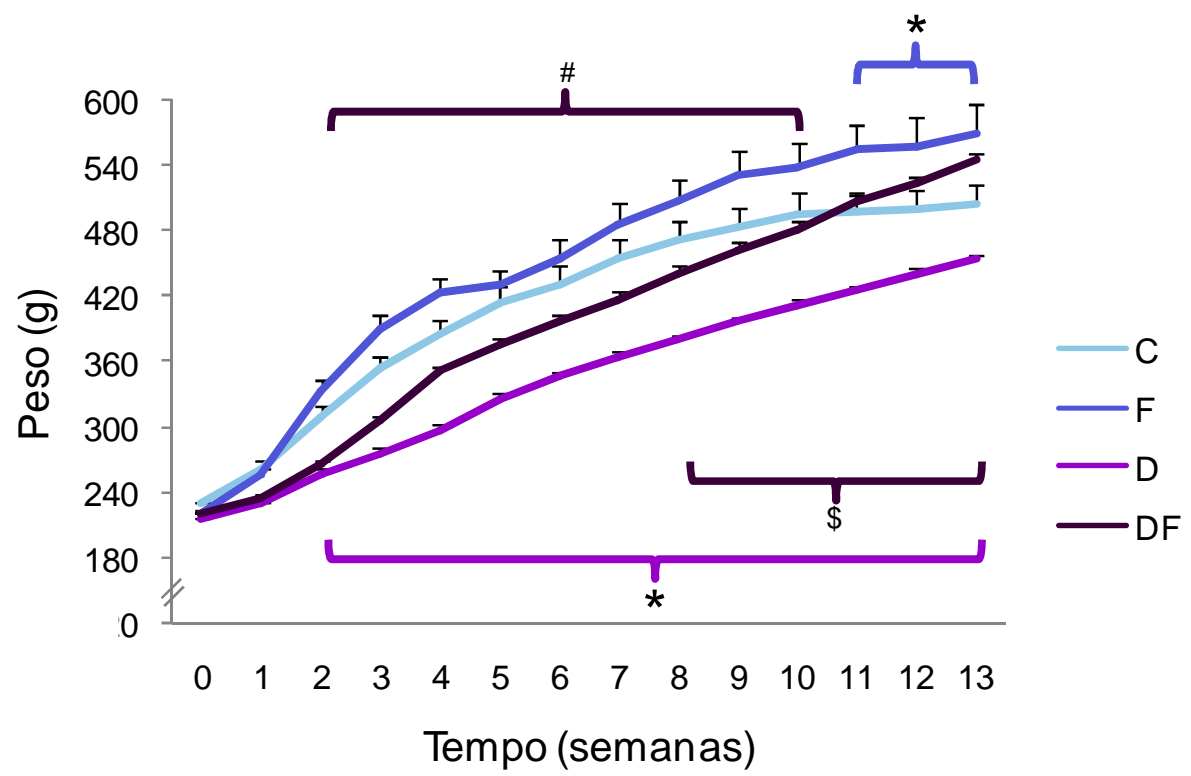

Figura 8: Peso corporal ao longo de 13 semanas de protocolo. Acompanhamento temporal no ganho de peso através de média e erro padrão dos grupos $(n=8)$ : controle $(C)$, frutose $(F)$, desnervado (D) e desnervado frutose (DF). * $p<0,05$ vs. $C, \# p<0,05$ vs. $F, \$ p<0,05$ vs. $D$.

Pode-se notar que o grupo $\mathrm{F}$ se mantém com peso corporal maior que todos os demais grupos durante todo o protocolo, sendo esta diferença notada com poder estatístico nas últimas três semanas em relação ao grupo $\mathrm{C}$, coincidentemente no mesmo momento em que a diferença entre os grupos $F$ e DF deixa de existir. Em paralelo, o $\mathrm{D}$ permanece com peso corporal menor que o $\mathrm{C}$ a partir da segunda 
semana de protocolo. Já o DF apresenta um retardo no ganho de peso corporal durante as primeiras semanas, porém por volta da quinta semana este comportamento muda, chegando ao final do procedimento com peso corporal semelhante ao do grupo $\mathrm{F}$.

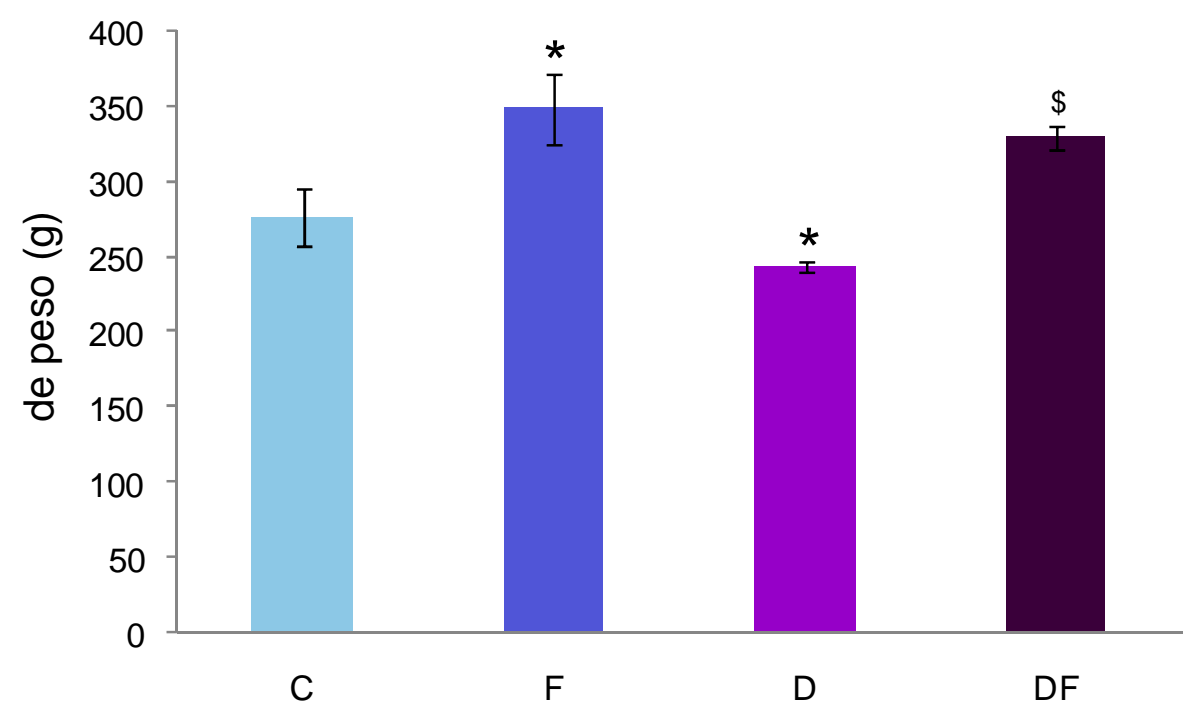

Figura 9: Ganho total de peso corporal. Representação do ganho de peso corporal por delta (peso final menos inicial) de 13 semanas nos grupos $(n=8)$ : controle $(C)$, frutose $(F)$, desnervado (D) e desnervado frutose (DF). ${ }^{*} p<0,05$ vs. $C, \$ p<0,05$ vs. $D$.

Observa-se na Figura 9 que os grupos tratados com frutose apresentam maior ganho de peso que seus respectivos controles, no entanto, apenas o $F$ foi significativamente maior que o $\mathrm{C}$, enquanto $\mathrm{O} \mathrm{D}$ foi menor que todos os outros, justificado por seu menor consumo calórico quando analisa-se pelo delta de peso corporal. Na Figura 10 podemos avaliar o ganho de peso semanal dos animais. 


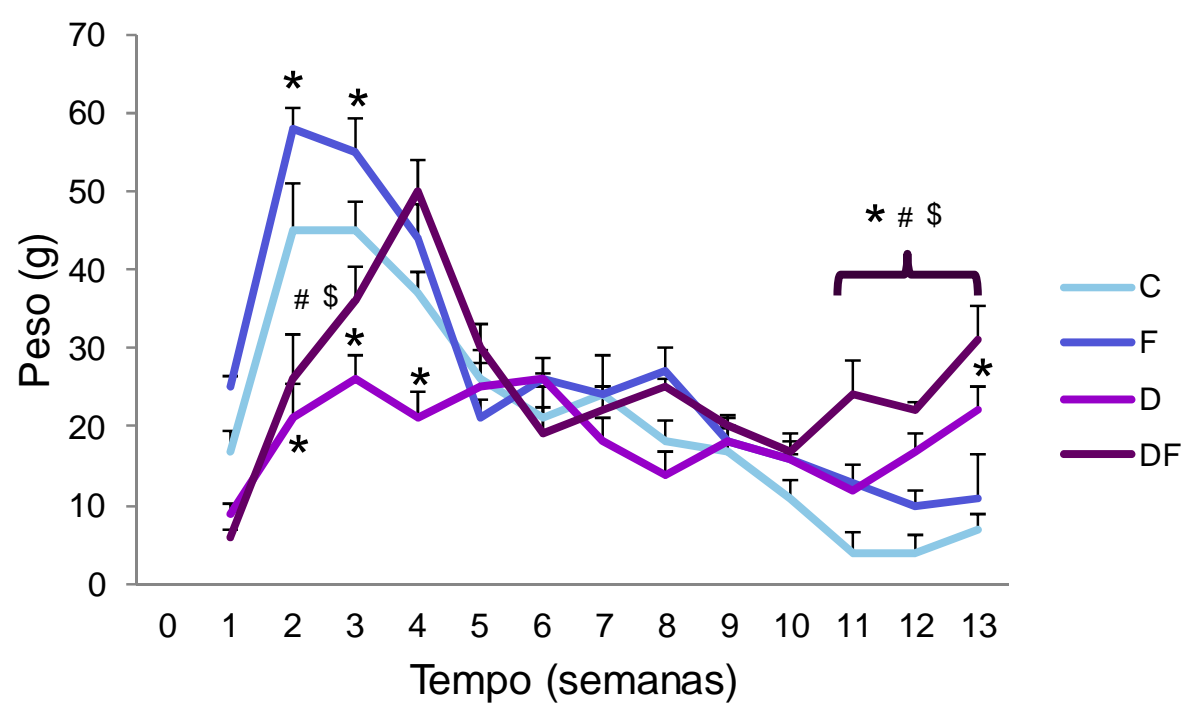

Figura 10: Ganho de peso semanal. Delta de peso corporal semanal nos grupos $(n=8)$ : controle $(C)$, frutose $(F)$, desnervado (D) e desnervado frutose (DF). ${ }^{*} p<0,05$ vs. $C, \# p<0,05$ vs. $F, \$ p<0,05$ vs. $D$.

Nota-se que em nenhum momento o grupo desnervado perdeu peso, no entanto, o seu ganho foi menor nas primeiras quatro semanas. O grupo $\mathrm{F}$ apresenta um ganho de peso exacerbado nas primeiras semanas, enquanto o DF parece se diferenciar dos demais a partir da décima semana. 


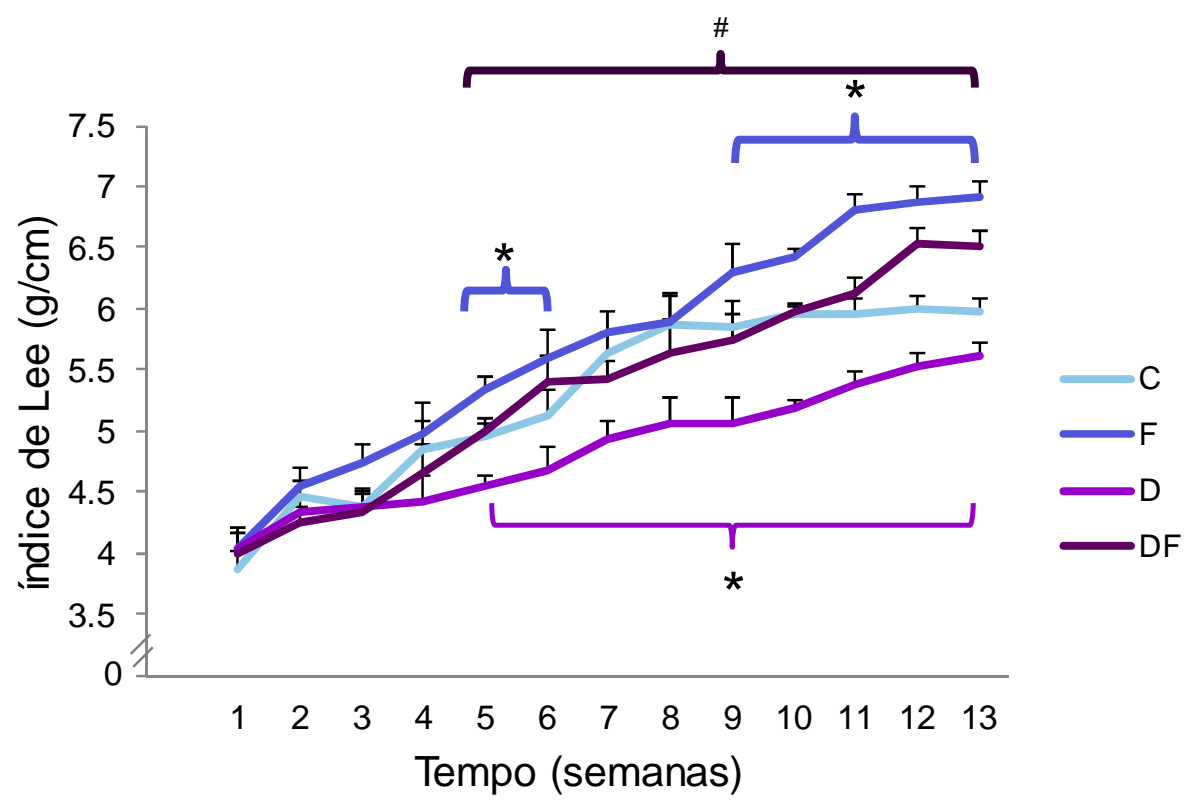

Figura 11: Índice de Lee. Relação entre peso e comprimento dos animais durante 13 semanas nos grupos $(n=8)$ : controle $(C)$, frutose $(F)$, desnervado $(D)$ e desnervado frutose $(D F) .{ }^{*} p<0,05$ vs. C, \# $p<0,05$ vs. $F$.

A partir destes resultados podemos gerar o índice de Lee, onde observamos na Figura 11 a relação entre peso corporal e tamanho dos animais. Nela podemos ver que os grupos com frutose apresentam maior índice que seus respectivos controles por quase todo o tempo de protocolo. Além disso, notamos que o grupo D permanece mais magro que o controle durante os experimentos.

\section{2) Perfil lipídico e gordura corporal}

Podemos observar na Figura 12 que os grupos tratados com frutose apresentam aumento dos níveis de triglicerídeos a partir da quinta semana, sendo que na sétima semana esta diferença já é comprovadamente devida ao procedimento. 


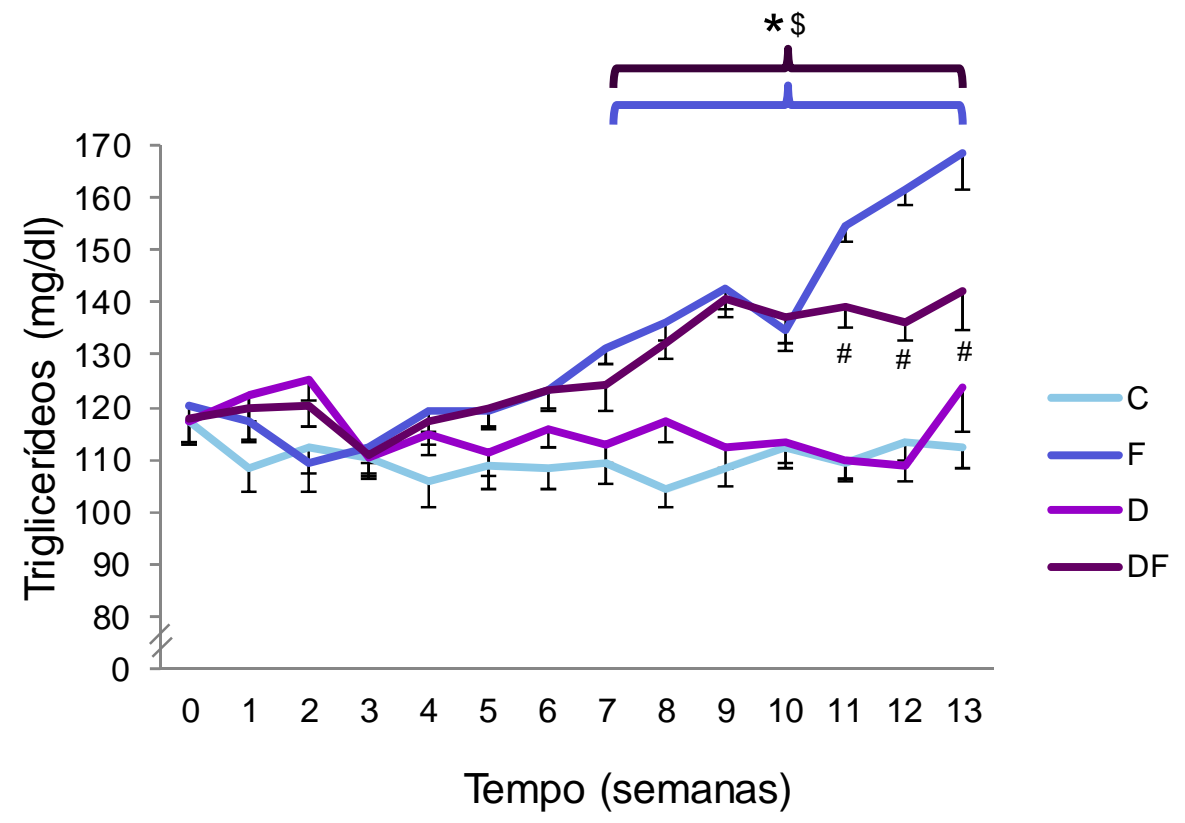

Figura 12: Triglicérides semanal. Avaliação semanal dos triglicerídeos durante 13 semanas nos grupos $(n=8)$ : controle $(C)$, frutose $(F)$, desnervado $(D)$ e desnervado frutose (DF). * $p<0,05$ vs. C, $\$$ $p<0,05$ vs. D.

Da mesma forma, podemos notar que os níveis de colesterol total também estão aumentados nos grupos que ingeriram frutose. $O$ grupo $F$ apresenta um aumento exponencial a partir da sétima semana, enquanto o DF mantém-se com uma elevação moderada (Figura 13). 


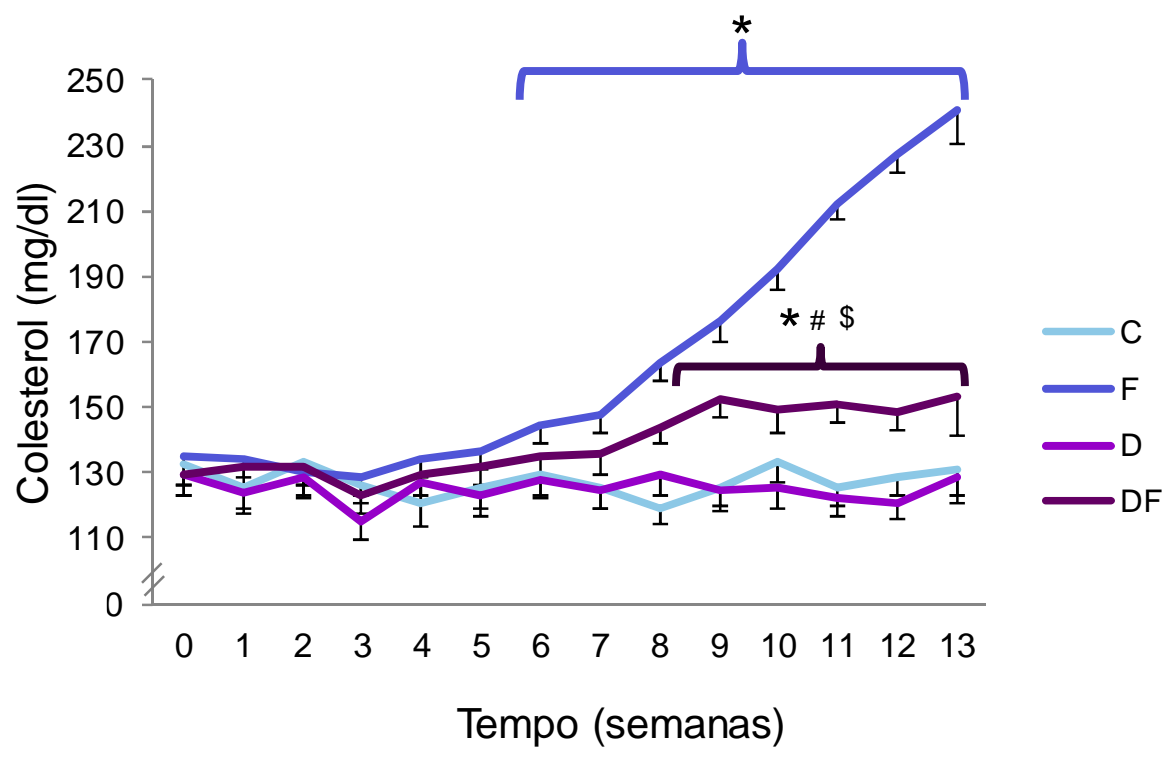

Figura 13: Colesterol semanal: Avaliação semanal do colesterol total durante 13 semanas nos grupos $(n=8)$ : controle $(C)$, frutose $(F)$, desnervado $(D)$ e desnervado frutose $(D F)^{\star} p<0,05$ vs. C, \# $p<0,05$ vs. $F, \$ p<0,05$ vs. $D$.

Justificando os valores alterados do perfil lipídico, podemos ver que o ganho de peso nos animais tratados com frutose gerou um acúmulo de gordura abdominal, como visto na Figura 14. 


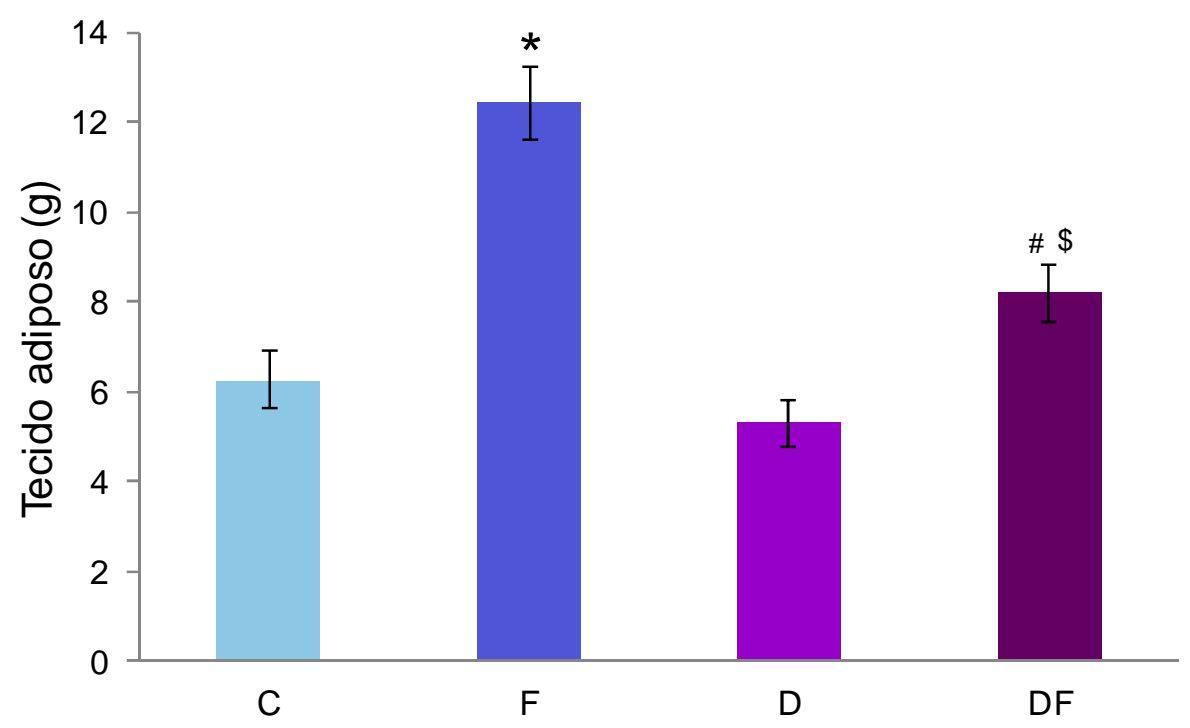

Figura 14: Tecido adiposo abdominal. Quantificação do tecido adiposo branco na cavidade abdominal dos animais ao final de 13 semanas nos grupos $(n=8)$ : controle $(C)$, frutose $(F)$, desnervado (D) e desnervado frutose (DF). ${ }^{*} p<0,05$ vs. $C, \# p<0,05$ vs. $F, \$ p<0,05$ vs. $D$.

\section{3) Glicemia e resistência à insulina.}

No período de 13 semanas de acompanhamento da glicemia em todos os grupos, observa-se que, apesar de não desenvolverem um quadro de hiperglicemia, o consumo de frutose no grupo $F$ foi capaz de aumentar os valores de glicemia a partir da segunda semana de experimento em relação ao grupo C (Figura 15). O mesmo comportamento foi observado no grupo DF, porém este aumento foi tardio, observado a partir do primeiro mês. Já o grupo D apresentou grande variação semanal nos valores de glicemia. 


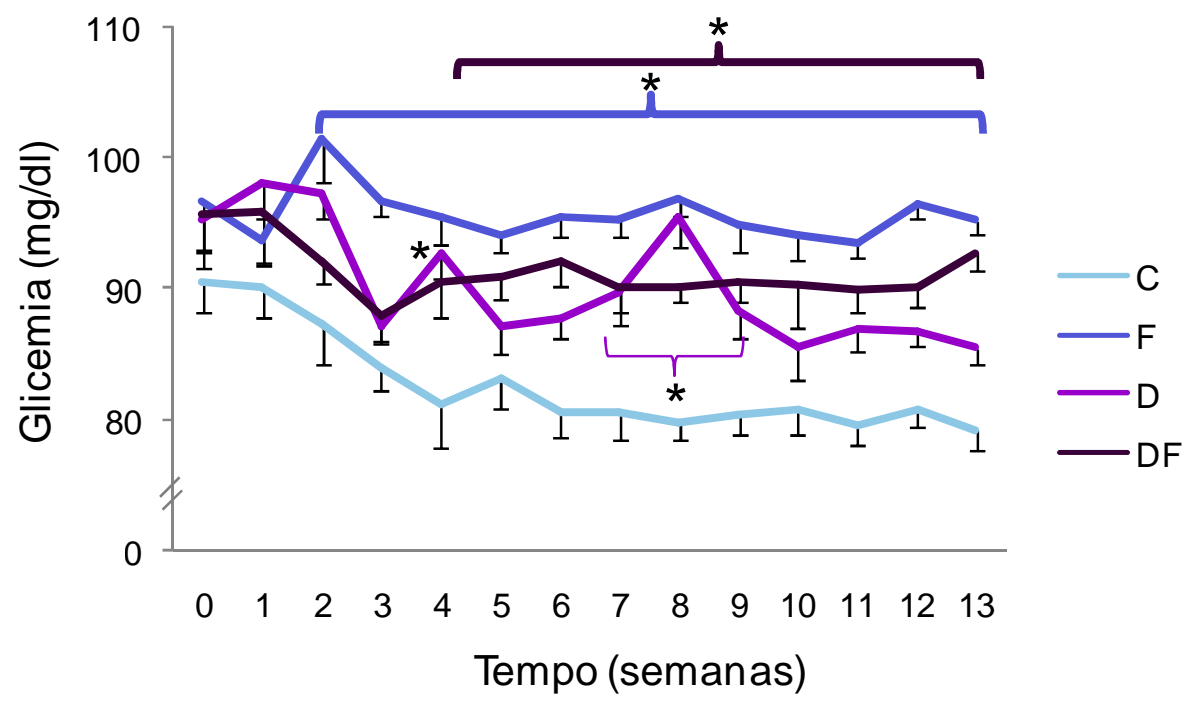

Figura 15: Glicemia de jejum. Valores de glicemia de jejum durante 13 semanas nos grupos $(n=8)$ : controle $(C)$, frutose $(F)$, desnervado (D) e desnervado frutose (DF). ${ }^{*} p<0,05$ vs. C.

Quanto ao índice de sensibilidade à insulina, nota-se que o grupo $\mathrm{F}$ apresentou redução do mesmo a partir do primeiro mês, indicando um quadro de resistência à insulina. $\mathrm{O}$ grupo $\mathrm{D}$ demonstrou, mais uma vez, grande variação de resposta ao longo do tempo, enquanto o grupo DF mantém-se com valores semelhantes ao grupo C (Figura 16). 


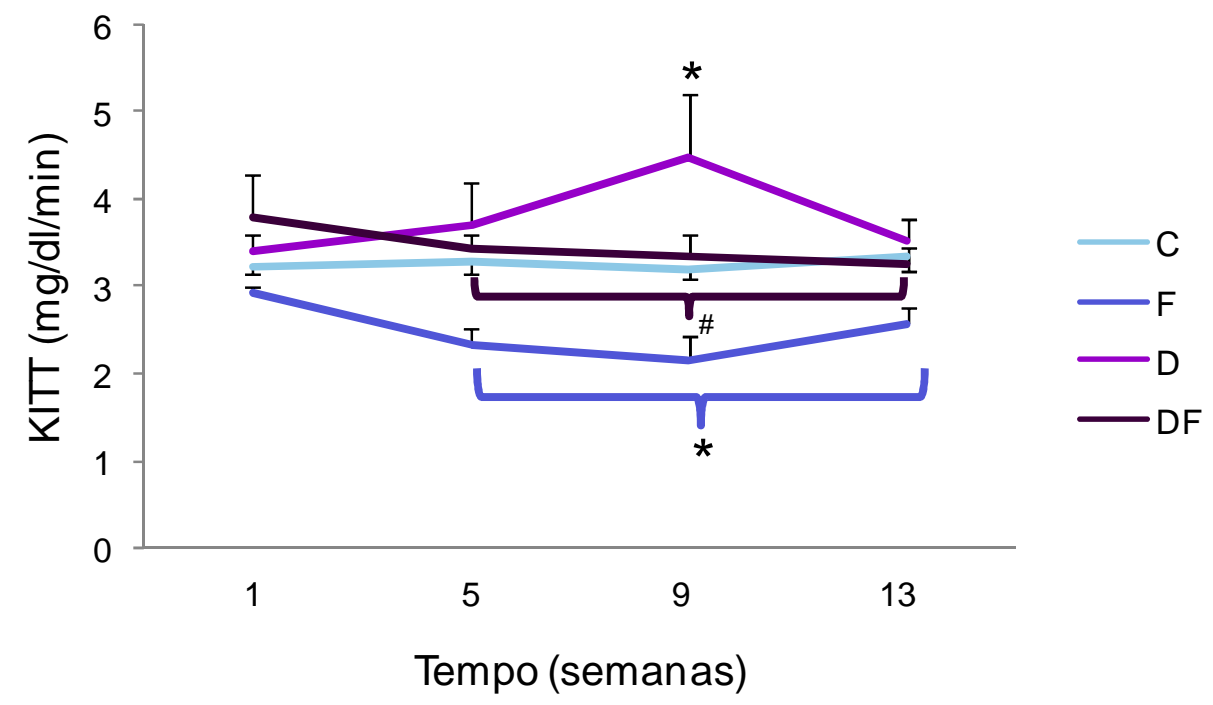

Figura 16: Índice de sensibilidade à insulina. Valores de KITT representando a sensibilidade à insulina nos grupos $(n=8)$ : controle $(C)$, frutose $(F)$, desnervado (D) e desnervado frutose (DF). ${ }^{*} p<0,05$ vs. $C, \# p<0,05$ vs. $F$.

\section{4) Gaiola metabólica}

Os valores do consumo de ração, assim como de água, coletados em gaiola metabólica são apresentados a seguir na Tabela 1. OS resultados são semelhantes aos anteriores onde os grupos experimentas consumiram menos ração e os grupos com frutose ingeriram mais água. 
Tabela 1: Consumo de água e ração.

\begin{tabular}{|c|c|c|c|c|}
\hline \multirow{2}{*}{ A } & \multicolumn{4}{|c|}{ Consumo de água(ml) } \\
\hline & C & $\mathrm{F}$ & D & DF \\
\hline Basal & $38,0 \pm 6,1$ & $53,1 \pm 7,9$ * & $23,0 \pm 6,4$ * & $24,8 \pm 3,1^{*}$ \# \\
\hline 1 mês & $38,6 \pm 3,7$ & $68,5 \pm 8,9$ * & $29,1 \pm 3,1$ * & $47,0 \pm 3,5^{*} \# \$$ \\
\hline 2 meses & $32,3 \pm 7,5$ & $94,1 \pm 10,9$ * & $31,4 \pm 4,1$ & $57,3 \pm 5,7$ \#\$ \\
\hline 3 meses & $23,6 \pm 6,5$ & $95,5 \pm 5,6^{*}$ & $37,8 \pm 6,3$ & $80,5 \pm 4,8^{*} \# \$$ \\
\hline \multirow{2}{*}{ B } & \multicolumn{4}{|c|}{ Consumo de ração(g) } \\
\hline & $\mathrm{C}$ & $\mathrm{F}$ & $D$ & DF \\
\hline Basal & $22,6 \pm 2,3$ & $22,6 \pm 2,1$ & $16,4 \pm 2,9$ * & $14,4 \pm 2,4$ * \# \\
\hline 1 mês & $58,0 \pm 3,7$ & $26,0 \pm 8,2^{*}$ & $25,9 \pm 2,6$ * & $17,0 \pm 2,8^{*} \# \$$ \\
\hline 2 meses & $23,8 \pm 4,5$ & $16,8 \pm 3,1^{*}$ & $23,0 \pm 3,5$ & $14,3 \pm 2,1^{*} \$$ \\
\hline 3 meses & $19,6 \pm 5,2$ & $14,0 \pm 4,5$ & $24,0 \pm 4,5$ & $14,5 \pm 2,1 *_{\$}$ \\
\hline
\end{tabular}

Consumo de água $(\mathbf{A})$ e ração $(\mathbf{B})$, em média e erro padrão, mensurados em gaiola metabólica durante o protocolo nos grupos $(n=8)$ : controle $(C)$, frutose $(F)$, desnervado (D) e desnervado frutose (DF). ${ }^{*} p<0,05$ vs. $C, \# p<0,05$ vs. $F, \$ p<0,05$ vs. $D$.

Observando a Figura 17 pode-se notar que o volume urinário nos grupos tratados com frutose foi superior aos demais grupos a partir da segunda medida, sendo que no grupo $\mathrm{F}$ o volume urinário foi superior ao do grupo $\mathrm{C}$ na primeira medida, realizada no início do protocolo, quando os animais haviam consumido frutose por apenas um dia. 


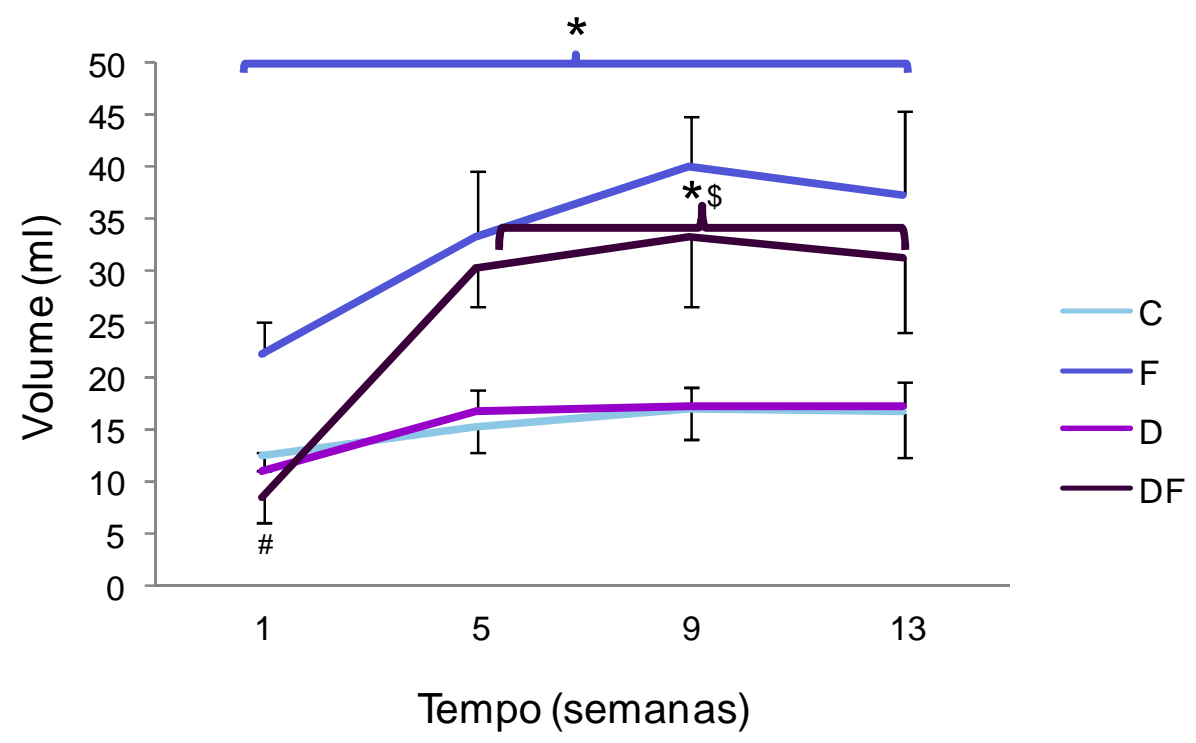

Figura 17: Volume urinário. Valores de urina médio \pm erro padrão da média produzida pelos grupos $(n=8)$ : controle $(C)$, frutose $(F)$, desnervado (D) e desnervado frutose (DF). * $p<0,05$ vs. $C, \$ p<0,05$ vs. D.

Quanto ao valor total de excretas fecais, pode-se notar na Figura 18 que todos os grupos experimentais apresentaram um menor valor de excretas no primeiro e segundo mês de protocolo, quando comparados ao $\mathrm{C}$, sendo que apenas o grupo D permaneceu com valores menores que este no terceiro mês. 


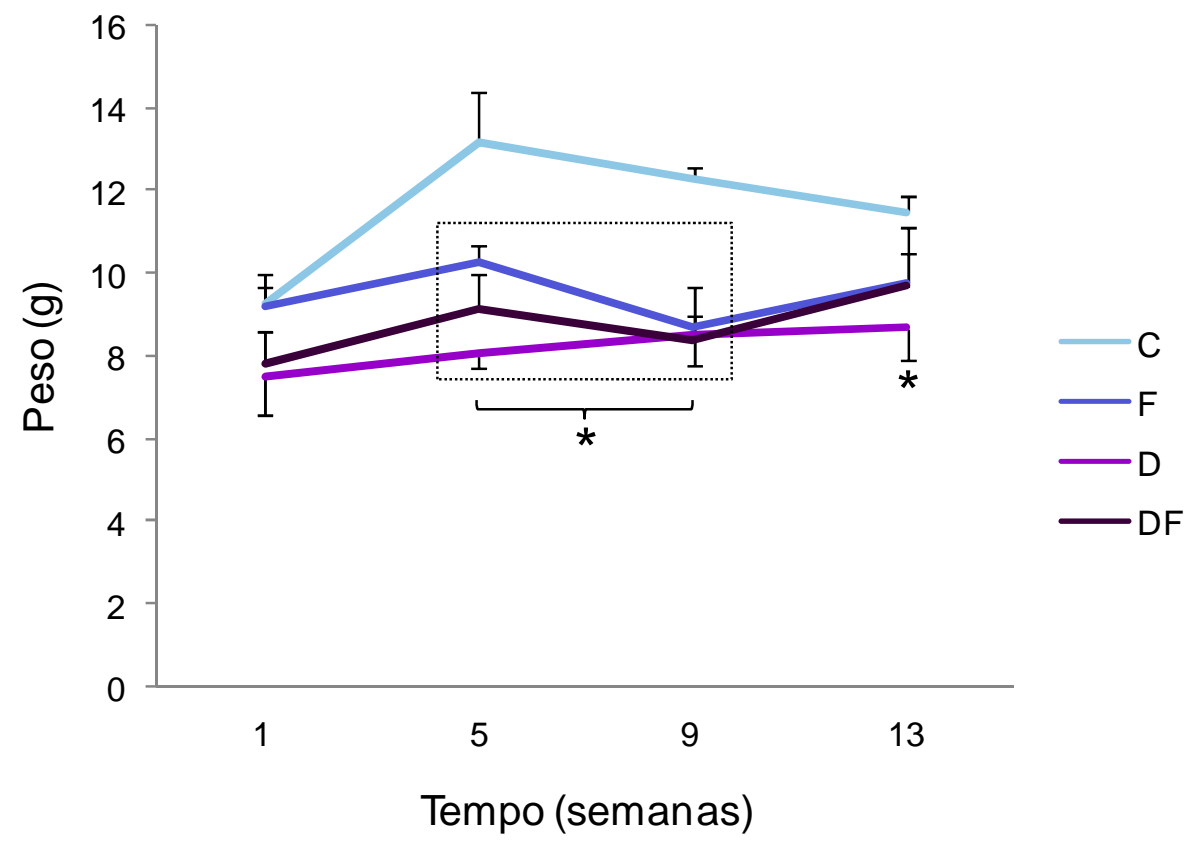

Figura 18: Peso fecal. Peso médio \pm erro padrão da média de fezes coletadas em gaiola metabólica nos grupos $(n=8)$ : controle $(C)$, frutose $(F)$, desnervado (D) e desnervado frutose (DF). * $p<0,05$ vs. C.

As análises laboratoriais realizadas em amostras de urina coletadas em todas as etapas podem ser observadas a seguir. 


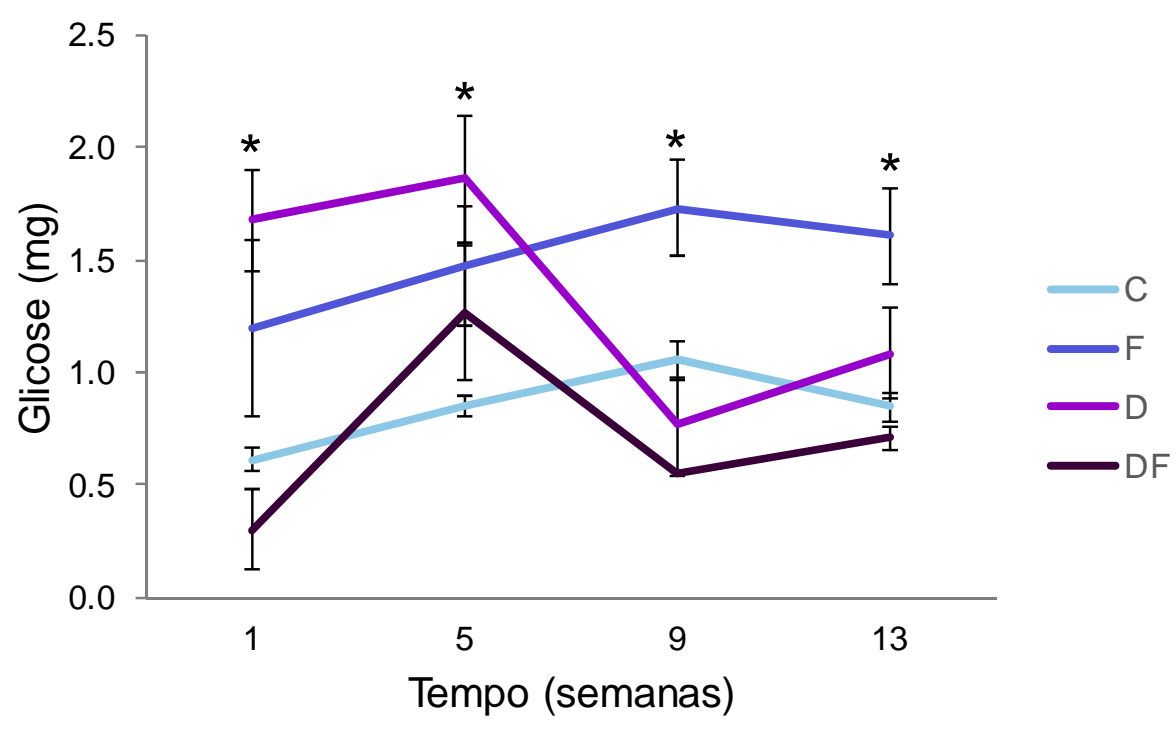

Figura 19: Glicose urinária. Dosagem de glicose na urina ao longo de 13 semanas nos grupos $(n=8)$ : controle $(C)$, frutose $(F)$, desnervado (D) e desnervado frutose (DF). * $p<0,05$ vs. C.

Podemos observar na Figura 19 expressivo aumento da glicose urinária após a DSA. Este aumento permanece presente mesmo um mês após a cirurgia, voltando à valores de normalidade nos meses seguintes. Vale mencionar que o consumo de frutose aumentou gradualmente os valores de glicose urinária, quando comparado ao controle. Não houve diferenças no grupo DF. 


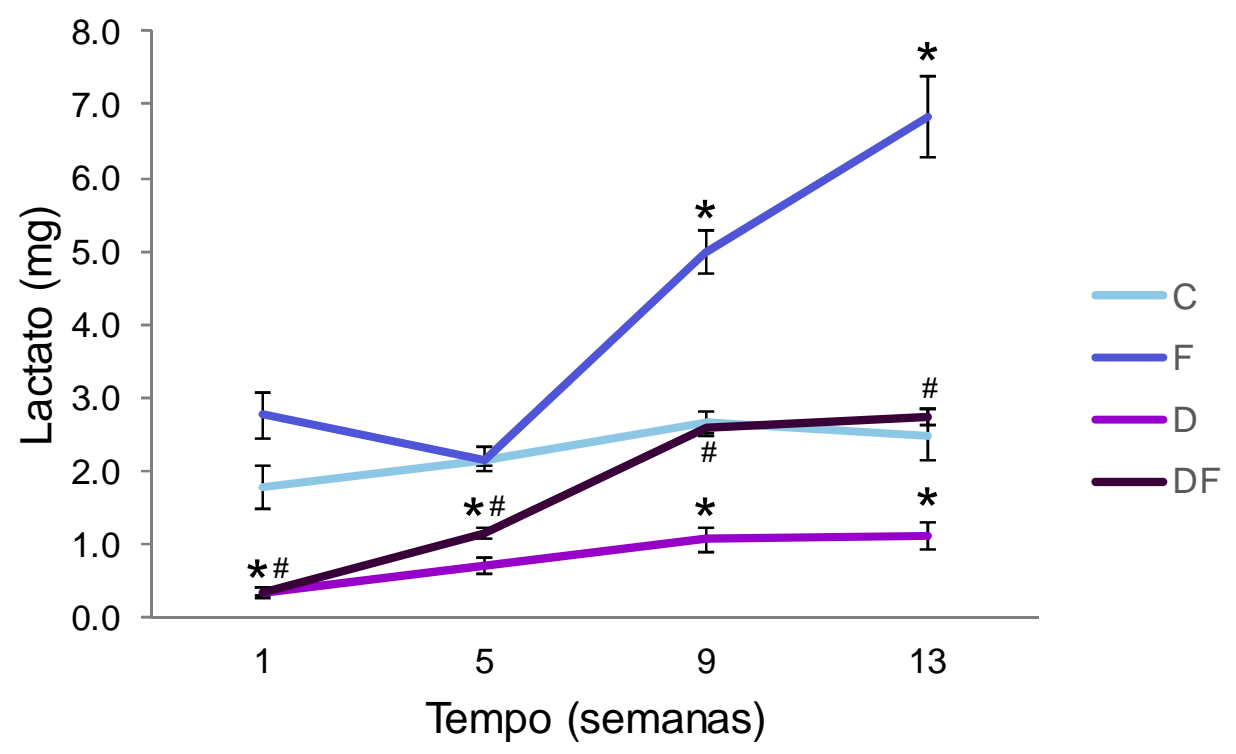

Figura 20: Lactato urinário. Dosagem de lactato na urina ao longo de 13 semanas nos grupos $(n=8)$ : controle (C), frutose (F), desnervado (D) e desnervado frutose (DF). ${ }^{*} p<0,05$ vs. $C, \# p<0,05$ vs. $F$.

Já em relação aos níveis de lactato na urina, podemos observar na Figura 20 que a desnervação promoveu redução deste parâmetro em ralação aos seus controles. Por outro lado a frutose isoladamente elevou os níveis de lactato a partir da segunda metade do protocolo. 


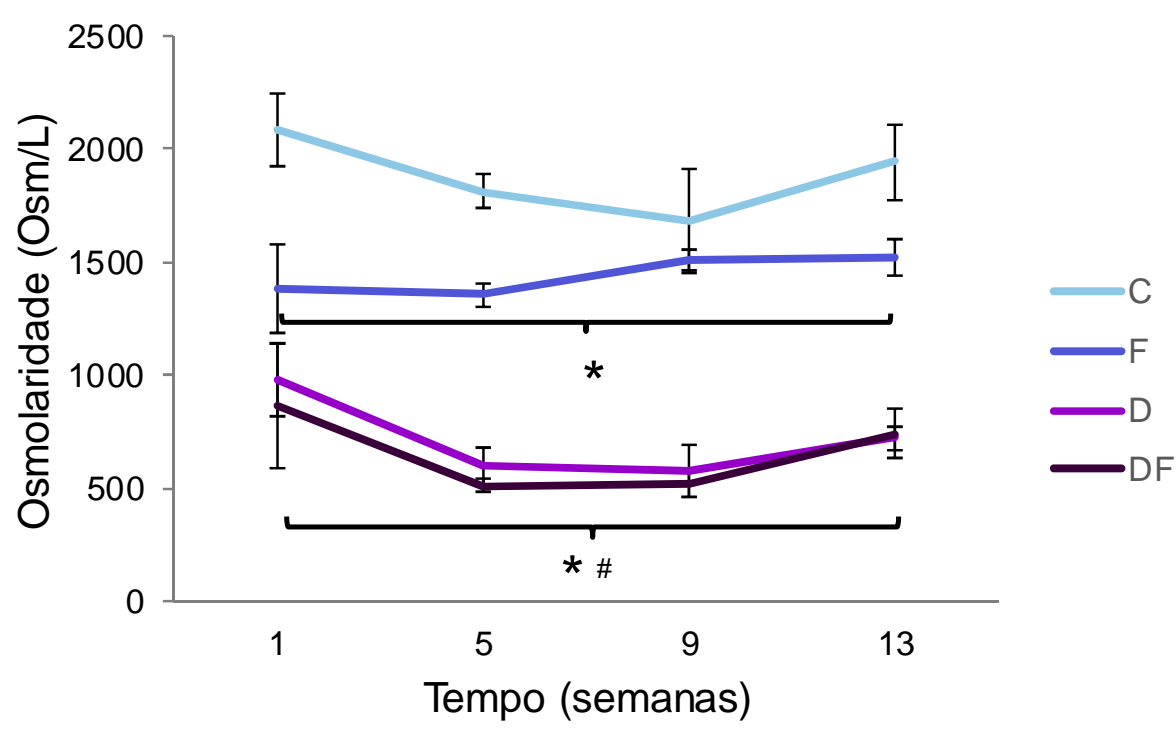

Figura 21: Osmolaridade urinária. Dosagem da osmolaridade na urina ao longo de 13 semanas nos grupos $(n=8)$ : controle $(C)$, frutose $(F)$, desnervado (D) e desnervado frutose (DF). * $p<0,05$ vs. C, \# $\mathrm{p}<0,05$ vs. $F$.

$\mathrm{Na}$ Figura 21 podemos notar como o consumo de frutose reduz a osmolaridade urinária quando comparado ao controle. No entanto, a DSA reduz muito mais, fazendo com que o grupo DF apresente redução de osmolaridade em todos os tempos analisados quando comparado ao $\mathrm{C}$ e também ao $\mathrm{F}$. 


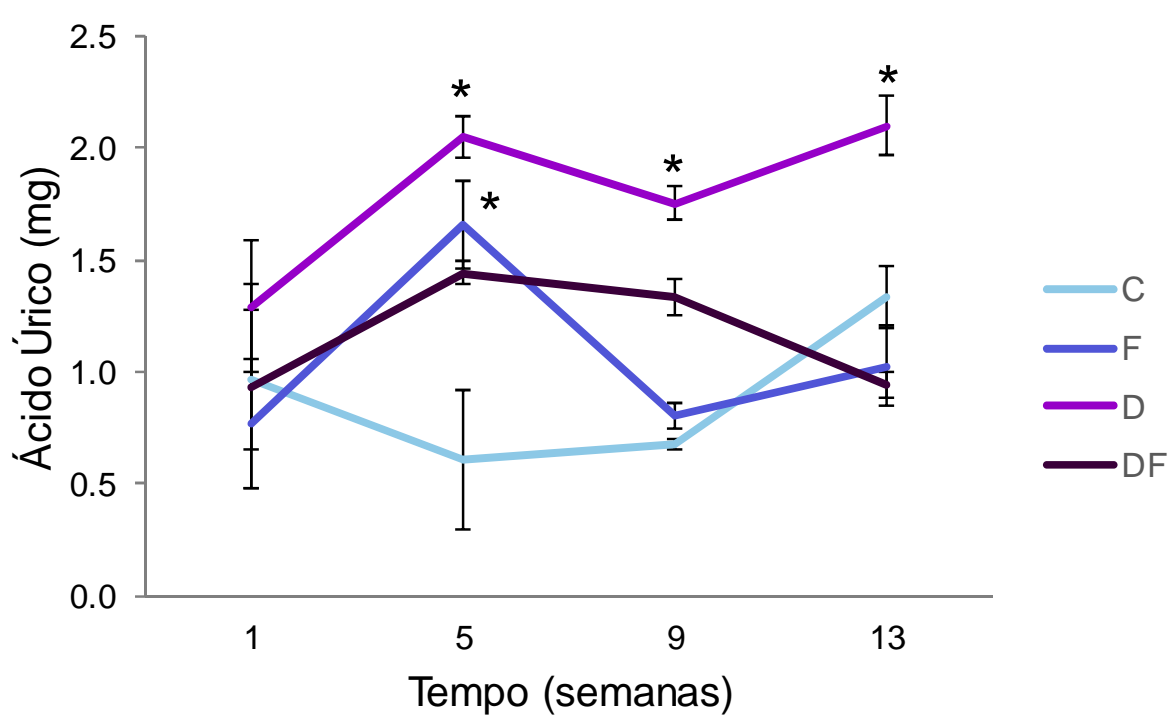

Figura 22 Ácido úrico urinário. Avaliação do ácido úrico urinário ao longo de 13 semanas nos grupos $(n=8)$ : controle $(C)$, frutose $(F)$, desnervado $(D)$ e desnervado frutose $(D F) .{ }^{*} p<0,05$ vs. C.

A ausência do controle barorreflexo foi capaz de alterar o ácido úrico na urina, como demonstrado na Figura 22. O grupo $\mathrm{D}$ possui aumento de ácido úrico urinário ao longo do tempo quando comparado ao $\mathrm{C}$. A ingesta de frutose foi capaz atenuar esse aumento no grupo DF. 


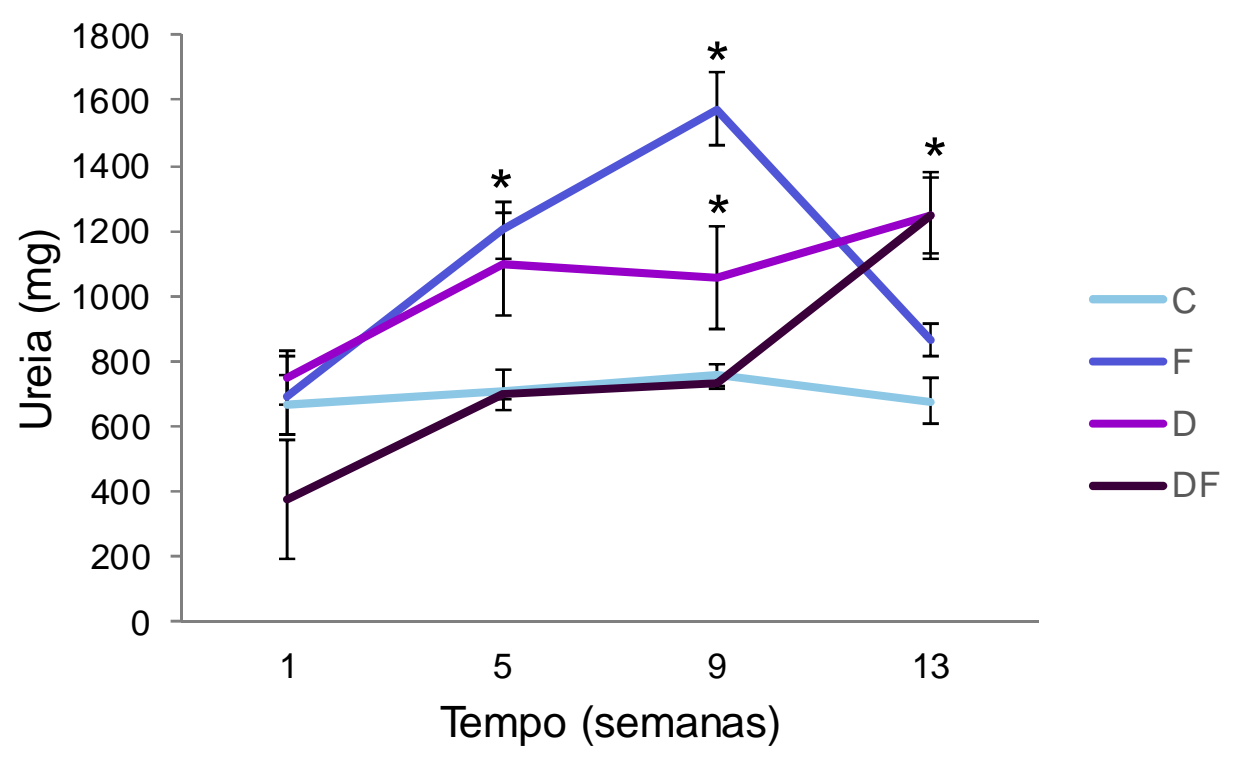

Figura 23: Ureia urinária. Dosagem dos valores ureia na urina ao longo de 13 semanas nos grupos $(n=8)$ : controle $(C)$, frutose $(F)$, desnervado(D) e desnervado frutose(DF). ${ }^{*} p<0,05$ vs. $C$.

O mesmo ocorreu com os valores de ureia na urina. O grupo D apresentou aumento dos níveis de ureia, enquanto a associação com frutose reduziu este parâmetro nas três primeiras medidas (Figura 23). Além disso, o grupo F apresentou aumento nos valores de ureia durante as medidas intermediárias. 


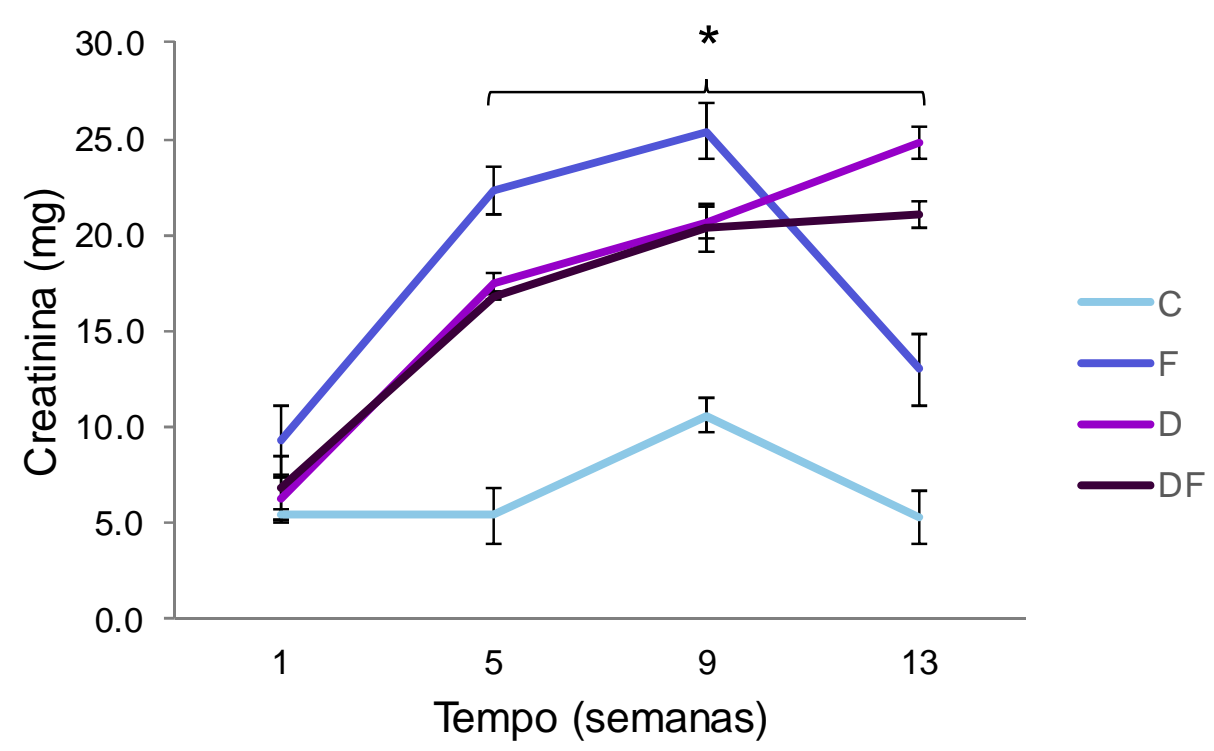

Figura 24: Creatinina urinária. Dosagem dos valores de creatinina na urina ao longo de 13 semanas nos grupos $(n=8)$ : controle $(C)$, frutose $(F)$, desnervado $(D)$ e desnervado frutose (DF). * $p<0,05$ vs. C.

Ao avaliarmos a creatinina presente na urina destes animais observamos que todas as intervenções foram capazes de aumentar este marcador na urina, como pode ser observado na Figura 24. A seguir podemos observar as dosagens de íons na urina. 
Tabela 2: Concentração iônica urinária.

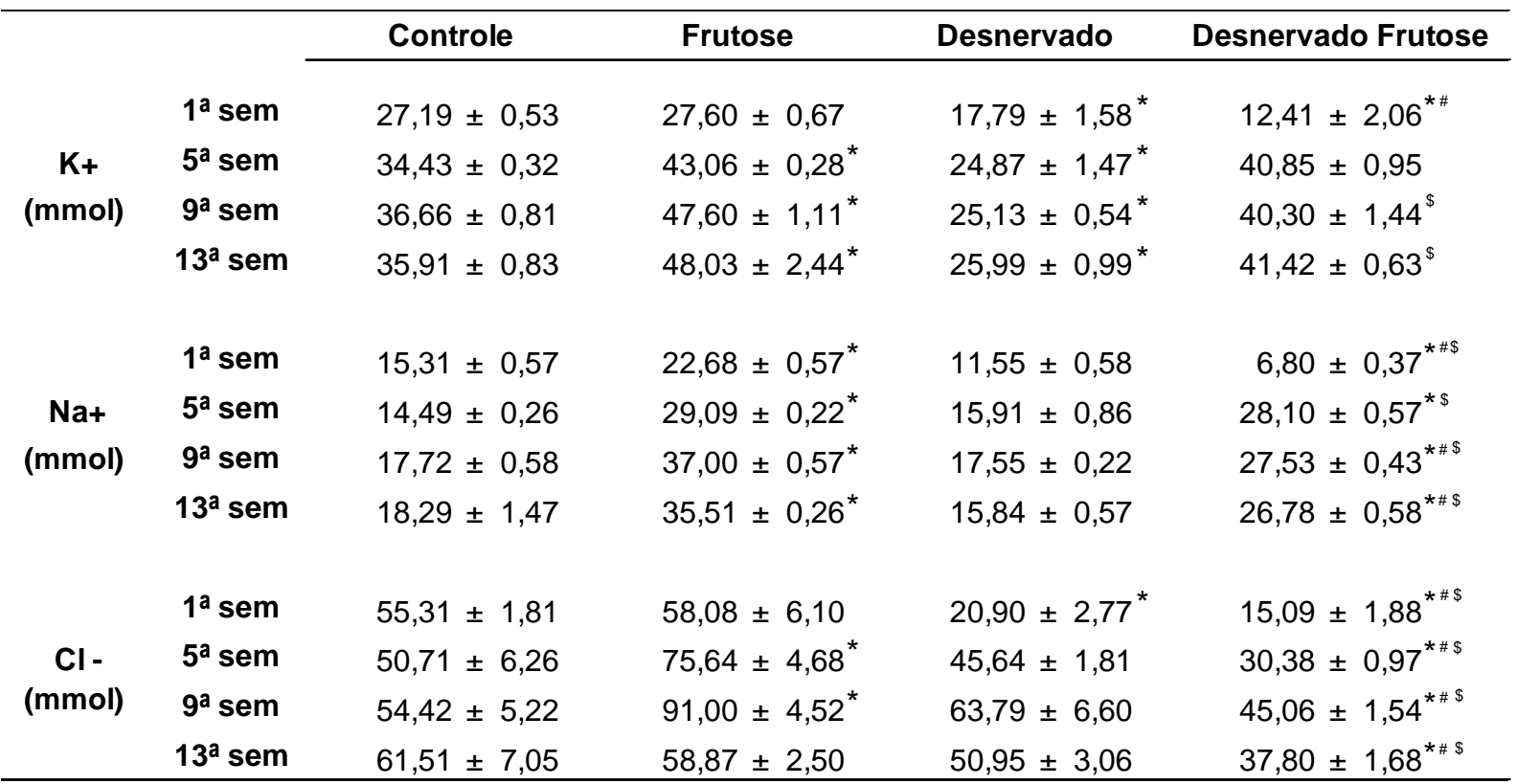

Valores de concentração dos íons potássio $\left(\mathrm{K}^{+}\right)$, Sódio $\left(\mathrm{Na}^{+}\right)$e Cloro $\left(\mathrm{Cl}^{-}\right)$na urina ao longo de 13 semanas nos grupos $(n=8)$ : controle $(C)$, frutose $(F)$, desnervado (D) e desnervado frutose (DF). ${ }^{*} p<0,05$ vs. C, \# $p<0,05$ vs. F, $\$ p<0,05$ vs. D.

De forma geral podemos observar que os grupos com frutose excretam mais íons na urina a partir da quinta semana (Tabela 2). Os animais desnervados reduziram a excreção de $\mathrm{K}^{+}$. Já no DF os parâmetros apresentaram-se como respostas intermediárias, tendo um comportamento diferente dos três demais grupos.

\section{5) Avaliações hemodinâmicas}

O registro hemodinâmico via radiotelemetria durante todo o procedimento possibilitou o acompanhamento temporal do comportamento dos parâmetros cardiovasculares durante as treze semanas de protocolo. Vale ressaltar que os resultados a seguir foram obtidos com os animais acompanhados por telemetria. 
Analisando o comportamento pressórico a partir da média de 24 horas ao longo das 13 semanas de protocolo nota-se comportamento observado na Figura 25.

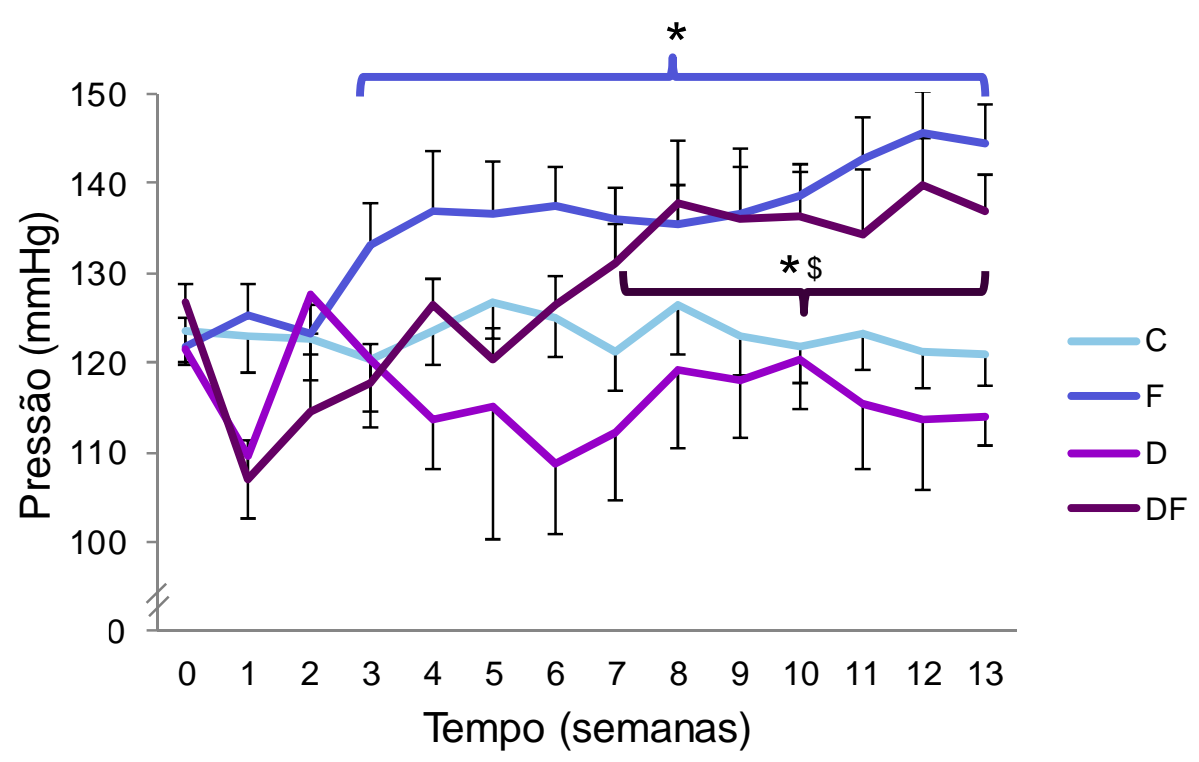

Figura 25: Pressão arterial sistólica. Pressão arterial sistólica ao longo de 13 semanas nos grupos $(n=8)$ : controle $(C)$, frutose $(F)$, desnervado $(D)$ e desnervado frutose (DF). * $p<0,05$ vs. $C, \$ p<0,05$ vs. D.

Os valores de pressão arterial sistólica indicam um progressivo aumento ao longo do tempo nos grupos que receberam frutose. Os valores de pressão no grupo desnervado apresentaram-se com acentuado aumento na labilidade, variando muito os níveis pressóricos a cada semana. O grupo $\mathrm{F}$ apresentou valores de PA mais elevados, comparando-se ao controle, em alguns momentos iniciais e a partir da terceira semana até o final do protocolo. Situação semelhante ocorreu com o grupo DF, porém este apresentou diminuição da PA na primeira semana e crescente aumento, até que a partir da sétima semana foi significativamente maior que a do grupo C. 


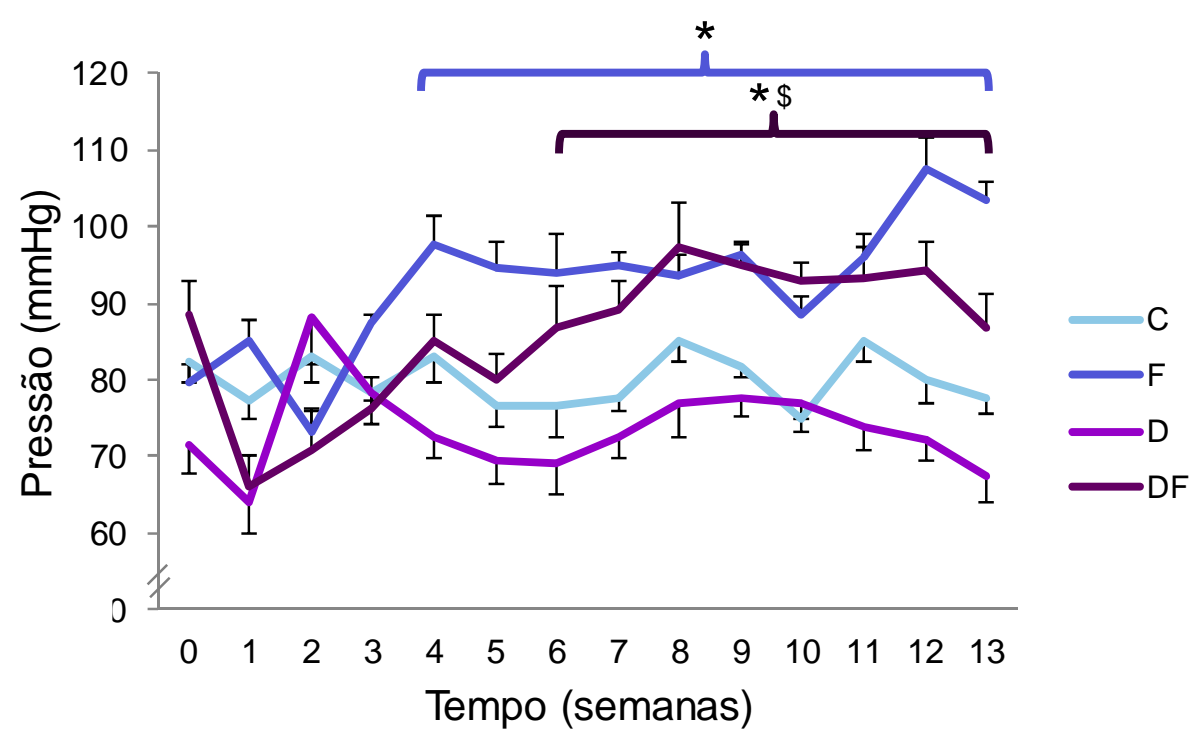

Figura 26: Pressão arterial diastólica. Pressão arterial diastólica ao longo de 13 semanas nos grupos $(n=8)$ : controle $(C)$, frutose $(F)$, desnervado $(D)$ e desnervado frutose $(D F) .{ }^{*} p<0,05$ vs. C, $\$$ $\mathrm{p}<0,05$ vs. $D$.

Este comportamento repetiu-se nos valores de pressão arterial diastólica (PAD) (Figura 26) e na pressão arterial média (PAM) (Figura 27). 


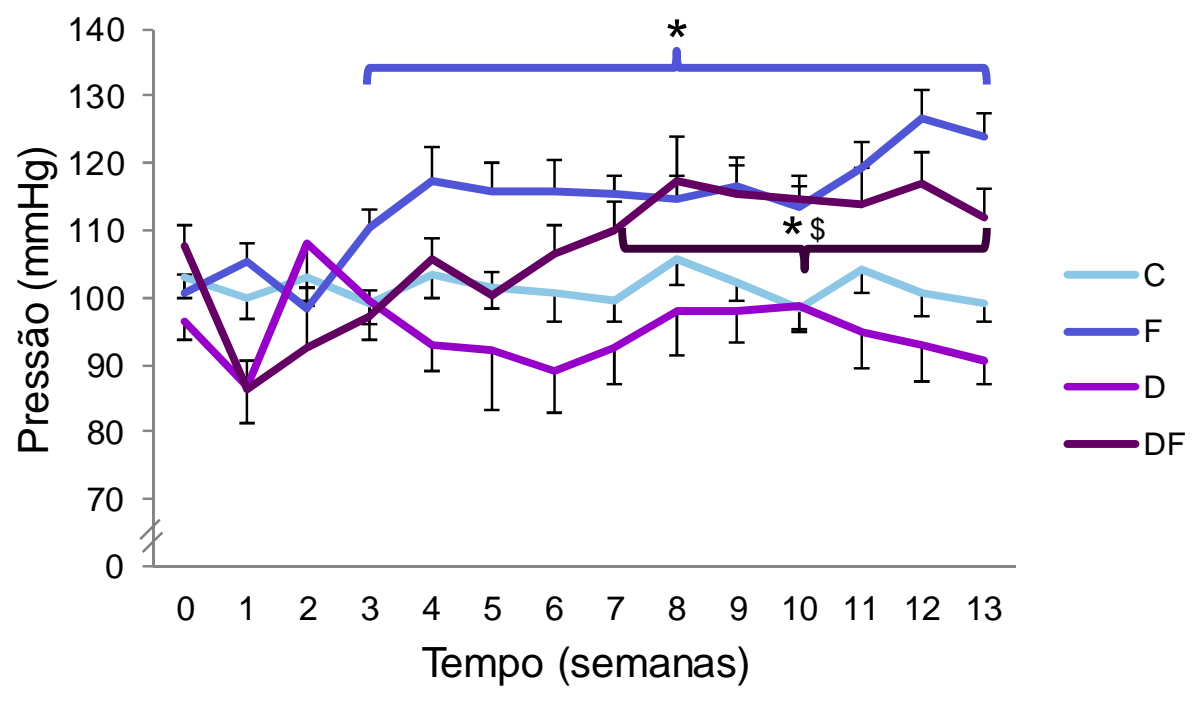

Figura 27: Pressão arterial média. Pressão arterial média ao longo de 13 semanas nos grupos $(n=8)$ : controle $(C)$, frutose $(F)$, desnervado (D) e desnervado frutose (DF). ${ }^{*} p<0,05$ vs. $C, \$ p<0,05$ vs. D.

Pode-se observar a seguir (Figura 28) os valores e comportamento observados quanto a FC. 


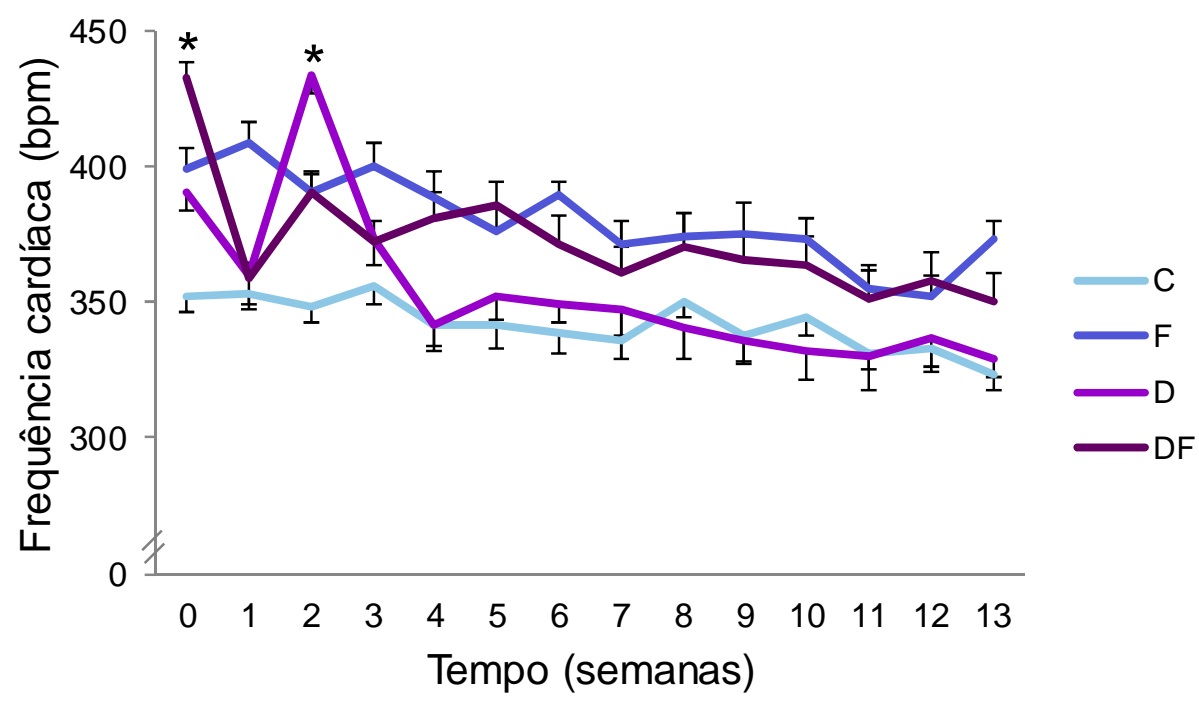

Figura 28: Frequência cardíaca. Frequência cardíaca ao longo de 13 semanas nos grupos $(n=8)$ : controle $(C)$, frutose $(F)$, desnervado (D) e desnervado frutose (DF). ${ }^{*} p<0,05$ vs. C.

Esses resultados evidenciam um comportamento de frequência cardíaca muito semelhante entre os grupos, não sendo possível notar possíveis alterações nos valores semanais. No entanto, nota-se que os grupos tratados com frutose parecem apresentar um pequeno aumento em relação aos demais.

\section{6) Análise de variabilidade da FC e da PAS}

A variância do intervalo de pulso está menor nos grupos desnervados, indicando uma diminuição da modulação total (Figura 29). 


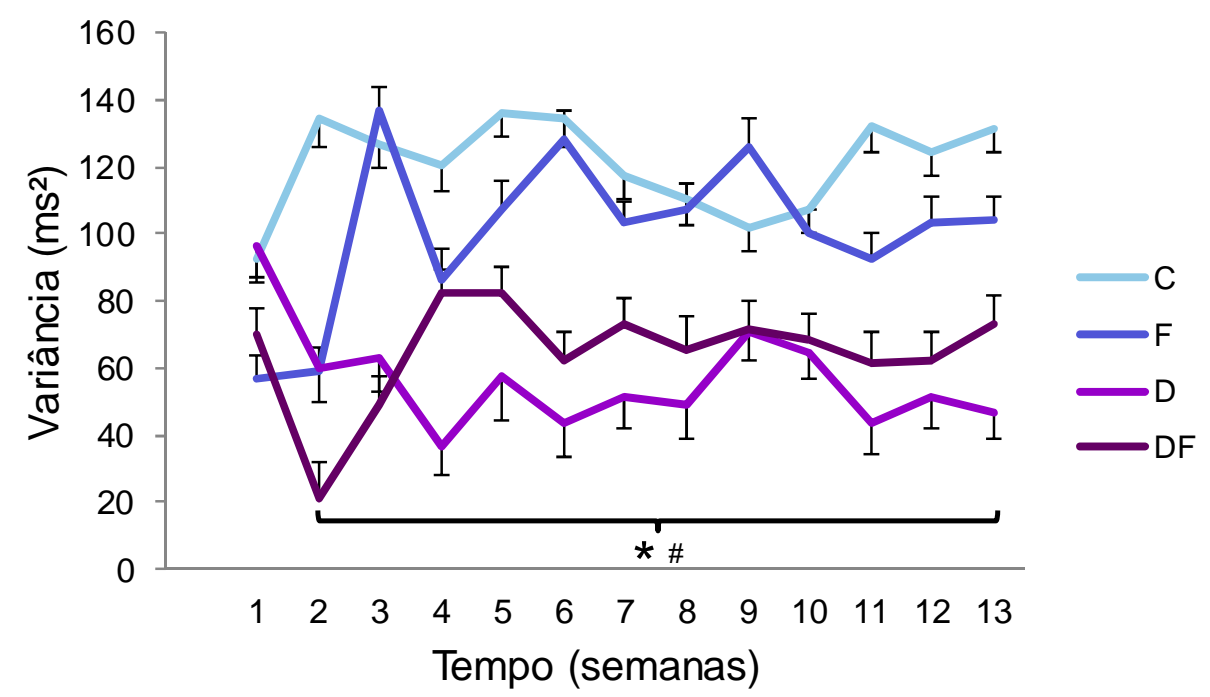

Figura 29: Variância do intervalo de pulso. Média da variância do intervalo de pulso durante 13 semanas nos grupos $(n=8)$ : controle $(C)$, frutose $(F)$, desnervado $(D)$ e desnervado frutose (DF). ${ }^{*} p<0,05$ vs. $C, \# p<0,05$ vs. $F$.

O RMSSD, índice relacionado à ativação vagal, não apresentou diferenças significativas como demonstrado na Figura 30.

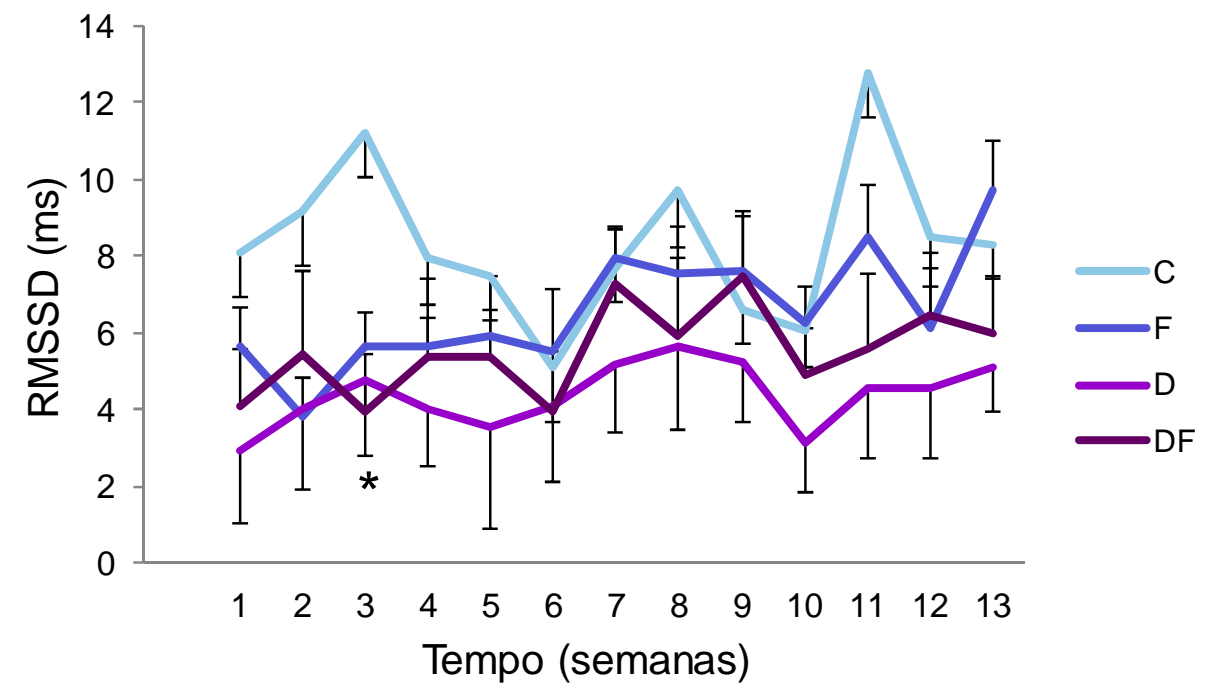

Figura 30: RMSSD. Média do RMSSD durante 13 semanas nos grupos $(n=8)$ : controle (C), frutose $(F)$, desnervado (D) e desnervado frutose (DF). 
Ao avaliarmos a variabilidade total cardíaca podemos observar que o grupo frutose apresenta aumento da modulação simpática absoluta a partir da terceira semana (Figura 31).

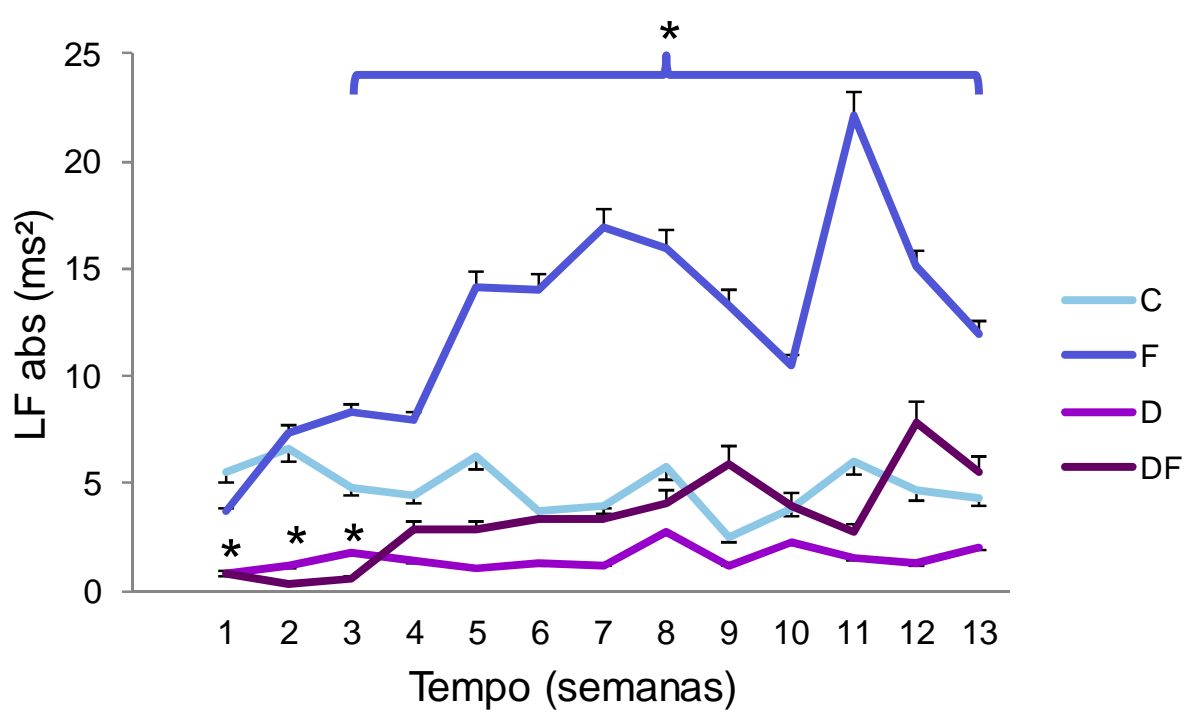

Figura 31: Modulação simpática cardíaca absoluta. Avaliação temporal de 13 semanas da modulação simpática cardíaca nos grupos $(n=8)$ : controle $(C)$, frutose $(F)$, desnervado (D) e desnervado frutose (DF). ${ }^{*} p<0,05$ vs. $C$.

Todos os tratamentos foram capazes de reduzir modulação parassimpática total nas seis primeiras semanas, sendo que o grupo $D$ permaneceu com valores reduzidos até o fim do protocolo (Figura 32). 


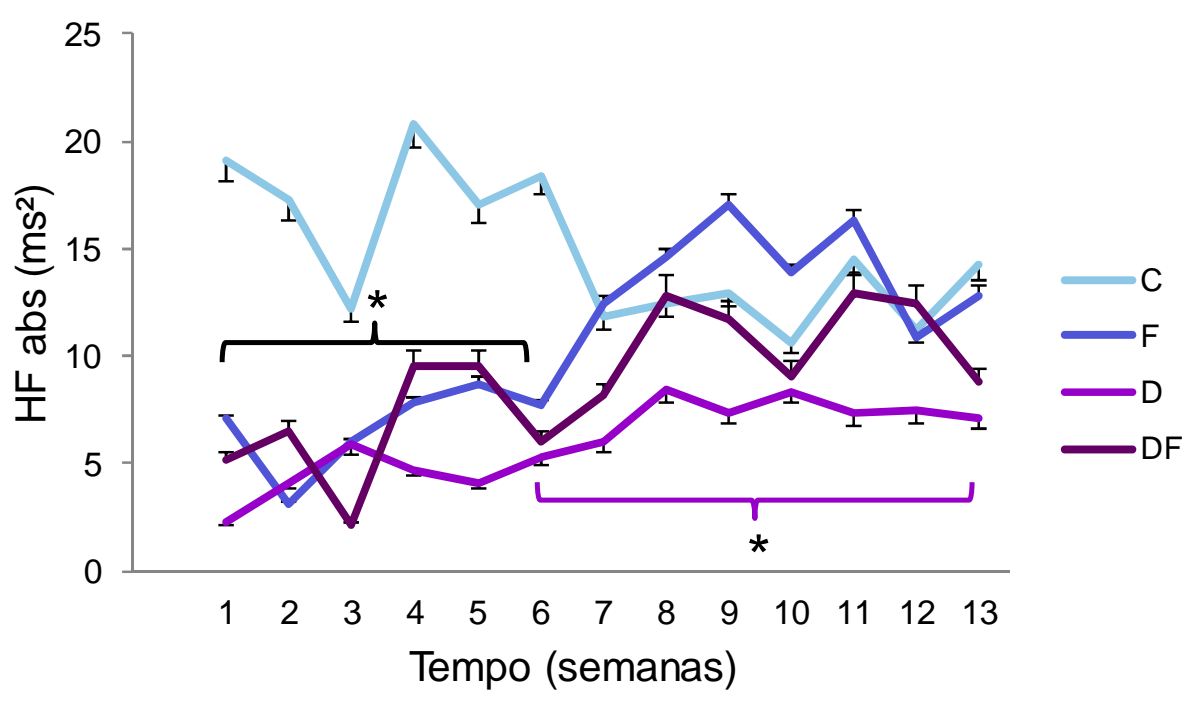

Figura 32: Modulação parassimpática cardíaca absoluta. Avaliação temporal de 13 semanas da modulação parassimpática cardíaca nos grupos $(n=8)$ : controle $(C)$, frutose $(F)$, desnervado (D) e desnervado frutose (DF). ${ }^{*} p<0,05$ vs. C.

Ao analisarmos a modulação percentual de cada componente sobre a frequência cardíaca podemos notar que o simpático se mantém aumentado no grupo F (Figura 33), enquanto a modulação vagal está diminuída quando comparado ao controle (Figura 34). 


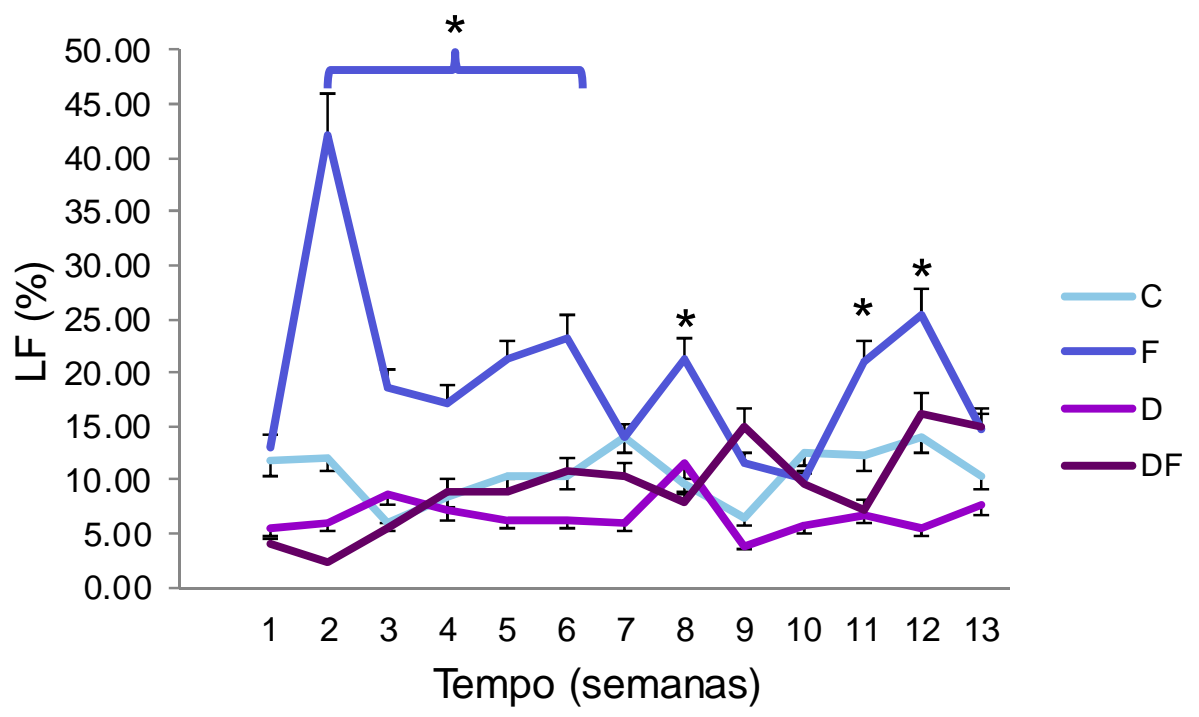

Figura 33: Modulação simpática cardíaca percentual. Avaliação temporal de 13 semanas da modulação simpática cardíaca percentual nos grupos $(n=8)$ : controle $(C)$, frutose $(F)$, desnervado (D) e desnervado frutose (DF). * $p<0,05$ vs. $C$.

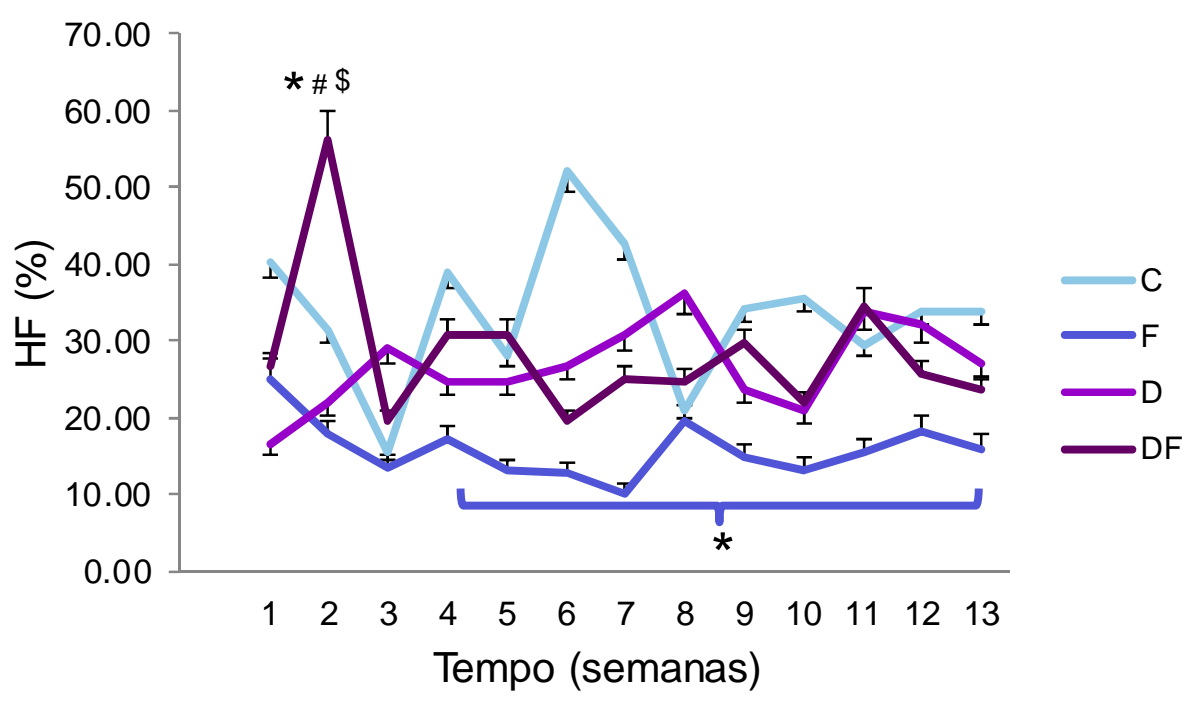

Figura 34: Modulação parassimpática cardíaca percentual. Avaliação temporal de 13 semanas da modulação parassimpática cardíaca percentual nos grupos $(n=8)$ : controle $(C)$, frutose $(F)$, desnervado (D) e desnervado frutose (DF). * $p<0,05$ vs. $C$, \# $p<0,05$ vs. F, $\$ p<0,05$ vs. $D$.

Quanto à modulação relativa, podemos observar que o grupo frutose manteve aumentado os valores de simpático por todo o protocolo (Figura 35) e a modulação 
vagal reduzida (Figura 36). Vale ressaltar que, apesar de os grupos desnervados apresentarem redução da modulação vagal absoluta, seus valores normalizados são semelhantes aos do grupo controle.

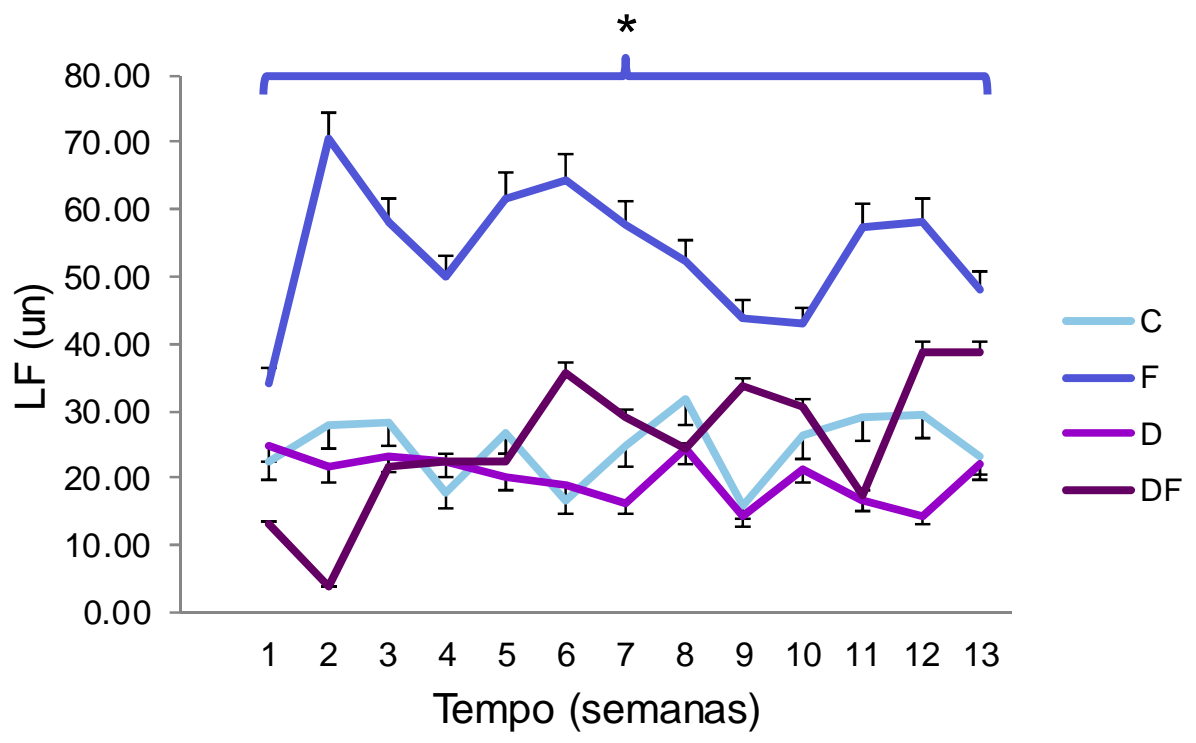

Figura 35: Modulação simpática cardíaca relativa. Avaliação temporal de 13 semanas da modulação simpática cardíaca relativa nos grupos $(n=8)$ : controle $(C)$, frutose $(F)$, desnervado (D) e desnervado frutose (DF). ${ }^{*} p<0,05$ vs. $C$. 


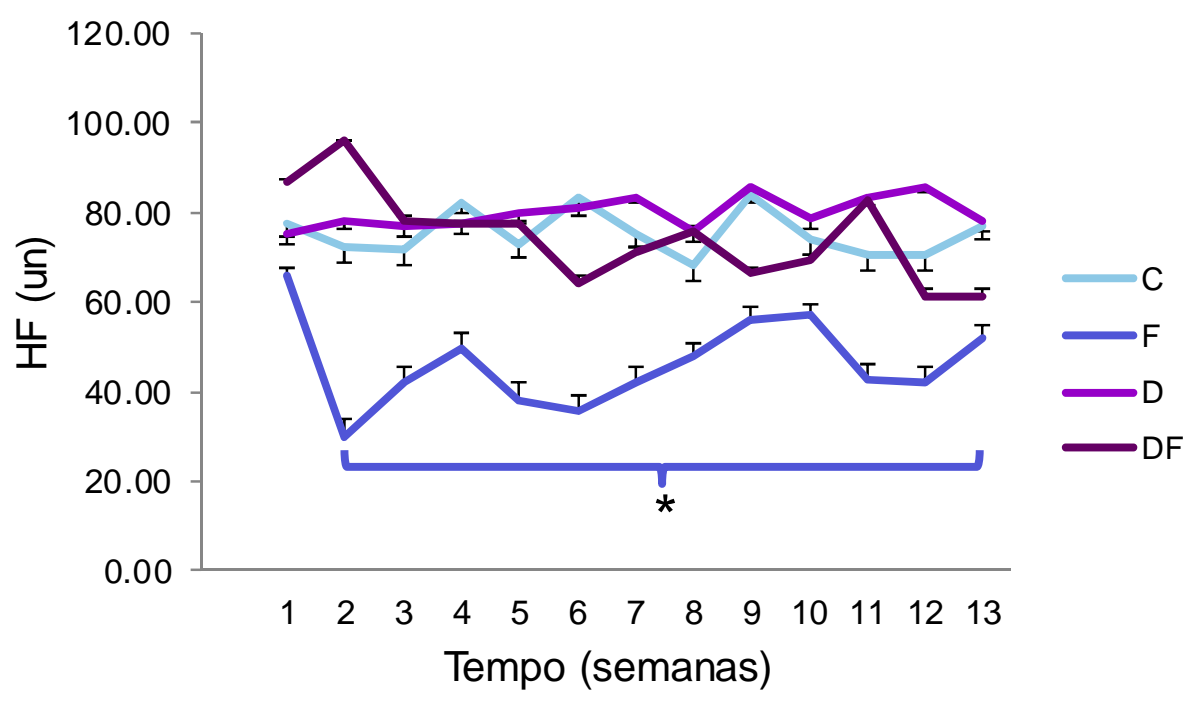

Figura 36: Modulação parassimpática cardíaca relativa. Avaliação temporal de 13 semanas da modulação parassimpática cardíaca relativa nos grupos $(n=8)$ : controle $(C)$, frutose $(F)$, desnervado (D) e desnervado frutose (DF). ${ }^{*} p<0,05$ vs. C.

A combinação desses resultados apresentados refletem em um aumento do balanço simpato-vagal no grupo submetido à sobrecarga de frutose quando comparado ao controle aos demais (Figura 37). 


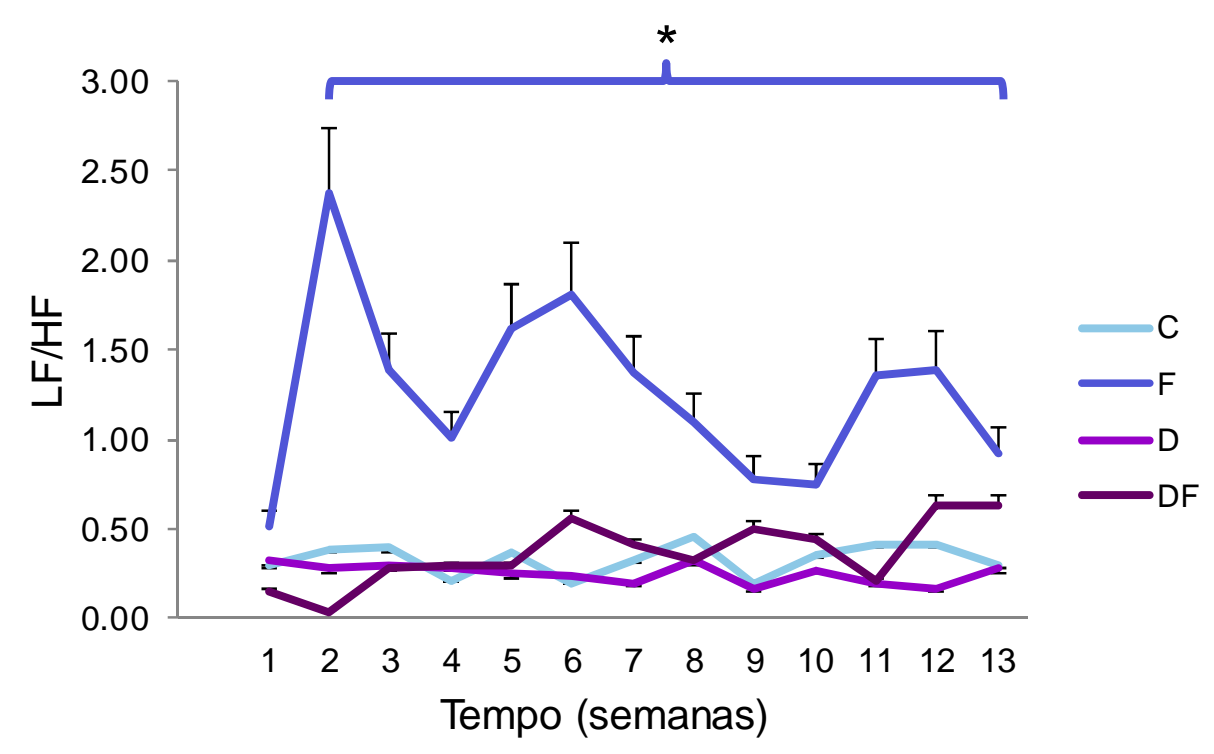

Figura 37: Balanço simpato-vagal. Avaliação do balanço simpato-vagal durante 13 semanas de protocolo nos grupos $(n=8)$ : controle $(C)$, frutose $(F)$, desnervado $(D)$ e desnervado frutose (DF). * $\mathrm{p}<0,05$ vs. $C$.

Com base na avaliação da variabilidade da pressão arterial, podemos observar na Figura 38 que ambos os grupos tratados com frutose apresentaram aumento da modulação simpática periférica em relação aos seus controles. 


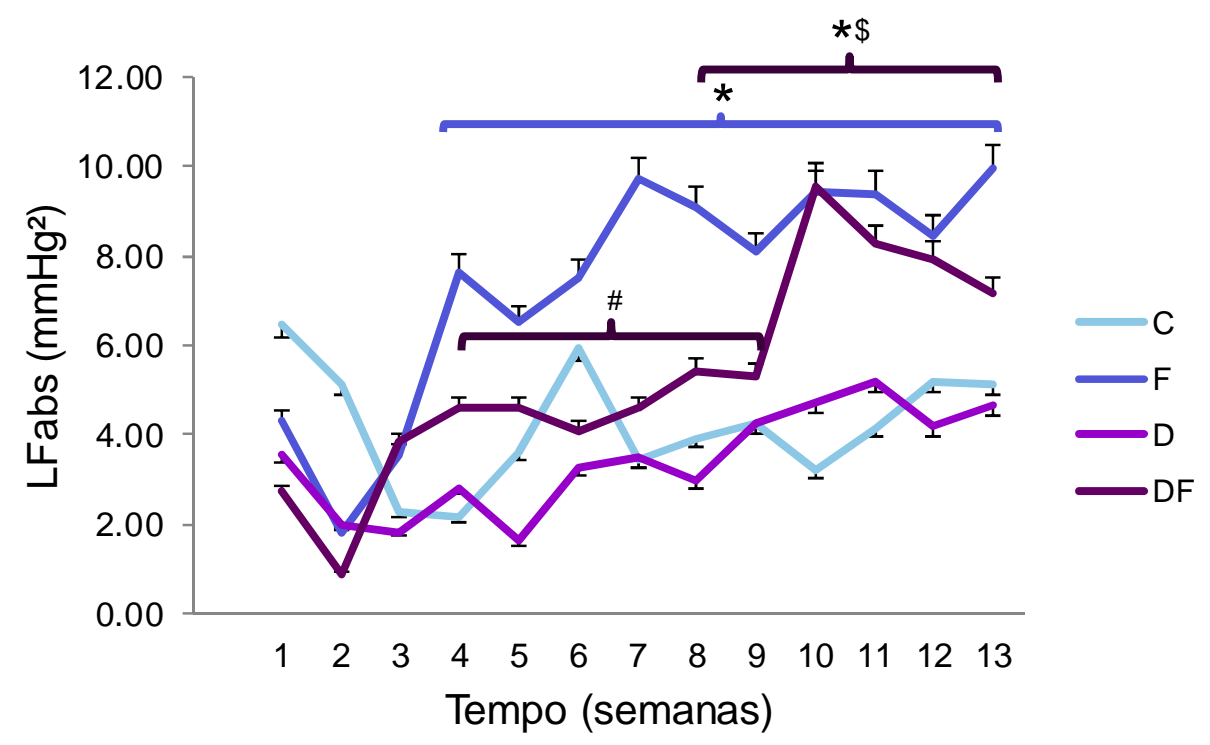

Figura 38: Modulação simpática periférica. Avaliação de 13 semanas da modulação simpática periférica avaliada nos grupos $(n=8)$ : controle $(C)$, frutose $(F)$, desnervado $(D)$ e desnervado frutose (DF). ${ }^{*} p<0,05$ vs. $C, \# p<0,05$ vs. $F, \$ p<0,05$ vs. $D$.

Esta alteração do sistema nervoso simpático resultou em aumento da variabilidade da pressão arterial nos grupos desnervados (Figura 39). 


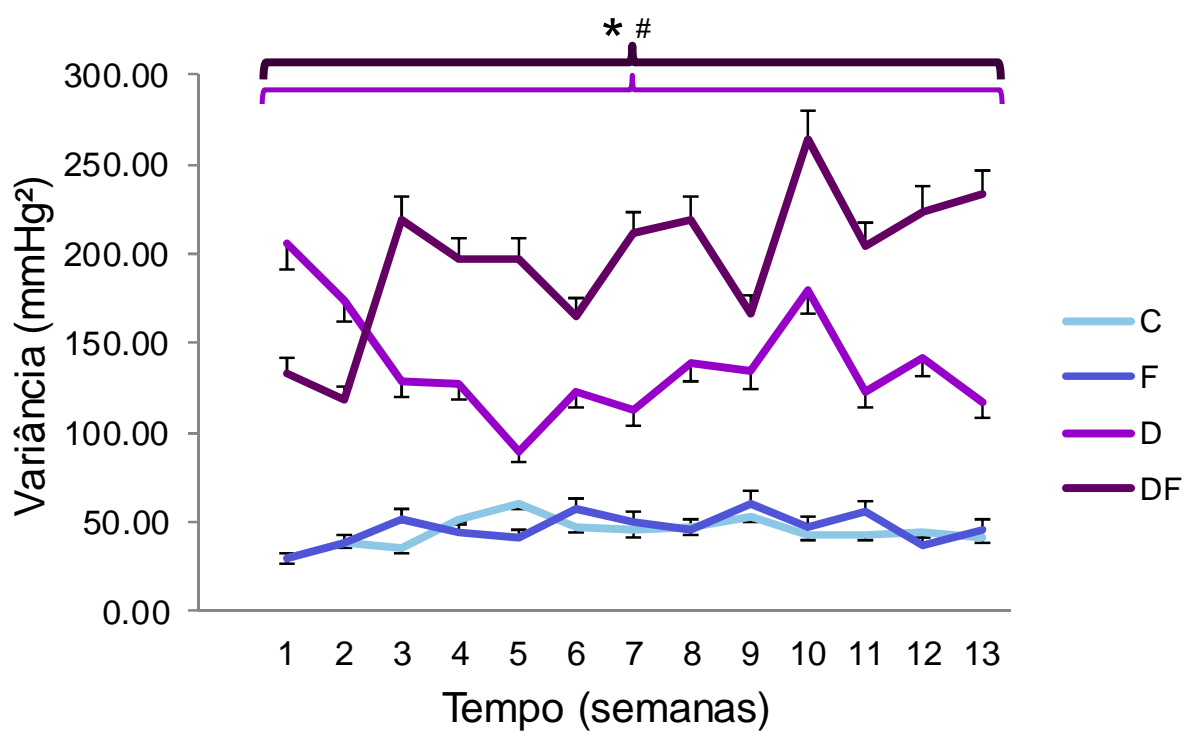

Figura 39: Variância da pressão arterial sistólica. Variabilidade total da pressão arterial sistólica durante 13 semanas nos grupos $(n=8)$ : controle $(C)$, frutose $(F)$, desnervado $(D)$ e desnervado frutose (DF). ${ }^{*} p<0,05$ vs. $C, \# p<0,05$ vs. $F$.

A sensibilidade do barorreflexo medida pelo índice alfa da banda de LF comprova o prejuízo deste sistema nos grupos desnervados durante todo 0 protocolo (Figura 40). Já o grupo frutose apresenta uma queda nos valores deste índice a partir da sétima semana, sendo menor que os valores do controle a partir da décima primeira semana. 


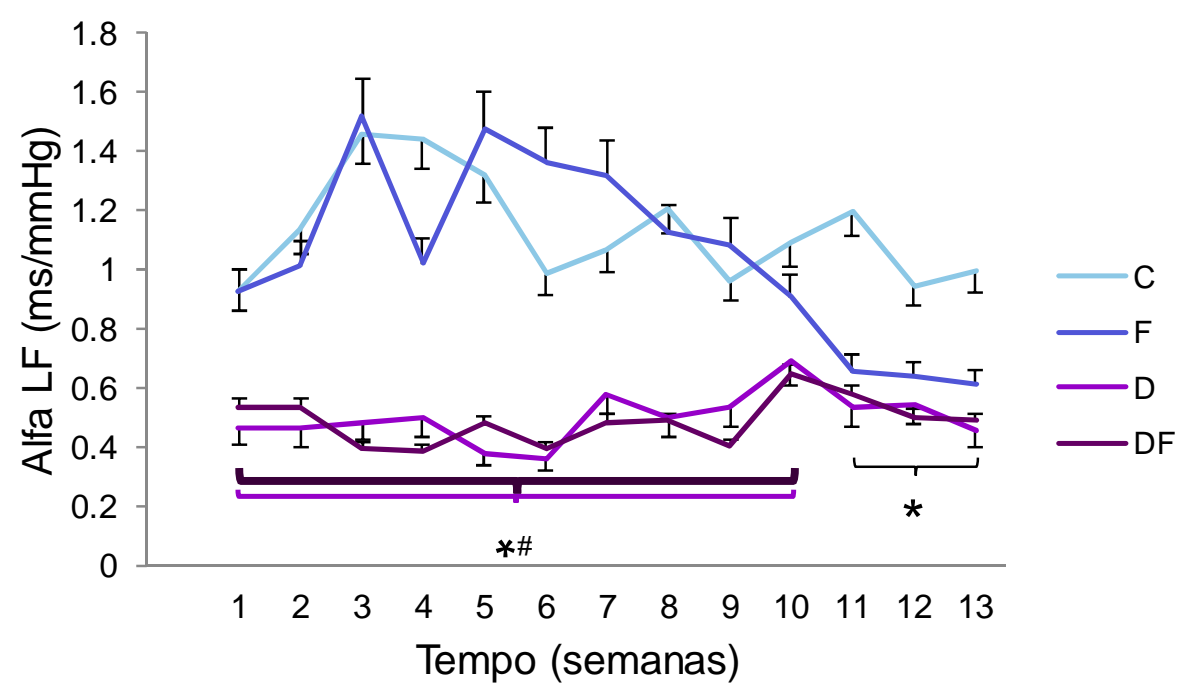

Figura 40: Índice alfa de LF. Sensibilidade do barorreflexo medida pelo índice alfa da banda de LF durante 13 semanas nos grupos $(n=8)$ : controle $(C)$, frutose $(F)$, desnervado $(D)$ e desnervado frutose (DF). ${ }^{*} p<0,05$ vs. $C, \# p<0,05$ vs. F.

\section{7) Receptores $\beta$-adrenérgicos}

A quantificação do RNAm para os receptores $\beta$-adrenérgicos no ventrículo esquerdo demonstrou aumento dos do tipo $\beta 1$ em ambos grupos tratados com frutose (Figura 41). Já os receptores tipo $\beta 2$ apresentam-se aumentados apenas no grupo frutose. O grupo com associação de frutose com desnervação apresentou redução do RNAm dos $\beta 2$ quando comparado à todos os demais grupos (Figura 42). 


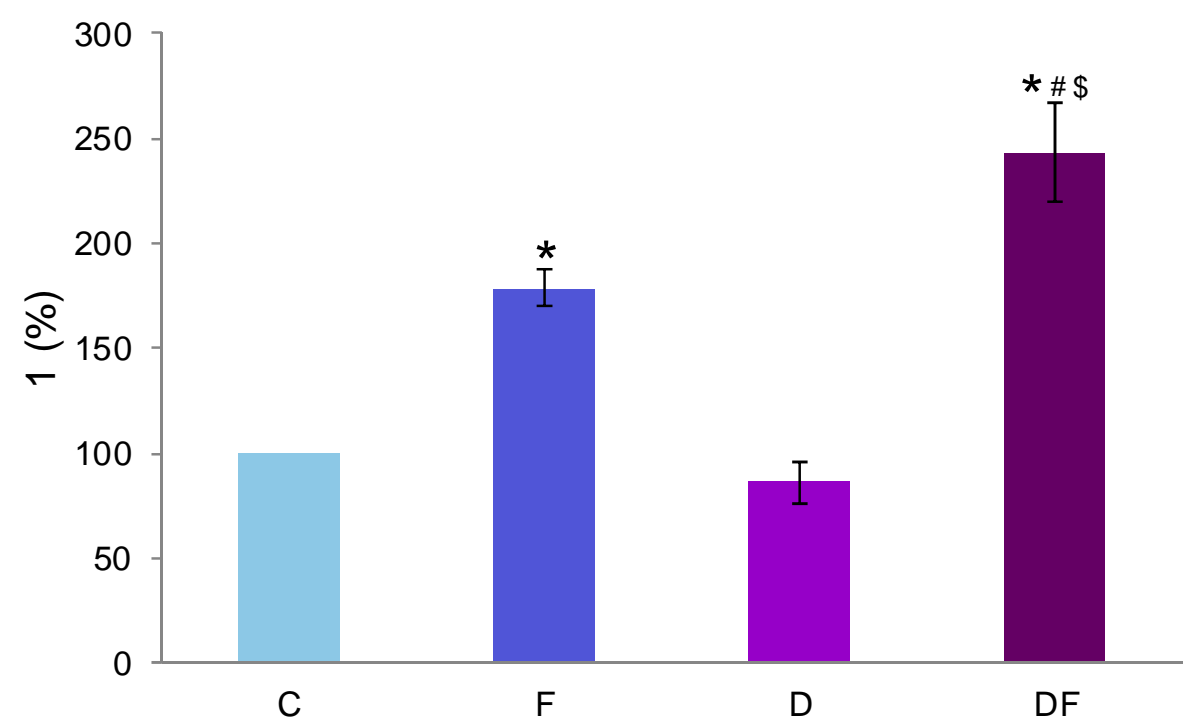

Figura 41: Receptores $\beta 1$ cardíacos. Quantificação dos receptores $\beta 1$ no ventrículo esquerdo via PCR nos grupos $(n=4)$ : controle $(C)$, frutose $(F)$, desnervado $(D)$ e desnervado frutose $(D F) .{ }^{*} p<0,05$ vs. $C, \# p<0,05$ vs. $F, \$ p<0,05$ vs. $D$.

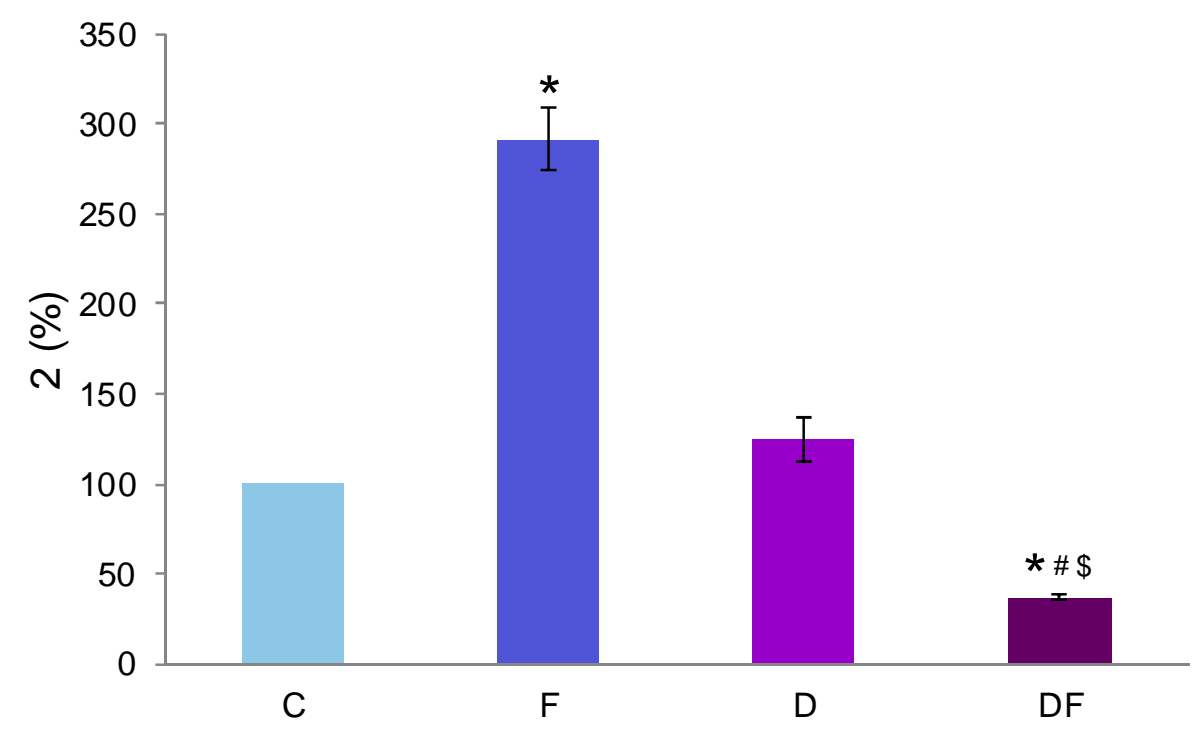

Figura 42: Receptores $\beta 2$ cardíacos. Quantificação dos receptores $\beta 2$ no ventrículo esquerdo via PCR nos grupos $(n=4)$ : controle $(C)$, frutose $(F)$, desnervado $(D)$ e desnervado frutose $(D F)$. ${ }^{*} p<0,05$ vs. $C, \# p<0,05$ vs. $F, \$ p<0,05$ vs. $D$. 


\section{8) Receptores AT1 renais}

A dosagem de receptores AT1 na medula renal mostrou-se aumentada nos grupos desnervados comparados aos controles (Figura 43). Já em relação à mesma avaliação no córtex renal, podemos observar na Figura 44 que os três grupos experimentais parecem diminuir a quantidade de AT1, no entanto esta diferença não provou-se significante $(p=0,09)$.
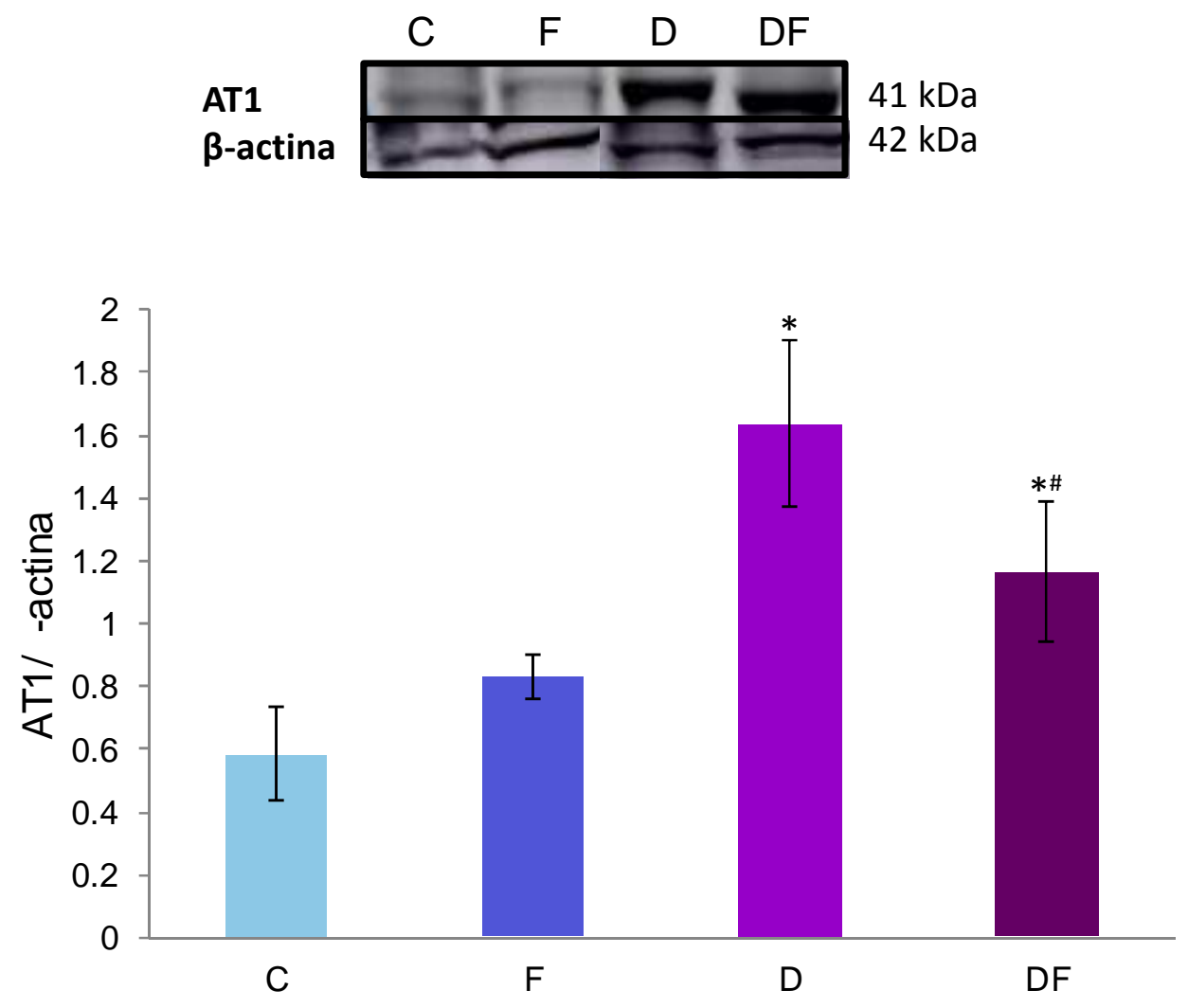

Figura 43: Receptor AT1 em medula renal. Quantificação dos receptores AT1 em medula renal por Western blot nos grupos $(n=4)$ : controle $(C)$, frutose $(F)$, desnervado (D) e desnervado frutose (DF). * $p<0,05$ vs. $C, \# p<0,05$ vs. $F$. 

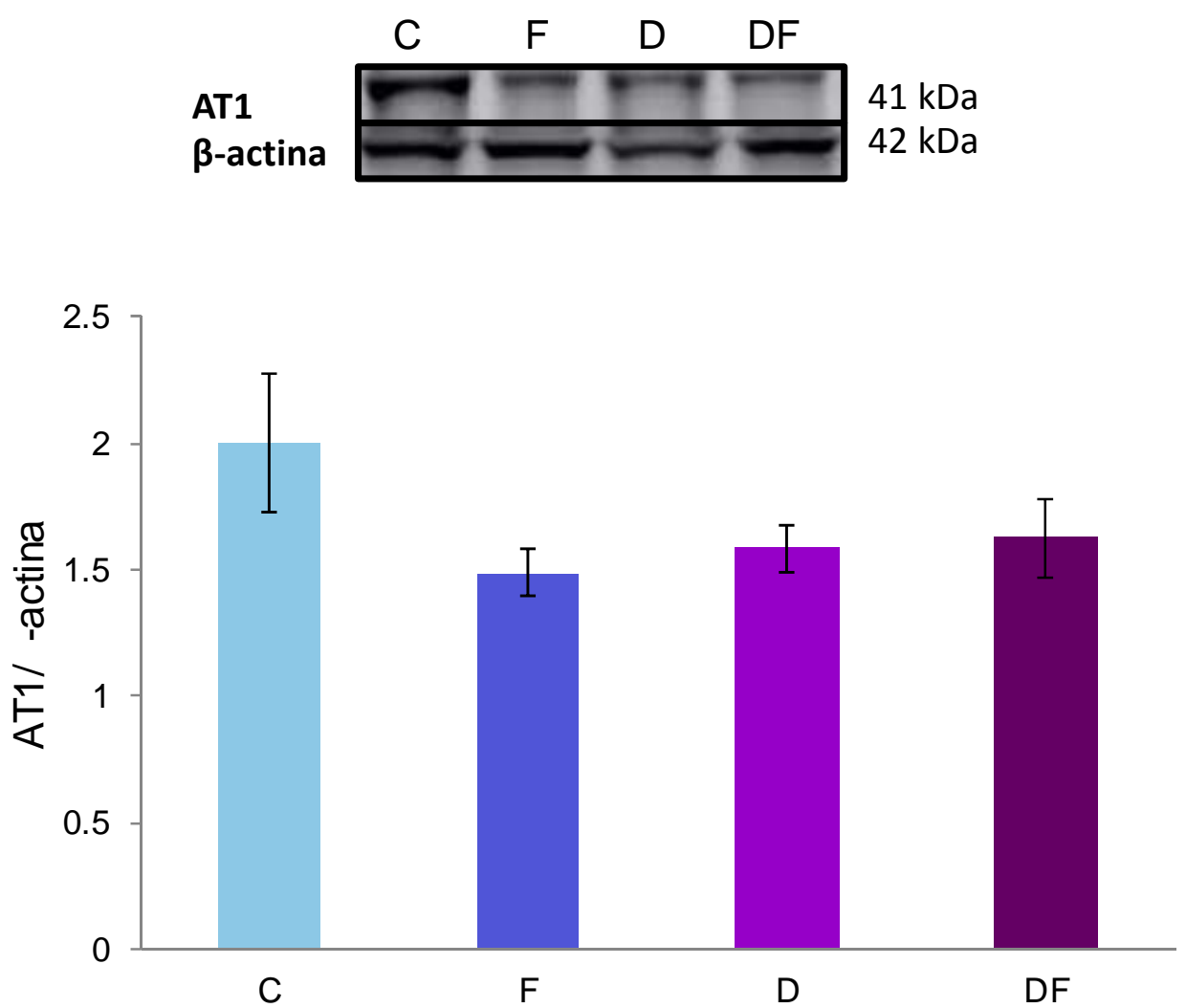

Figura 44: Receptor AT1 em córtex renal. Quantificação dos receptores AT1 em córtex renal por Western blot nos grupos $(n=4)$ : controle $(C)$, frutose $(F)$, desnervado (D) e desnervado frutose (DF).

\section{9) Avaliação de imunohistoquímica}

A marcação da citocina inflamatória IL-6 apresentou-se aumentada no tecido cardíaco dos grupos desnervados como pode ser observado pela quantificação na Figura 45 e através das representações (Figura 46). 


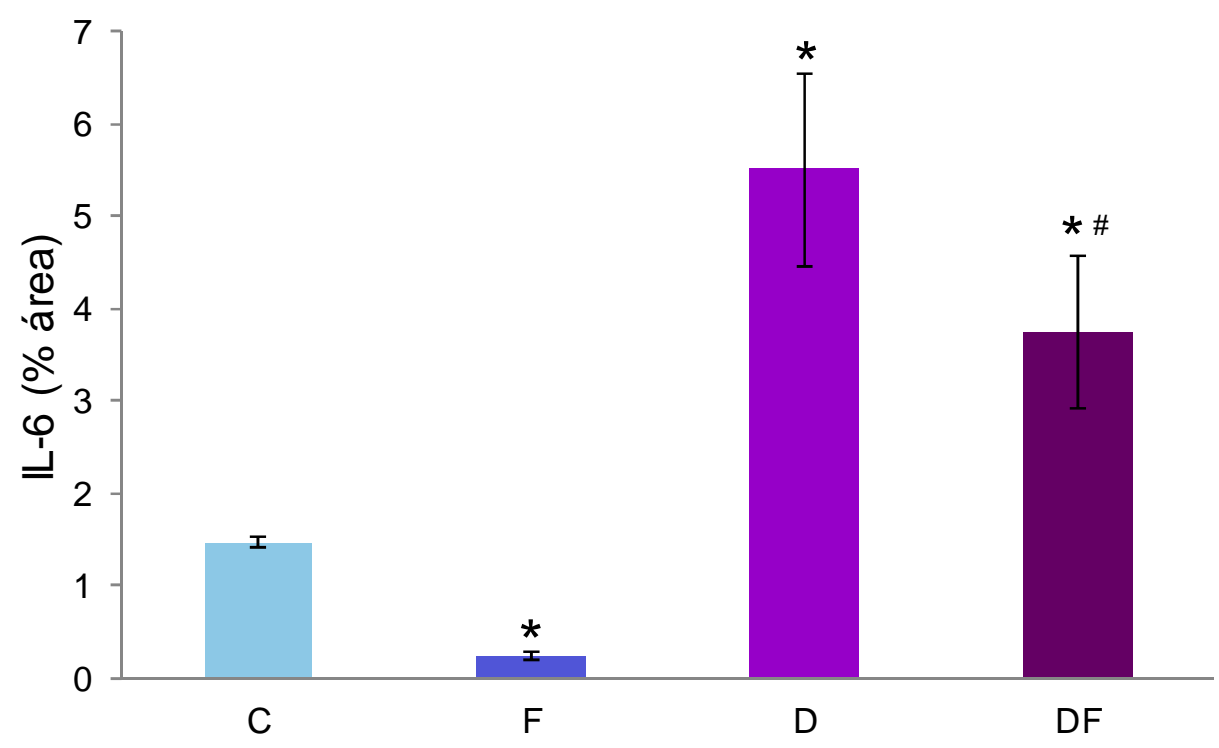

Figura 45: IL-6 cardíaco quantificado. Avaliação do percentual de área marcada com a presença de IL-6 no ventrículo esquerdo nos grupos $(n=4)$ : controle $(C)$, frutose $(F)$, desnervado $(D)$ e desnervado frutose (DF). ${ }^{*} p<0,05$ vs. $C, \# p<0,05$ vs. F. 


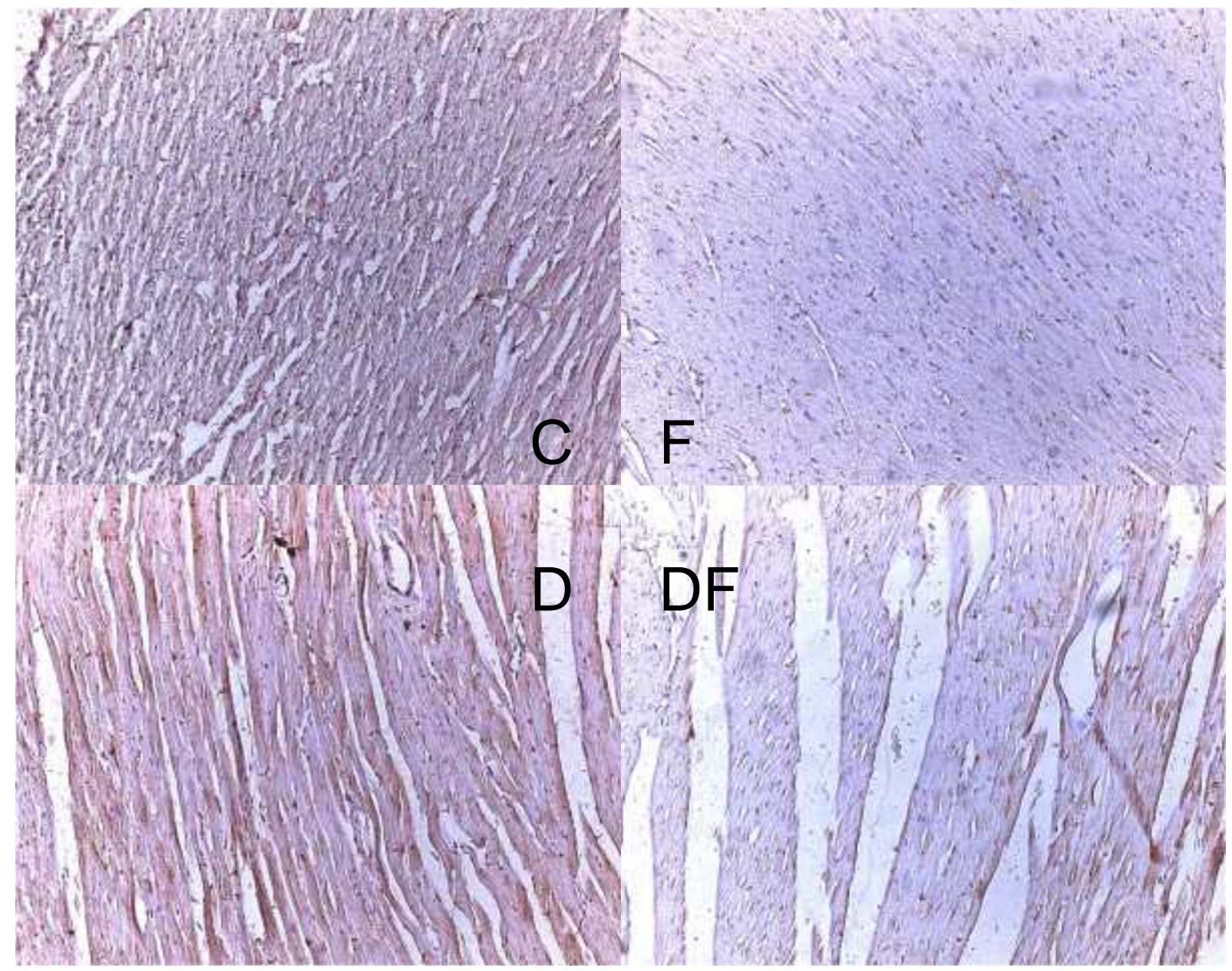

Figura 46: IL-6 cardíaco. Dosagem de IL-6 por imunohistoquímica (marcação positiva em marrom) em corte histológico do ventrículo esquerdo. Controle $(C)$, frutose $(F)$, desnervado $(D)$ e desnervado frutose (DF). Aumento 200x.

Na Figura 47 podemos ver que a marcação nos brônquios da citocina IL-6 está aumentada em todos os grupos, sendo que o grupo DF apresenta maior marcação de área (Figura 48). 


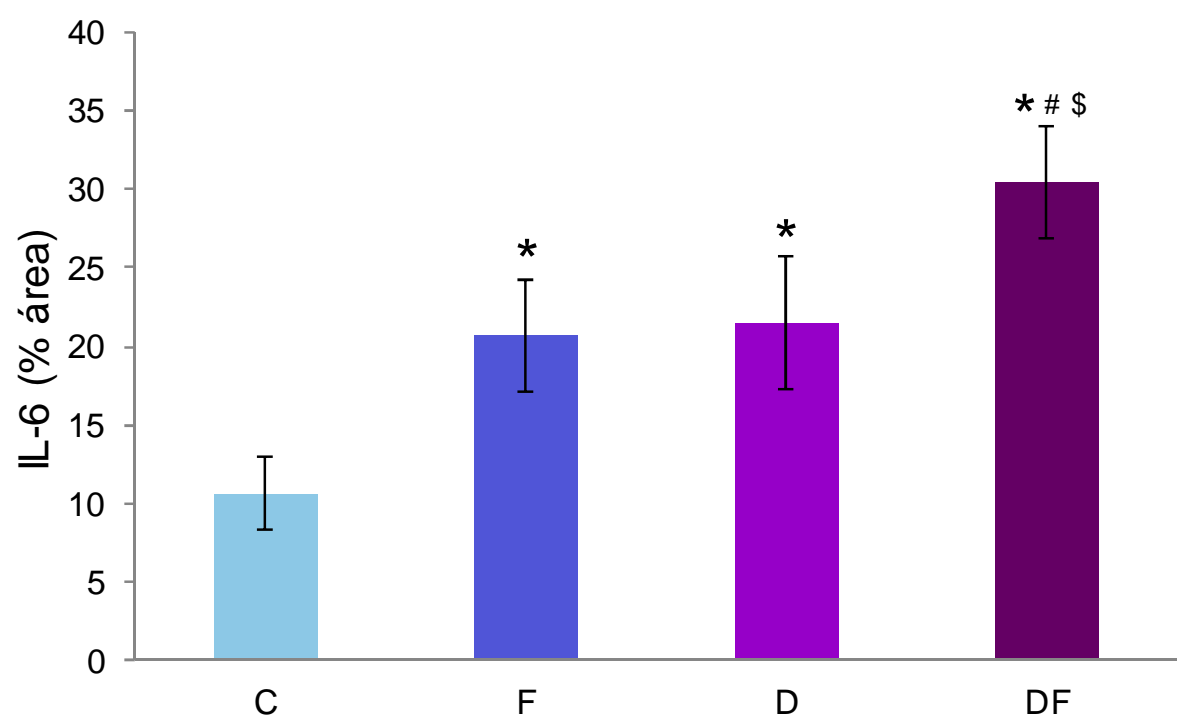

Figura 47: IL-6 quantificado nos brônquios. Avaliação do percentual de área marcada com a presença de IL-6 nos brônquios dos grupos $(n=4)$ : controle (C), frutose (F), desnervado (D) e desnervado frutose (DF). ${ }^{*} p<0,05$ vs. $C, \# p<0,05$ vs. $F, \$ p<0,05$ vs. $D$. 


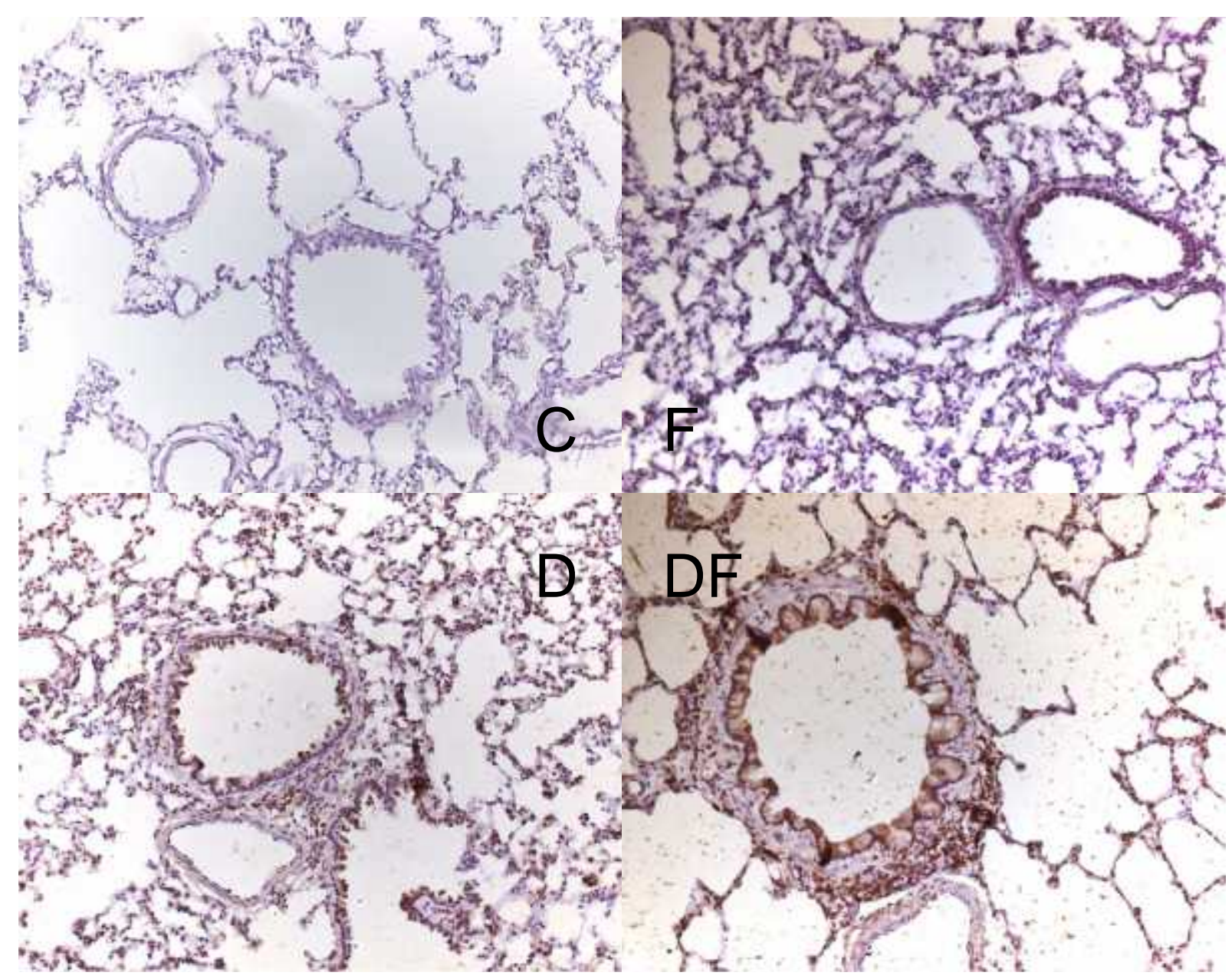

Figura 48: IL-6 nos brônquios. Dosagem de IL-6 por imunohistoquímica (marcação positiva em marrom) em corte histológico do pulmão. Controle (C), frutose (F), desnervado (D) e desnervado frutose (DF). Aumento 200x.

Já para o tecido renal, o uso de frutose foi o principal responsável pelo aumento da marcação de IL-6 (Figura 49). Podemos notar que a desnervação diminuiu este marcador inflamatório nos rins. Representação na Figura 50. 


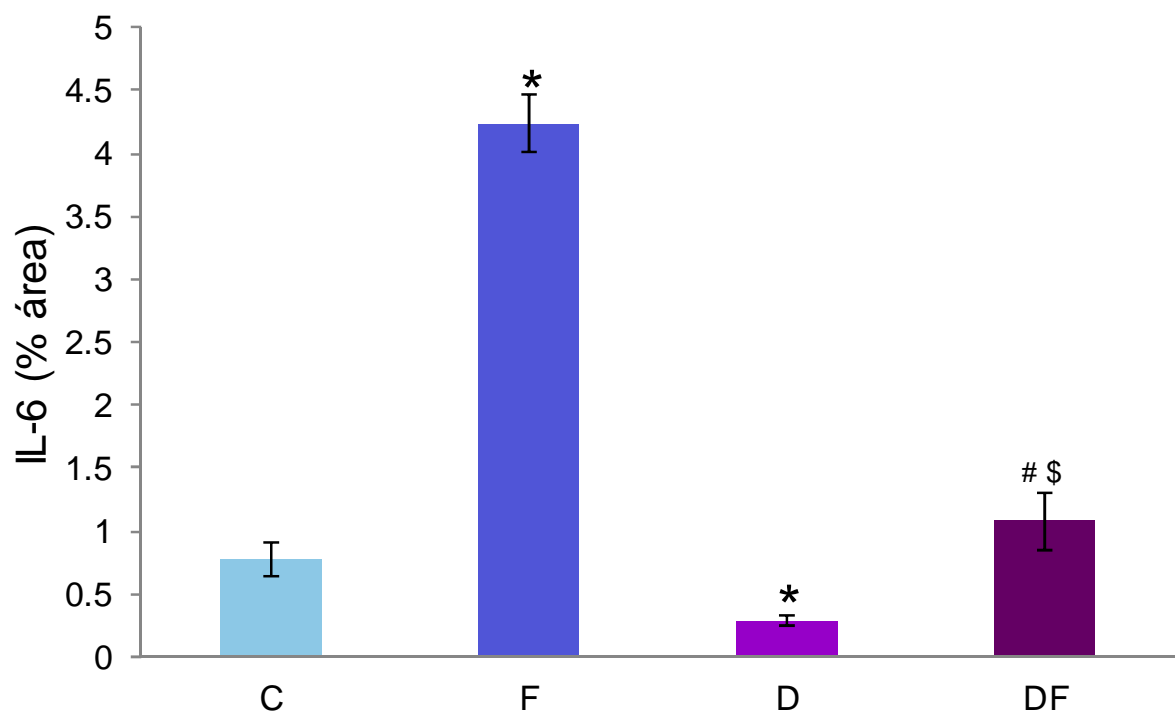

Figura 49: IL-6 renal quantificado. Avaliação do percentual de área marcada com a presença de IL6 nos rins dos grupos $(n=4)$ : controle $(C)$, frutose $(F)$, desnervado (D) e desnervado frutose (DF). * $p<0,05$ vs. $C, \# p<0,05$ vs.F, $\$ p<0,05$ vs. $D$. 


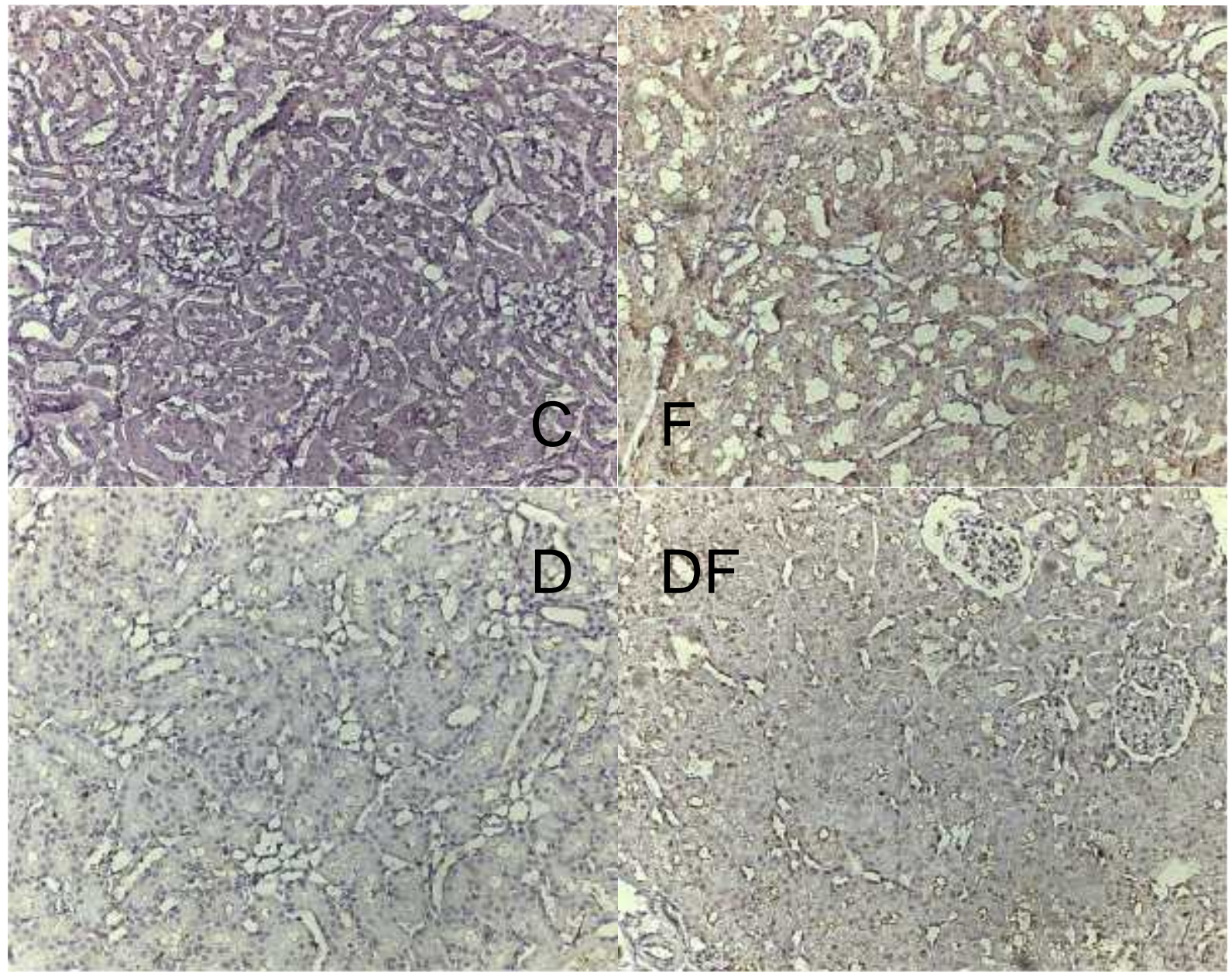

Figura 50: IL-6 renal. Dosagem de IL-6 por imunohistoquímica (marcação positiva em marrom) em corte histológico do rim. Controle (C), frutose (F), desnervado (D) e desnervado frutose (DF). Aumento 200x.

NA quantificação de NFkB cardíaco podemos notar na Figura 51 que a frutose promoveu aumento deste marcador, sendo que a associação com a desnervação preveniu este aumento. Foto ilustrativa (Figura 52). 


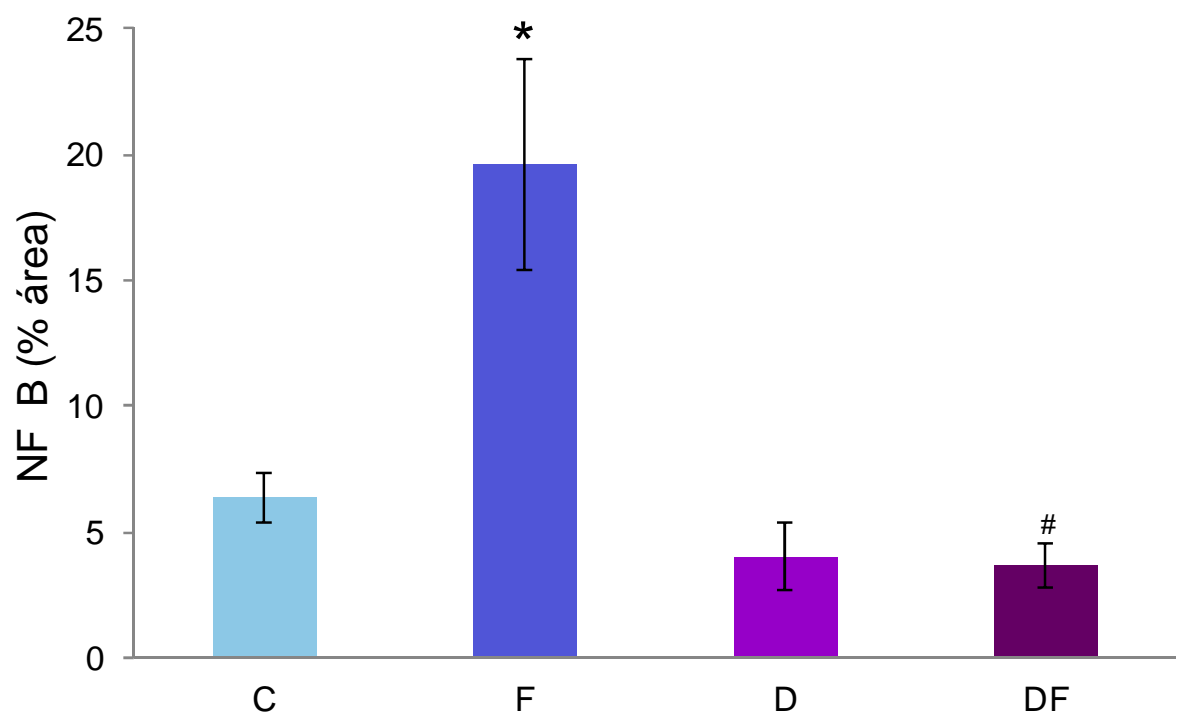

Figura 51: NF-kB cardíaco quantificado. Avaliação do percentual de área marcada com a presença de NF-kB no ventrículo esquerdo nos grupos $(n=4)$ : controle $(C)$, frutose $(F)$, desnervado (D) e desnervado frutose (DF). ${ }^{*} p<0,05$ vs. $C, \# p<0,05$ vs. $F$. 


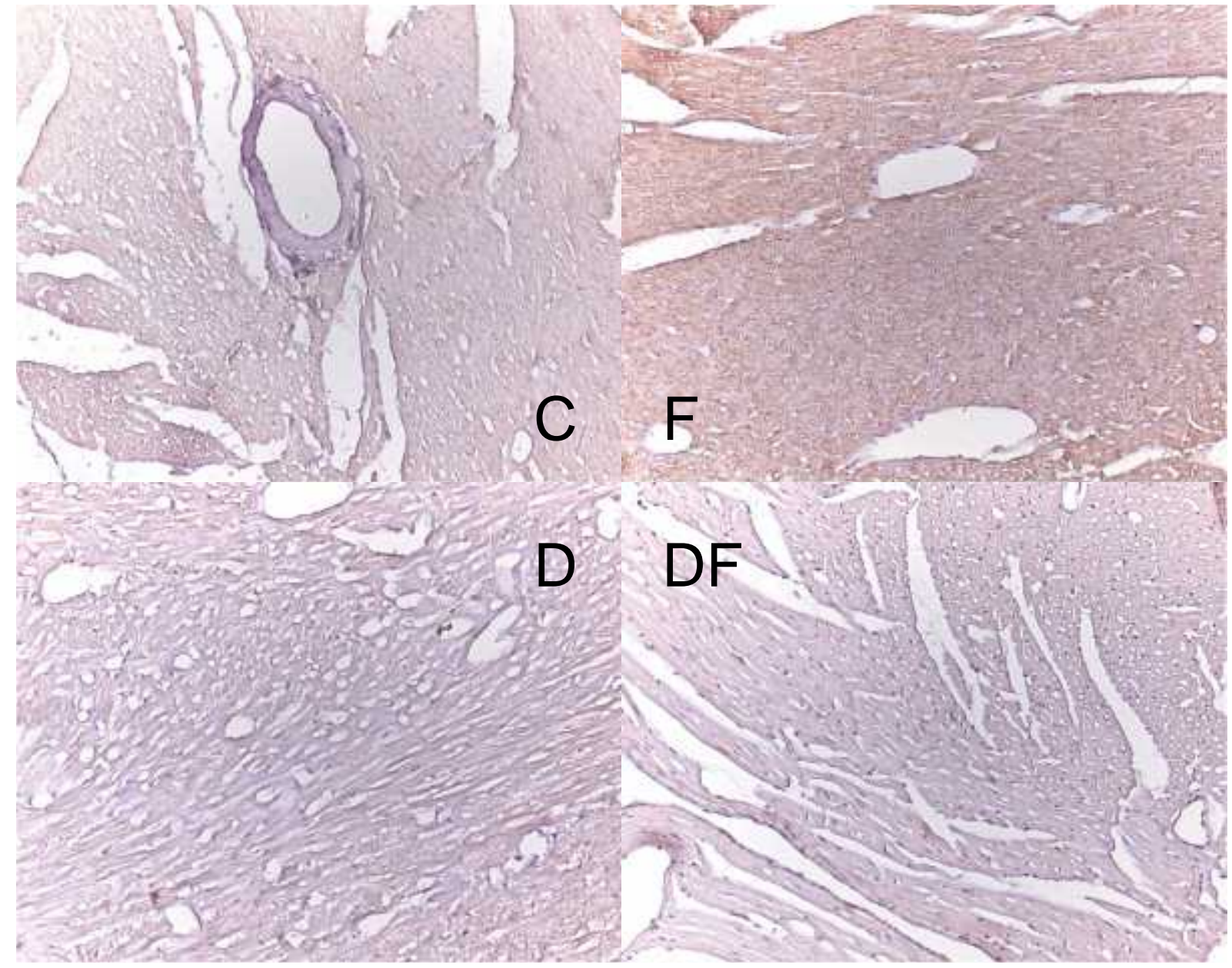

Figura 52: NF-kB cardíaco. Dosagem de NF-kB por imunohistoquímica (marcação positiva em marrom) em corte histológico do ventrículo esquerdo. Controle (C), frutose (F), desnervado (D) e desnervado frutose (DF). Aumento 200x.

Mais uma vez a desnervação mostrou-se capaz de aumentar a inflamação nos brônquios. Podemos notar na Figura 53 que a área marcada como positiva para NFkB foi maior nos grupos que passaram pela cirurgia. Representação na Figura 54. 


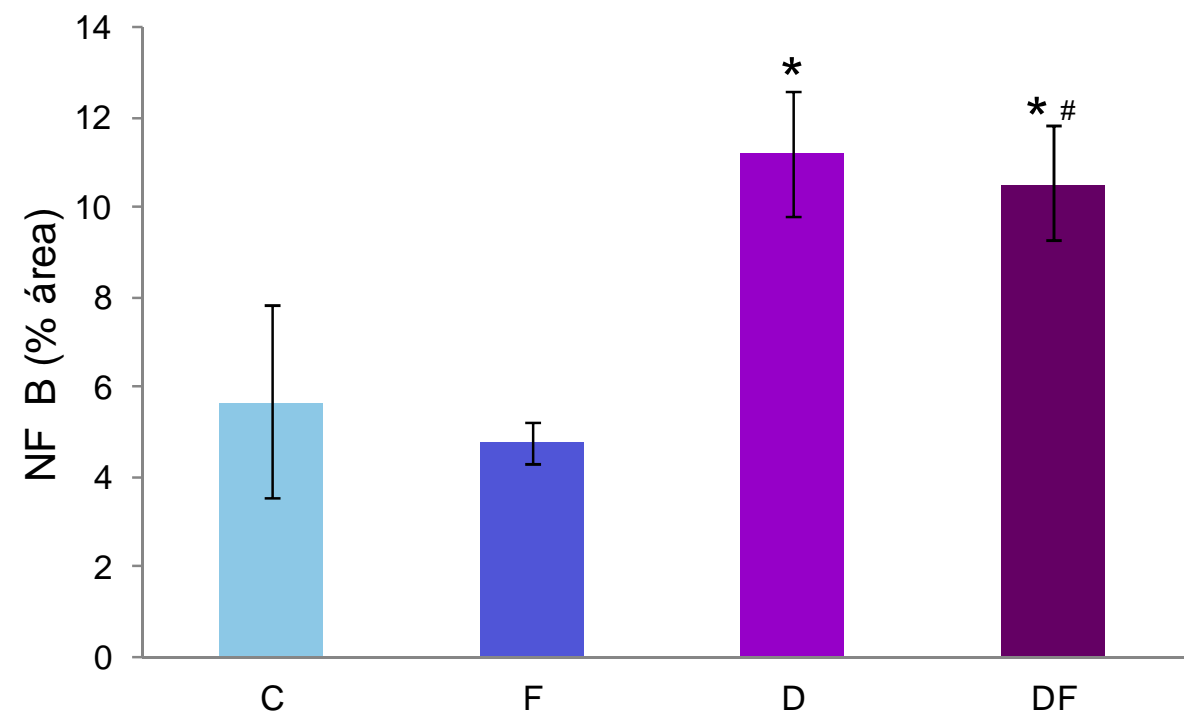

Figura 53: NF-kB quantificado nos brônquios. Avaliação do percentual de área marcada com a presença de NF-kB nos brônquios dos grupos $(n=4)$ : controle $(C)$, frutose $(F)$, desnervado (D) e desnervado frutose (DF). ${ }^{*} p<0,05$ vs. $C, \# p<0,05$ vs. F. 


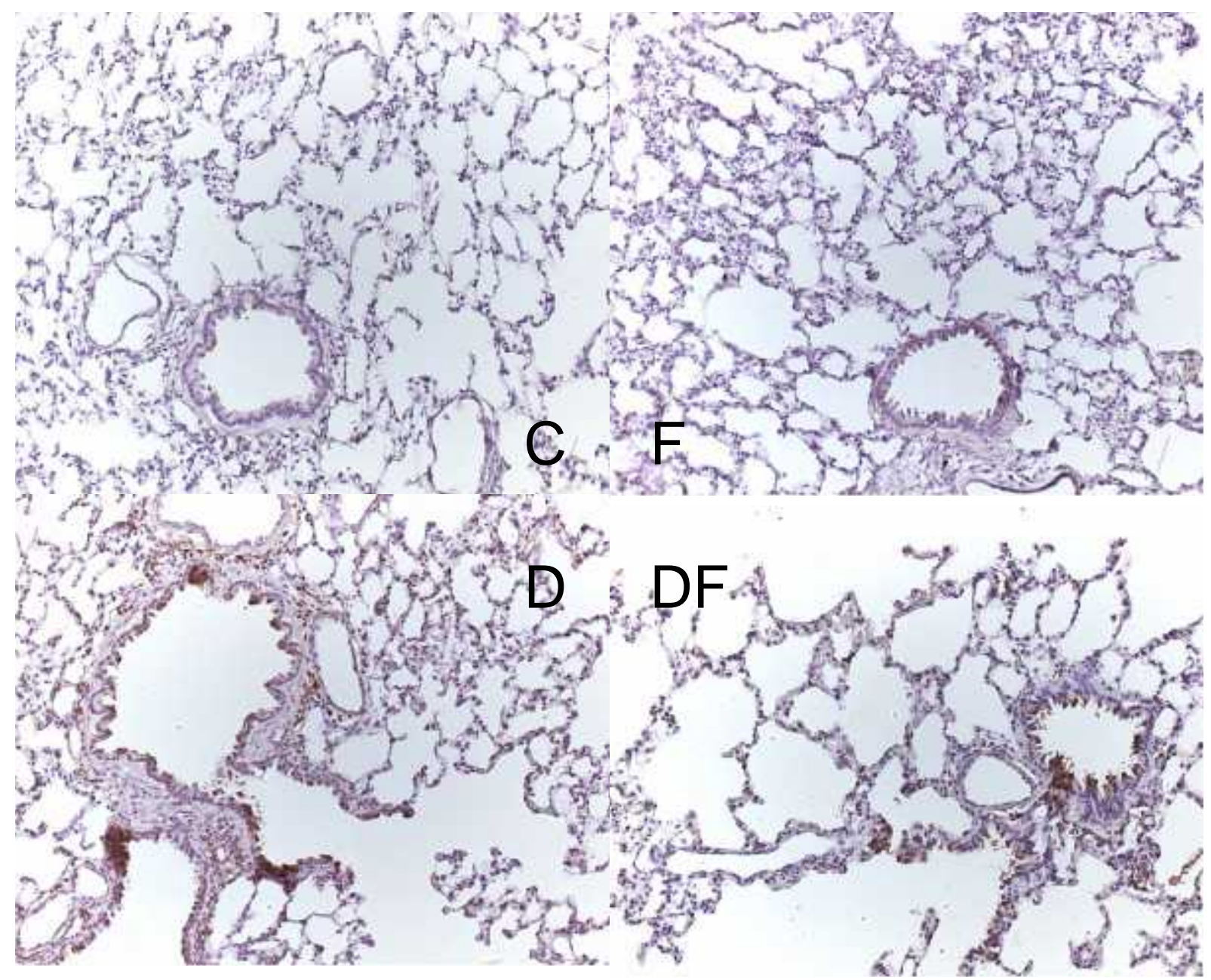

Figura 54: NF-kB nos brônquios. Dosagem de NF-kB por imunohistoquímica (marcação positiva em marrom) em corte histológico do pulmão. Controle $(C)$, frutose $(F)$, desnervado $(D)$ e desnervado frutose (DF). Aumento 200x.

Já no tecido renal, todas as intervenções se mostraram igualmente capazes de aumentar os valores de NF-kB (Figura 55). llustração na Figura 56. 


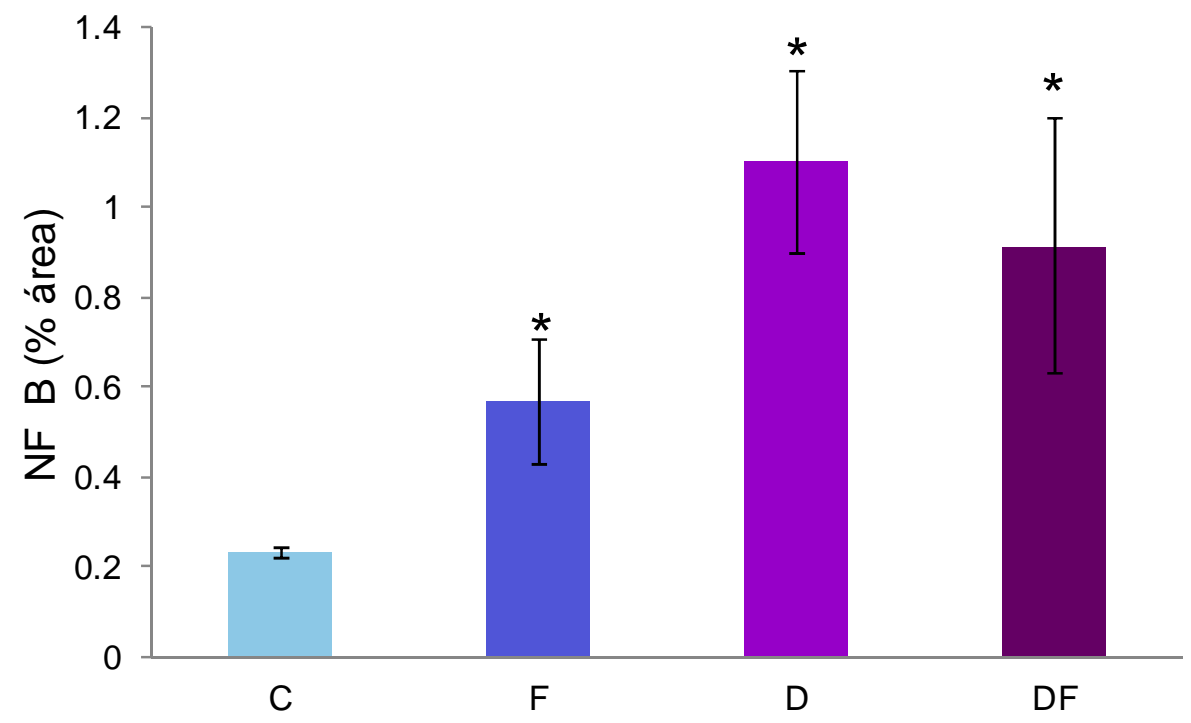

Figura 55: NF-kB renal quantificado. Avaliação do percentual de área marcada com a presença de NF-kB nos rins dos grupos $(n=4)$ : controle $(C)$, frutose $(F)$, desnervado (D) e desnervado frutose (DF). ${ }^{*} p<0,05$ vs. C. 


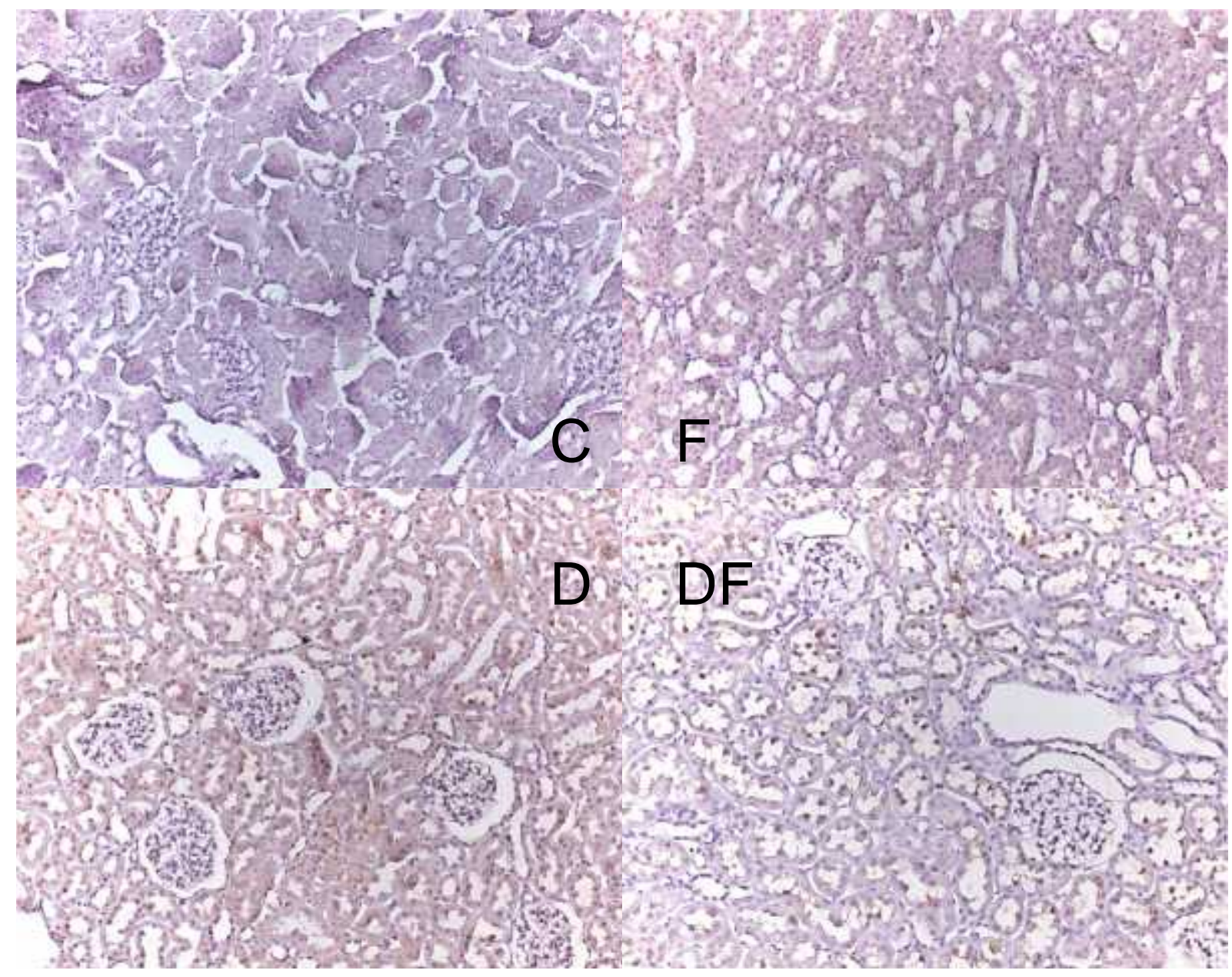

Figura 56: NF-kB renal. Dosagem de NF-kB por imunohistoquímica (marcação positiva em marrom) em corte histológico do rim. Controle (C), frutose (F), desnervado (D) e desnervado frutose (DF). Aumento 200x.

\subsection{0) Marcadores inflamatórios cardíacos}

A avaliação de citocinas inflamatórias por dosagem via ELISA, demonstrou que todos os grupos experimentais apresentam aumento nos valores de TNF- $\alpha$ em relação ao grupo controle (Figura 57). Por sua vez, os valores de IL-1 estão 
aumentados apenas no grupo D (Figura 58). Podemos notar na Figura 59 que apenas no grupo F há aumento da citocina anti-inflamatória IL-10.

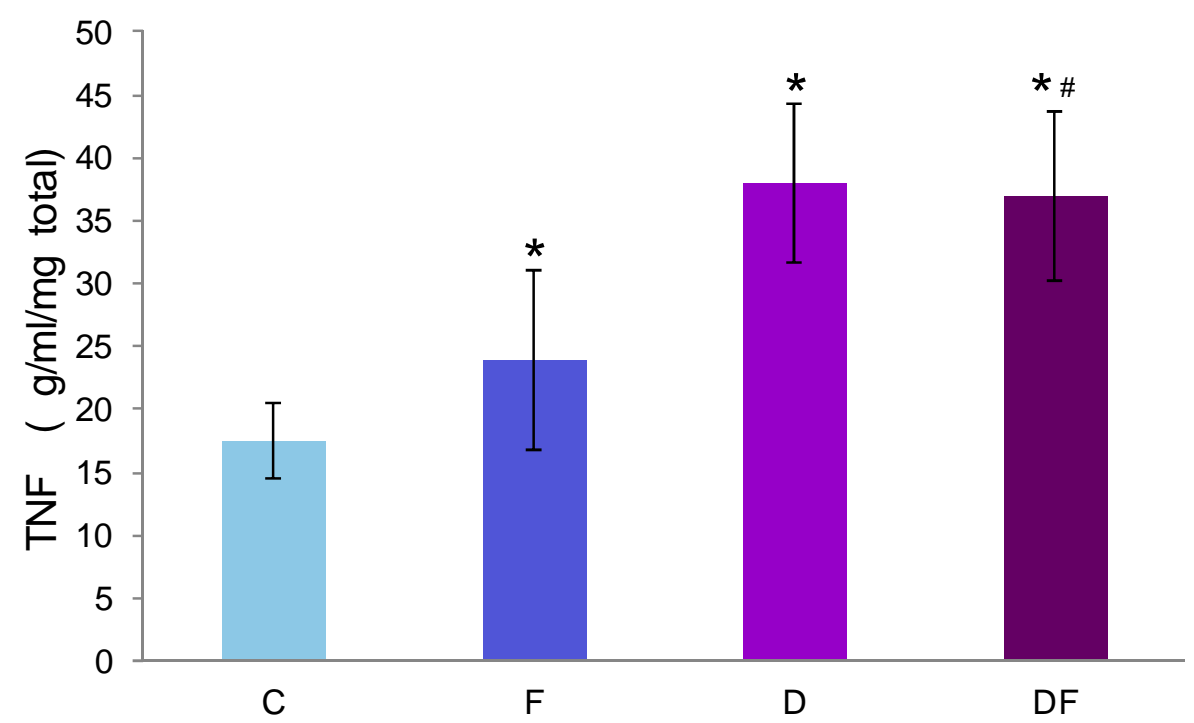

Figura 57: TNF- $\alpha$ cardíaco: Quantificação de TNF- $\alpha$ no ventrículo esquerdo por ELISA nos grupos $(n=4)$ : controle $(C)$, frutose $(F)$, desnervado (D) e desnervado frutose (DF). ${ }^{*} p<0,05$ vs. $C, \# p<0,05$ vs. F.

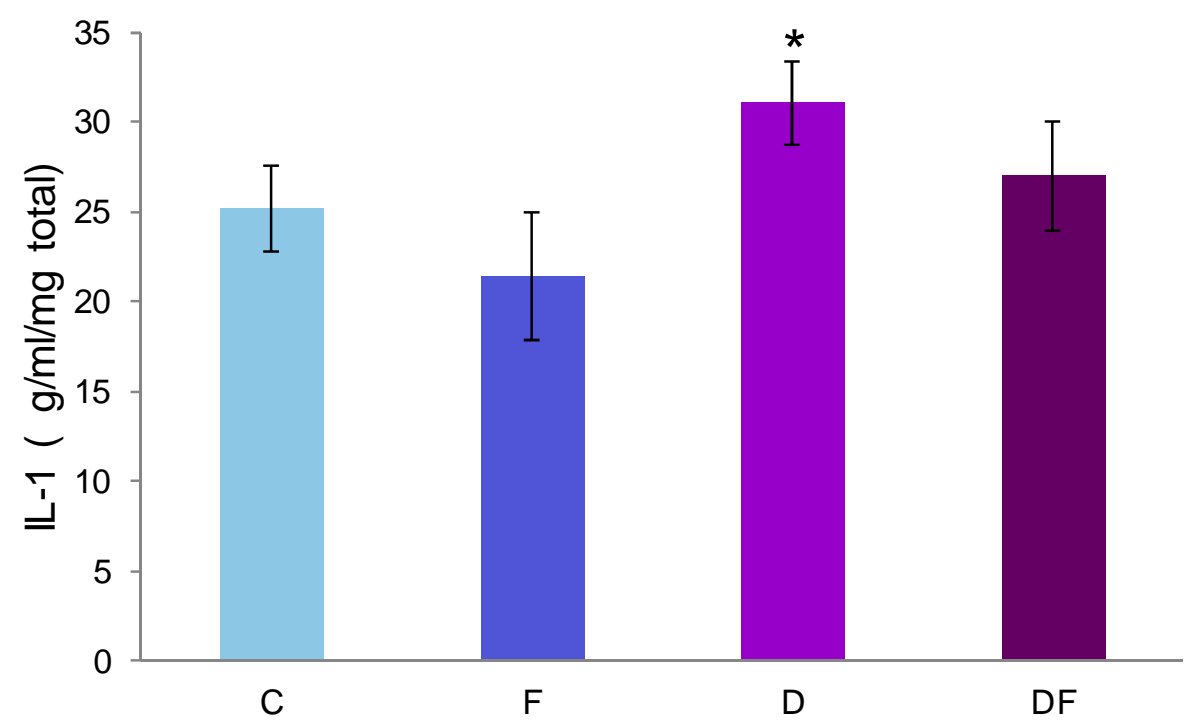

Figura 58: IL-1 cardíaco. Quantificação de IL-1 no ventrículo esquerdo por ELISA nos grupos $(n=4)$ : controle $(C)$, frutose $(F)$, desnervado $(D)$ e desnervado frutose $(D F) .{ }^{*} p<0,05$ vs. 


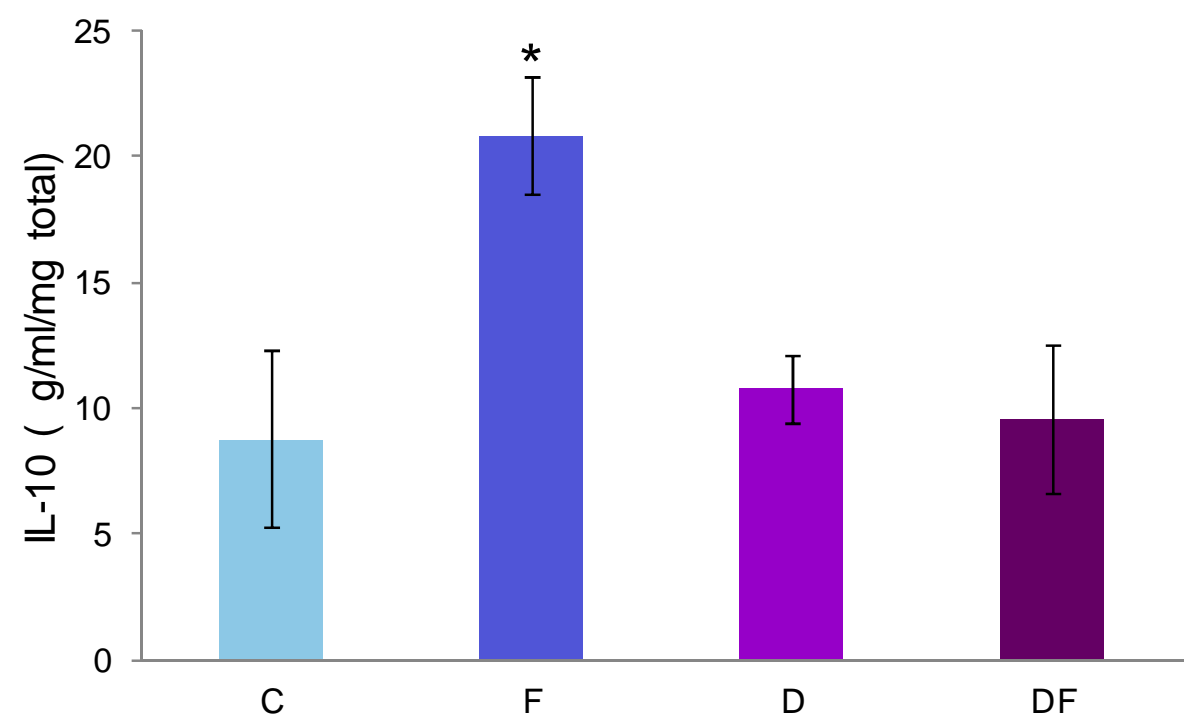

Figura 59: IL-10 cardíaco. Quantificação de IL-10 no ventrículo esquerdo por ELISA nos grupos $(n=4)$ : controle $(C)$, frutose $(F)$, desnervado (D) e desnervado frutose (DF). * $p<0,05$ vs. $C$.

\subsection{1) Estudos de associação}

A avaliação de associação entre algumas variáveis feitas pelo teste de correlação mostrou que a IL-6 apresenta uma relação positiva com os triglicerídeos, com um coeficiente de determinação de 0,9241 . Na Figura 60 pode se observar que o grupo frutose ficou acima e à direita em comparação aos demais grupos, conforme esperado. 


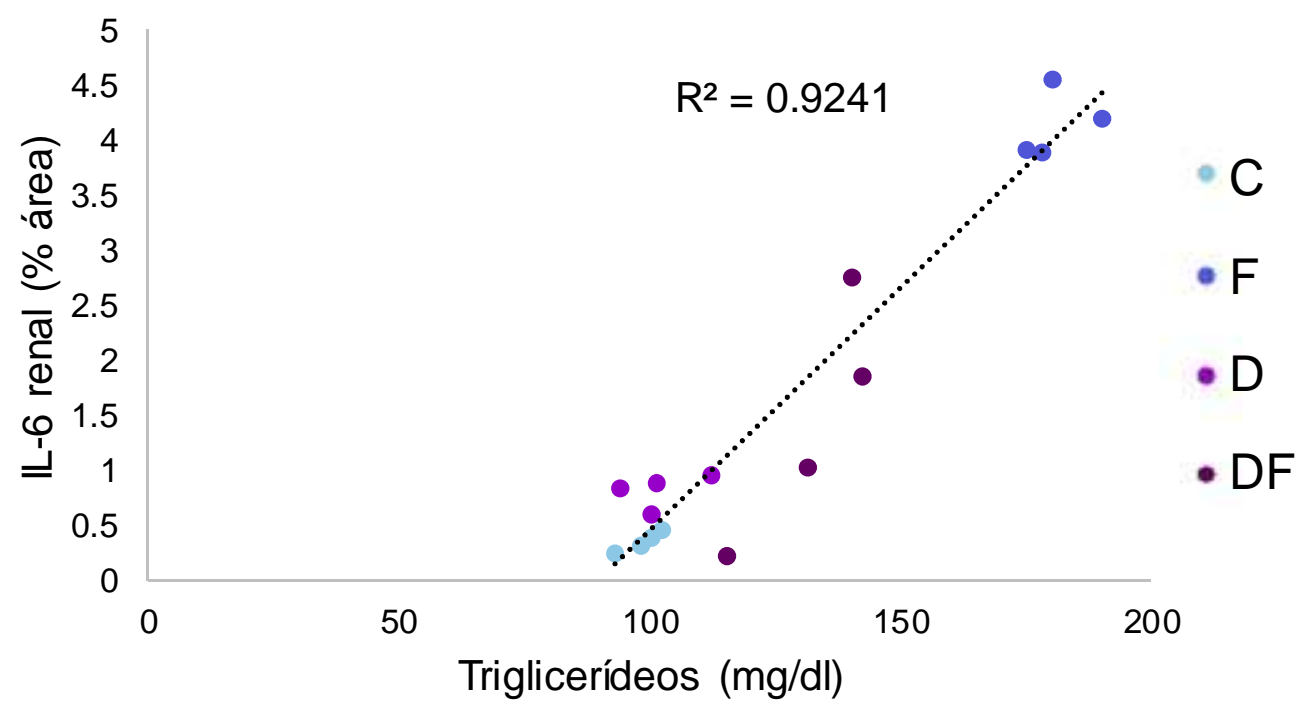

Figura 60: Correlação Triglicerídeos/IL-6 renal. Associação entre os valores de triglicerídeos sanguíneos e IL-6 renal nos grupos $(n=4)$ : controle $(C)$, frutose $(F)$, desnervado (D) e desnervado frutose (DF).

Quando olhamos a relação entre o NF-kB e o balanço simpato-vagal em todos os grupos, também identificamos uma relação positiva. Entretanto, ao observarmos a posição dos diferentes grupos experimentais, detectamos que novamente o grupo frutose apresenta-se acima a direita nessa relação mostrando que quanto maior o balanço, maior os níveis de NF-kB (Figura 61). 


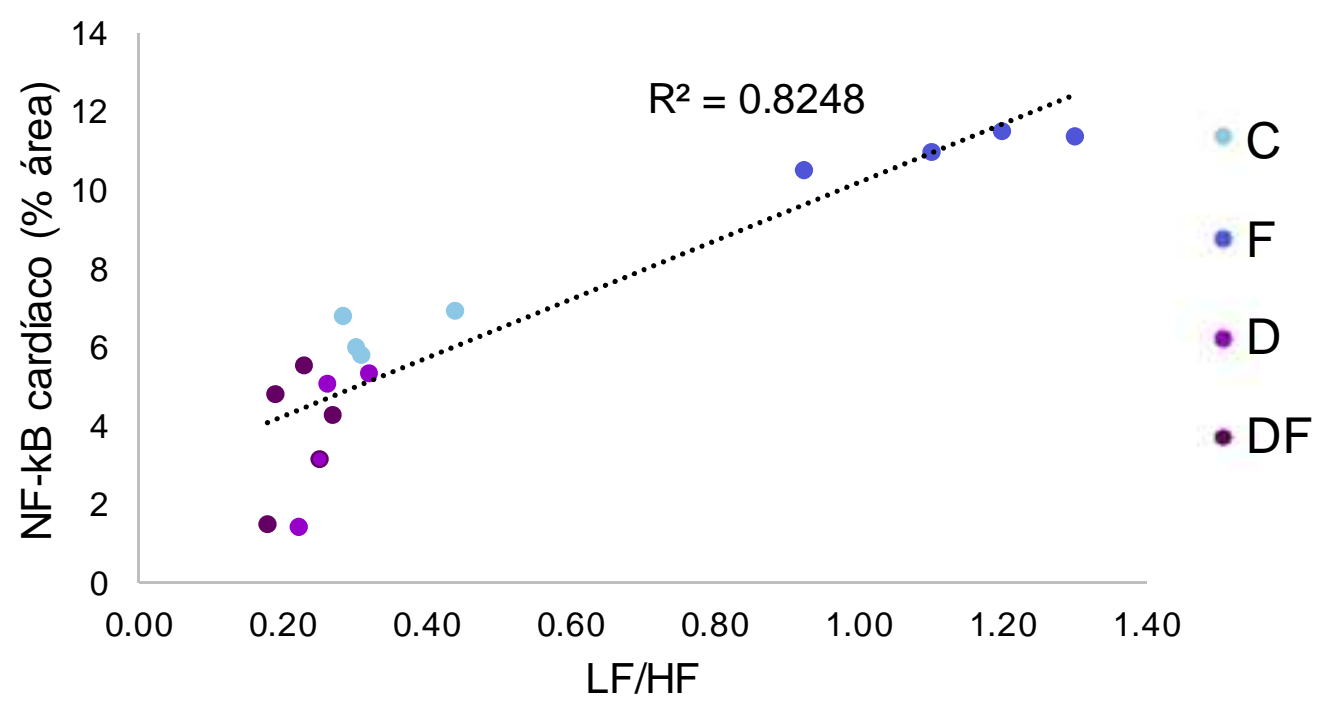

Figura 61: Correlação LF/HF/NF-kB cardíaco. Associação entre os valores de balanço simpatovagal (LF/HF) e NF-kB cardíaco nos grupos $(n=4)$ : controle $(C)$, frutose $(F)$, desnervado (D) e desnervado frutose (DF).

Com relação a associação entre NF-kB e a Variabilidade da PAS (Figura 62), entretanto, observamos que os grupos desnervados estão localizados mais acima a direita, sugerindo que quanto maior a variabilidade, maiores os níveis de NF-kB. Esses dados sugerem que tanto o balanço como a Variabilidade da PAS se associam com aumentos deste fator de transcrição o que favoreceria o processo inflamatório. 


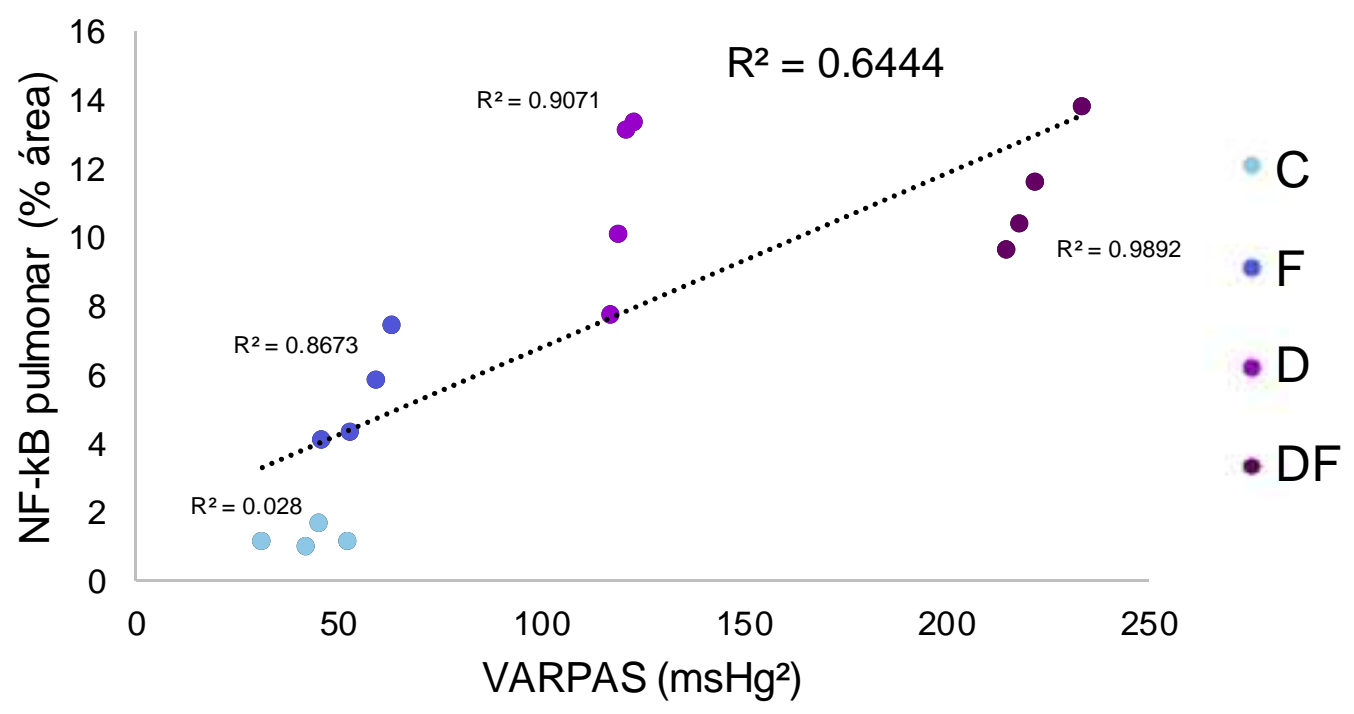

Figura 62: Correlação VARPAS/NF-kB pulmonar. Associação entre os valores de variância da pressão (VARPAS) e NF-kB pulmonar nos grupos $(n=4)$ : controle $(C)$, frutose $(F)$, desnervado (D) e desnervado frutose (DF). 


\section{5) Discussão}

Afim de facilitar o entendimento dos dados obtidos e para podermos interpretar de forma clara nossos resultados, dividiremos esta discussão nos seguintes tópicos:

\section{1) Barorreflexo e desenvolvimento de síndrome metabólica.}

A cirurgia de DSA foi bem sucedida e isso fica evidente, pela análise da sensibilidade do baroreflexo pelo índice alfa. De fato, ambos os grupos que tiveram remoção das fibras aferentes apresentaram redução da função dos barorreceptores. Isto também indica que provavelmente não houve reinervação, uma vez que este prejuízo se manteve durante todo o protocolo. Vale ressaltar que o tratamento com frutose em animais intactos foi capaz de promover perda gradual da função dos barorreceptores avaliada pela sensibilidade do barorreflexo, a partir da sexta semana de experimentos.

Quanto à eficácia em desenvolver SM, nossos resultados demonstram que o tratamento com frutose foi capaz de promover SM assim como esperado (WAJCHENBERG et al., 1994). Pode-se notar pelo aumento no consumo de água, e consequentemente frutose na água de beber, o que resultou em uma ingesta calórica mais elevada, e assim, um aumento no ganho de peso corporal nos animais tratados quando comparados ao controle. É provável que o uso de frutose dissolvida na água de beber favoreça o aparecimento de tais alterações, quando comparado com o consumo de frutose provocado por sua inclusão na ração (ABDULLA et al., 
2011), já que não estimula fatores associados à saciedade, levando a um aumento cada vez maior em seu consumo, o que poderia também induzir um aumento no volume urinário.

Os efeitos deste consumo elevado de frutose podem ser evidenciados observando-se o aumento da glicemia de jejum nos animais submetidos à sobrecarga e também à diminuição da sensibilidade à insulina encontrada já no primeiro mês de tratamento. Além disso, os dois grupos que receberam frutose apresentaram aumento da gordura abdominal ao fim do protocolo, aumento nos níveis de colesterol total e triglicerídeos por volta da sétima semana de tratamento. Quanto à pressão arterial, a frutose causou elevação na PAS, PAD e consequentemente na PAM já na quarta semana de protocolo. A somatória destes resultados serve de base para caracterizar nosso modelo como SM.

Avaliando a influência do baroreflexo pela desnervação dos aferentes aórticos e carotídeos, foi possível observar que, o grupo desnervado apresentou menor consumo geral, tanto de água quanto de ração, provavelmente levando a um consumo calórico e peso corporal menores do que o observado no grupo controle. Vale ressaltar que em nenhum momento durante as 13 semanas de protocolo o grupo D perdeu peso corporal, apenas seu ganho de peso foi menor. A DSA também alterou o comportamento da glicemia de jejum semana a semana, sendo que em alguns momentos ela foi maior do que nos controles, embora em outros não se tenha observado essa diferença. A sensibilidade à insulina parece também estar alterada, como se pode observar com o aumento desta sensibilidade apenas no segundo mês de protocolo. Estes resultados indicam que a ausência do controle barorreflexo pode influenciar indiretamente os valores de glicemia circulante (HONG 
et al., 2012; WEHRWEIN et al., 2012), alterando a sua regulação e gerar grandes variações ao longo do tempo. Considerando que o barorreflexo pode modular a atividade autonômica periférica e que a desnervação dos aferentes barorreceptores está associada com perda dessa modulação, liberando a atividade simpática e parassimpática desse controle, poderia se esperar alterações de funções como a homeostase glicêmica nessa condição, uma vez que o pâncreas é inervado pelo sistema nervoso autônomo. De fato, o aumento da atividade parassimpática sobre o pâncreas estimula a secreção de insulina enquanto o aumento da atividade simpática pode inibir essa secreção (KIBA, 2004).

A desnervação isolada não foi capaz de alterar sob nenhuma perspectiva os valores de colesterol, triglicerídeos ou pressão arterial. No entanto, quando associada ao consumo de frutose parece atenuar de diversas maneiras o desenvolvimento da síndrome. Primeiramente o ganho de peso é semelhante ao do grupo C. Este ganho de peso corporal aumenta progressivamente ao longo do experimento, sendo que, após a décima semana, os animais do grupo DF apresentam peso corporal semelhantes aos do grupo $\mathrm{F}$, com nítida tendência a continuar aumentando. Em outras palavras, o aumento de peso no grupo DF ocorre tardiamente. Estes eventos remetem à uma quantidade de gordura abdominal semelhante ao $\mathrm{C}$ e em um aumento dos níveis de colesterol e triglicérides muito mais moderados que no grupo $\mathrm{F}$.

Nesta primeira seção fica evidente que a frutose é capaz de desenvolver um quadro clínico muito semelhante ao da SM. Podemos inferir que o baroreflexo não possui influência direta para o acometimento, uma vez que a associação entre DSA e frutose não potencializa ou favorece o progresso desta doença. Ao contrário, o que 
se observou é que a ausência do controle barorreflexo sobre a atividade simpática e parassimpática periféricas, incluindo mudanças sobre o pâncreas e outros tecidos como o tecido adiposo e o fígado podem ter contribuído para a manutenção da resistência à insulina e da glicemia. Por outro lado, quando se observa o prejuízo do barorreflexo no grupo $\mathrm{F}$ intacto, ou seja, sem a DSA, ele aparece por volta da décima semana, não podendo estar relacionado como causa pois a SM já está estabelecida, mas provavelmente como consequência das alterações metabólicas induzidas pela F. Apesar de a DSA parecer suavizar os efeitos da frutose como dito anteriormente, não podemos afirmar neste momento que a ausência do controle baroreflexo teria um efeito protetor. Afinal, como mencionado, o grupo $\mathrm{F}$ também apresenta disfunção do baroreflexo.

\section{2) Hemodinâmica}

Como citado anteriormente, notamos que a pressão arterial foi o primeiro parâmetro observado à sofrer alterações. Tanto o aumento da PAS como da PAD ou da PAM, observou-se que a frutose causou elevação constante e progressiva destes valores a partir da terceira semana de tratamento. Isto se deve, muito provavelmente, à alterações do sistema nervoso autônomo e à disfunção renal. Apesar de não se alterar de forma marcante os valores de pressão arterial, a DSA em 90 dias de observação promoveu aumento na variabilidade da pressão, sem promover maior modulação simpática periférica, como descrito (FRANCHINI \& KRIEGER, 1992; IRIGOYEN et al., 1995). A frutose isolada, por sua vez, foi capaz de induzir aumento da modulação simpática para os vasos a partir da terceira semana, permanecendo elevada durante todo o protocolo. Quando associamos as 
duas intervenções, observamos um efeito somatório, onde obtivemos aumento da modulação simpática e um aumento ainda mais evidente da variabilidade da pressão, fator que isoladamente já é conhecido como indutor de lesão à órgãos alvo (FRATTOLA et al., 1993; KIKUYA et al., 2000). Chama a atenção, portanto, que as alterações autonômicas (ocorridas a partir da segunda semana) de fato precedem as alterações metabólicas (a partir da sétima semana) que vão caracterizar a síndrome metabólica induzida pela sobrecarga de frutose. Esse resultado está em acordo com outros semelhantes obtidos em camundongos (YOSHIDA et al., 2003).

Apesar de os valores de frequência cardíaca não serem diferentes entre os grupos, a desnervação mostrou-se eficaz em diminuir a variabilidade total do intervalo de pulso. Uma vez que não há mais o controle fino da pressão arterial, a regulação autonômica cardíaca se modifica, com liberação do controle tônico inibitório do drive simpático e excitatório do parassimpático, restando os demais mecanismos controladores a médio e longo prazo (KRIEGER, 1970). Com a redução da variabilidade cardíaca temos por consequência redução da modulação total, incluindo as bandas de LF e HF representativas da modulação simpática e parassimpática, respectivamente. No entanto, quando avaliamos os valores percentuais, relativos e o balanço entre simpático e vago, podemos observar que os animais desnervados mantiveram a normalidade do sistema, mesmo reduzindo a modulação total (MORAES-SILVA, I. C. et al., 2010).

Já o uso de frutose isolada, apesar não alterar a variabilidade cardíaca, promoveu um aumento da modulação simpática e redução da parassimpática. Surpreendentemente, a frutose é capaz de elevar os valores da modulação simpática já na segunda semana de tratamento. A maioria dos trabalhos relaciona o 
aumento da atividade simpática por frutose devido à resistência à insulina (MUNTZEL et al., 1995; TAKAGI et al., 2003; ISGANAITIS \& LUSTIG, 2005). Nosso trabalho fornece evidencias de que este não é o caso, uma vez que a sensibilidade à insulina só parece estar diminuída a partir da quarta semana e o aumento da glicemia ainda é modesto neste período. É bem provável que a resistência à insulina e o aumento na atividade simpática formem um loop de feedback positivo, em que o aumento de ambos atue com elemento permissivo para novos aumentos. Em nosso estudo não há avaliação da atividade simpática, no entanto é nítido que alterações na modulação cardíaca são o primeiro passo no desencadeamento da SM. É provável que essa modulação esteja acompanhada de hiperatividade do sistema nervoso simpático, uma vez que essa é uma característica comum encontrada na obesidade, em modelos animais e humanos (HALL et al., 2010). A ativação simpática estaria associada à vasoconstrição periférica e aumento da reabsorção tubular de sódio (HALL, 2003). Além disso, mesmo não tendo sido medida nesse estudo, a ação da leptina, dentre outros mecanismos, poderia ser o elo entre o excesso de adiposidade e o aumento da atividade simpática cardiovascular, uma vez que a concentração plasmática desse hormônio, que é secretado pelo adipócito, aumenta proporcionalmente ao grau de adiposidade (MARK et al., 2009).

Outra adaptação encontrada foi na regulação dos receptores $\beta$ adrenérgicos no ventrículo esquerdo. Primeiramente vale ressaltar que a desnervação isolada não foi capaz de promover nenhuma alteração na população destes receptores, considerando que esses dados foram obtidos aos 90 dias de DSA. Assim, alterações funcionais já descritas, como a dessensibilização dos $\beta$ receptores após exposição prolongada a aumentos do simpático podem ser associadas com esse achado de 
não alteração da expressão gênica dos receptores $\beta$ (VASQUEZ \& KRIEGER, 1982). Isto posto, chamamos atenção para o nítido aumento nos receptores $\beta 1$ nos animais tratados com frutose. Sabemos que estes apresentam papel de destaque no desenvolvimento da SM, uma vez que o bloqueio destes receptores podem prevenir o surgimento de hipertensão por sobrecarga de frutose (TRAN et al., 2014). As adaptações crônicas ao aumento da modulação simpática envolvem mudanças (redução) no número ou funcionais (redução da afinidade com o ligante) desses receptores afim de compensar o aumento da atividade via modulação de seus efeitos. Seria esperado um processo de down regulation nesses receptores (ZANESCO et al., 1997), provavelmente associado com a manutenção da frequência cardíaca nesses animais. Isto talvez possa ter ocorrido em outro período do desenvolvimento, não acompanhado neste trabalho. Porém, notamos que houve um grande aumento dos receptores $\beta 2$, que por sua ação antagônica ao $\beta 1$, são capazes de ser ativado pelo mesmo fluxo adrenérgico, gerando respostas cardíacas inversas. Podemos então atribuir os resultados de não haver maiores alterações de frequência cardíaca ou variabilidade às respostas compensatórias desses adrenorreceptores.

O mesmo não ocorre no grupo DF. Há sim aumento dos receptores $\beta 1$, porem como há diminuição dos $\beta 2$ e este grupo não apresenta qualquer indício de alteração na frequência cardíaca, variabilidade do intervalo de pulso ou na modulação autonômica para o coração, podemos admitir que o controle cardíaco está sendo efetuado devido à atuação do sistema parassimpático. Na verdade, nosso grupo já descreveu que na DSA, após redução do tônus vagal central, há uma compensação periférica caracterizada por maior expressão e responsividade dos 
receptores muscarínicos (SOARES et al., 2006) o que mantém a função parassimpática operante. Nesse sentido, vale lembrar que a estimulação vagal é um meio eficaz de prevenir SM (DAS, 2011) e portanto, frente à manutenção de uma função vagal adequada podemos esperar uma atenuação do processo de instalação da SM, conforme observado no grupo DF.

\section{3) Alterações renais}

Nossos modelos experimentais demonstraram grande capacidade de promover alterações renais. As mais significantes foram geradas pelo uso isolado da frutose. É bem descrito que a frutose ingerida em solução aquosa é palatável aos animais e que sua absorção não estimula regulação de saciedade (RAO et al., 2007; TAPPY \& LE, 2010), fazendo com que haja maior consumo. Com aumento do volume hídrico é necessário que aconteça uma regulação compensatória renal, afim de eliminar o volume excedente na urina. Este mecanismo torna-se de grande utilidade no nosso modelo, uma vez que podemos observar aumento na excreção de glicose e lactato. O primeiro contribuindo para que não ocorra hiperglicemia sanguínea e o segundo sendo necessário por tratar-se de um produto energético do metabolismo de frutose (HENRY et al., 1991).

Este aumento no volume urinário faz com que a urina seja mais diluída, como pode ser observado pelos valores de osmolaridade. No entanto, em valores absolutos de 24 horas podemos notar que, apesar da urina diluída, estes animais excretam muito mais ureia, creatinina e íons. Podemos sugerir que o aumento de ureia e creatinina na urina, juntamente com o aumento da modulação simpática 
periférica, são marcadores de aumento da filtração glomerular. É comum que pacientes renais crônicos sejam portadores de SM, sendo que 2/3 deles apresentam diabetes ou hipertensão (DURVASULA \& HIMMELFARB, 2011). Com base nos nossos dados podemos notar que mais uma vez o aumento do simpático exerce grande influência no acometimento por uma doença. Neste modelo não houve alteração dos valores de AT1, indicando que o aumento da filtração glomerular não é regulado pela angiotensina, e sim pelo sistema nervoso simpático. Podemos encontrar na literatura descrição de diminuição dos receptores AT1, devido à down regulation dos mesmos em presença de elevados níveis de Angiotensina 2 no tratamento de frutose (SHINOZAKI et al., 2004), mais uma vez indicando que o simpático pode estar sobrepondo-se em efeito à ação do sistema renina angiotensina. A maior liberação iônica na urina, provavelmente está associada a uma medida contra regulatória, afim de compensar o aumento de pressão e controlar os valores de PA a longo prazo.

Por sua vez, a DSA isolada também apresenta indícios de hiperfiltração glomerular, como aumento da ureia, ácido úrico e creatinina. No entanto, neste caso não é devido à aumento do simpático, pois estes animais não apresentam alteração neste parâmetro. Logo, este aumento de filtração pode ser justificado indiretamente devido ao aumento da ação da Angiotensina II na medula renal (ICHIKAWA \& BRENNER, 1980), uma vez que encontramos aumento na quantidade de receptores AT1 nesta região. Outro fator ligado à ação do sistema Renina Angiotensina é a reabsorção iônica nos túbulos distais(DZAU, 1988). De fato, pode ser essa a ligação entre o aumento dos receptores AT1 e a menor excreção de íons na urina levando à diminuição da osmolaridade nesses animais. 
Como discutido anteriormente, os animais desnervados apresentam ganho de peso menor que os do grupo controle por comerem menos. Este fato faz com que seja necessário obter um aproveitamento nutricional melhor. Com base na diminuição na excreção de lactato observada no grupo $D$, podemos sugerir que este metabólito está sendo utilizado como fonte de energia, e consequentemente há menos moléculas disponíveis para filtração. Nos resta discutir qual mecanismo estaria envolvido no aumento do AT1 e da filtração renal. Como vimos, parece não ser devido à atividade simpática, porém este modelo apresenta uma característica diferencial que é a grande variabilidade da PA. Dados não publicados do nosso grupo demonstram que alterações no eixo Renina Angiotensina são capazes de alterar o fluxo plasmático renal. Nestes resultados, o bloqueio do AT1 foi capaz de aumentar o fluxo plasmático renal, afim de compensar queda na filtração. No nosso caso, o aumento da variabilidade da pressão arterial poderia se associar a maior fluxo plasmático renal, que acompanhado do aumento dos receptores AT1, encontrados na medula renal, estariam causando o aumento da filtração glomerular.

Após avaliar os efeitos isolados das intervenções sobre a função renal, podemos notar que a junção dos dois tratamentos potencializou algumas alterações encontradas. No DF temos aumento da modulação simpática periférica, causado pela frutose, juntamente com aumento dos receptores AT1, provavelmente devido a VARPA. Para outros fatores, como o lactato, onde cada intervenção resultou em uma resposta contrária, o resultado foi um valor intermediário, sendo iguais aos níveis no controle. Neste grupo (DF), devido ao aumento no consumo de água, observou-se aumento do volume urinário acompanhado de menor osmolaridade, sem alteração na excreção de ureia ou ácido úrico. É interessante notar que, em 
relação aos íons urinários, na primeira semana há predomínio do comportamento encontrado na desnervação, onde há maior reabsorção iônica. Nas demais semanas, conforme aparece um aumento no consumo de frutose, os animais do grupo DF excretam mais íons, padrão encontrado no grupo F.

\section{4) Inflamação}

Os fatores inflamatórios, apesar de serem necessários e fundamentais para sobrevivência de um indivíduo, em alguns casos patológicos pode atuar de forma exacerbada contribuindo com o agravamento do quadro clínico. Sabemos que o aumento da inflamação é característica comum na SM, principalmente devido a maior quantidade de tecido adiposo (THORP \& SCHLAICH, 2015). De fato, existem inúmeras evidências que suportam a envolvimento direto do tecido adiposos visceral no desenvolvimento da aterosclerose e suas complicações, conforme revisado no artigo de Alexopoulos e colaboradores (2014).

Mais recentemente tem crescido o interesse na regulação neuro-imune, investigando a influência do sistema nervoso autônomo sobre o controle da inflamação (TRACEY, 2009), caracterizando o papel regulatório do Sistema Nervoso sobre os processos de adaptação homeostática. Foi possível observar que nossos tratamentos causaram respostas inflamatórias diferentes no músculo cardíaco. O grupo $F$, que possui aumento da modulação simpática, apresentou aumento do TNF$\alpha$ indiciando lesão celular, provavelmente causada por stress. Apesar de possuir aumento no fator de transcrição de citocinas, há também aumento do IL-10 que tem por função inibir a ação pró-inflamatória. Isso nos indica que para o coração o SNA 
pode exercer influência regulatória quanto ao surgimento de resposta inflamatória na SM. Vale aqui lembrar que o teste de associação entre o NF-kb e o balanço simpatovagal mostrou uma relação direta entre os dois com um alto coeficiente de determinação. Isto sugere que apenas a ativação simpática, observada principalmente no grupo tratado com frutose, pode contribuir para a inflamação. De fato o NF-kB é o fator de transcrição exclusivo para a indução de IL-6 em resposta ao TNF- $\alpha$ (VANDEN BERGHE et al., 2000).

Já os grupos desnervados apresentam, além de aumento do TNF- $\alpha$, aumento da IL-1 e do IL-6. Este aumento do perfil inflamatório pode estar associado com aumento da variabilidade da pressão, lesando endotélio e favorecendo resposta inflamatória. De fato, a DSA induz inflamação crônica no miocárdio caracterizada por infiltração de macrófagos e up regulation do MCP-1 (proteína quimiotática de monócitos) que é particularmente evidente em animais espontaneamente hipertensos, mas que também ocorre em normotensos (KUDO et al., 2009). Nesse sentido, a associação entre o NF-kB e a variabilidade da PAS mostrou que os grupos desnervados parecem ser os que estão mais acima e a direita no gráfico, indicando que a variabilidade da PAS pode ser um mecanismo de lesão associado com a inflamação. Adicionalmente, trabalho anterior de nosso grupo (FLUES et al., 2012) mostrou remodelamento cardíaco após DSA em ratos normotensos, mostrando que o aumento da expressão gênica do colágeno tipo I e tipo III no ventrículo esquerdo (VE) e no ventrículo direito (VD) de animais com DSA foi acompanhado do aumento da expressão gênica dos marcadores de hipertrofia cardíaca ANF (fator natriurético atrial) e alfa actina esquelética , o que caracteriza também a possibilidade do quadro inflamatório nessa circunstância. 
A relação entre remodelamento e as respostas de hipertrofia cardíaca em diferentes tecidos tem sido foco de atenção de vários grupos de pesquisa, pois atualmente aceita-se que a despeito de diferentes estímulos patológicos existe também muitas características em comum no desenvolvimento desse processo em resposta a diferentes doenças incluindo as cardíacas. Ao lado do aumento da massa, do rearranjo sarcomérico e a deposição de matriz extracelular, outras características comum ao processo como a sinalização inflamatória e a ativação de células imunes, tem sido valorizadas (FRIELER \& MORTENSEN, 2015).

Para o pulmão, observamos através da análise de imunohistoquímica que a DSA promoveu aumento expressivo dos marcador de inflamação IL-6 e do NFKB. Nosso grupo já descreveu que o modelo de prejuízo baroreflexo é capaz de causar um quadro de hipertensão pulmonar (FLUES et al., 2012). Este fato associado ao aumento da VARPA podem estar contribuindo para lesão endotelial e levando ao aumento da inflamação crônica. De fato, estudo de Miao et al (2004) demonstraram que a maior hipertrofia do VD em animais com DSA se deveu principalmente à vasculopatia pulmonar encontrada nesse modelo. Além disso, a atividade de ligação ao DNA do NF-kB aumentou significativamente nos pulmões de animais expostos cronicamente à hipóxia acompanhada do aumento de algumas citocinas inflamatórias incluindo a IL-6 do NF-kB. Esse aumento, bem como o edema pulmonar, foi revertido pela atenuação da hipóxia induzida pelo bloqueio do NF-kB, indicando um papel para esse fator de transcrição nesses quadros pulmonares. 0 NF-kB participa no regulação da expressão de diversos genes ligados à resposta inflamatória, portanto não é surpreendente sua ativação na DSA, um conhecido modelo de disfunção associado à hipertensão pulmonar na fase crônica 
No rim temos uma situação um pouco diferente. Todas as intervenções resultaram em aumento do fator de transcrição, indicando maior atividade das citocinas inflamatórias. No entanto, o marcador de inflamação IL-6 está aumentado no grupo $F$, diminuído no grupo $D$ e com um discreto aumento no grupo DF. A lesão inflamatória renal está associada com deposição de gordura nos rins (ISHIGAKI et al., 2007). Esta deposição se dá principalmente devido grande quantidade de gordura abdominal e do aumento do triglicérides circulantes (BOBULESCU et al., 2014). Isso está de acordo com os nossos achados. Tendo o grupo $\mathrm{F}$ aumento da gordura abdominal e triglicerídeos, o D diminuição e o DF um padrão intermediário entre os dois, podemos esperar diferentes respostas da inflamação renal em cada grupo experimental. 


\section{6) Sumário}

O quadro abaixo sumariza os achados obtidos no presente estudo após 90 dias de acompanhamento. De forma geral foi possível observar que a sobrecarga de frutose aumentou a PA e alterou parâmetros metabólicos e autonômicos, caracterizando um aumento da modulação simpática e da inflamação em coração e rim nesse grupo. 0 grupo desnervado somente, conforme esperado, não apresentou mudanças no nível da PA, ganhou menos peso em relação ao controle e não alterou significativamente o perfil metabólico, mas aumentou a variabilidade da PA. Apresentou também aumento de alguns marcadores inflamatórios em coração, rim e pulmões. Já o grupo desnervado tratado com frutose mostrou atenuação do perfil metabólico quando comparado ao grupo frutose, manteve a variabilidade da PA e a maioria das mudanças induzidas pela frutose nos fatores inflamatórios em coração, rim e pulmão. $\mathrm{O}$ tratamento com frutose nos animais desnervados mostrou que a frutose modificou os parâmetros metabólicos nesses animais, aproximando o perfil dos mesmo ao da SM ou ao do grupo tratado com frutose em comparação ao grupo só desnervado. A maioria dos demais parâmetros permaneceu semelhante ao do grupo desnervado, mantendo a variabilidade da PA aumentada bem como os fatores inflamatórios nos diferentes tecido examinados. Finalmente, deve-se chamar a atenção que a avaliação temporal dos eventos no grupo frutose mostrou que as alterações autonômicas precedem as metabólicas e que a desnervação alterou esse comportamento, uma vez que podemos caracterizar SM no grupo DF por volta da décima semana de tratamento, sem prejuízo marcante na modulação simpática. 
Tabela 3:Sumário.

\begin{tabular}{|c|c|c|c|c|c|}
\hline & $\mathbf{F} \times \mathbf{C}$ & $\mathrm{D} \times \mathrm{C}$ & DF $\times C$ & DF $\times$ F & DF x D \\
\hline Ração & Diminuiu & Diminuiu & Diminuiu & lqual & lqual \\
\hline Água & Aumentou & Aumentou & Diminuiu & Diminuiu & Aumentou \\
\hline Calorias & Aumentou & Diminuiu & lqual & lqual & Aumentou \\
\hline Peso & Aumentou & Diminuiu & lqual & & Aumentou \\
\hline Triglicérides & Aumentou & lqual & Aumentou & Diminuiu & Aumentou \\
\hline Colesterol & Aumentou & lqual & Aumentou & Diminuiu & Aumentou \\
\hline Tecido adiposo & Aumentou & lqual & lqual & Diminuiu & Aumentou \\
\hline Glicemia & Aumentou & lqual & Aumentou & lqual & lqual \\
\hline Resistencia a insulina & Aumentou & lqual & lqual & lqual & lqual \\
\hline Volume de urina & Aumentou & laual & Aumentou & laual & Aumentou \\
\hline Glicose urinária & Aumentou & lqual & lqual & lqual & lqual \\
\hline Lactato Urinario & Aumentou & Diminuiu & lqual & Diminuiu & lqual \\
\hline Osmolaridade da urina & Diminuiu & Diminuiu & Diminuiu & Diminuiu & lqual \\
\hline Ácido úrico na urina & lqual & Aumentou & lqual & lqual & Diminuiu \\
\hline Ureia na urina & lqual & Aumentou & Aumentou & lqual & lqual \\
\hline Creatinina na urina & Aumentou & Aumentou & Aumentou & lqual & lqual \\
\hline PA & Aumentou & lqual & Aumentou & lqual & Aumentou \\
\hline FC & lqual & lqual & lqual & lqual & lqual \\
\hline Variancia FC & lqual & Diminuiu & Diminuiu & Diminuiu & lqual \\
\hline RMSSD & lqual & lqual & lqual & lqual & lqual \\
\hline LF abs, $\%$ e nu & Aumentou & lqual & lqual & Diminuiu & lqual \\
\hline HF abs & lqual & Diminuiu & lqual & lqual & lqual \\
\hline HF \% & Diminuiu & lqual & lqual & lqual & lqual \\
\hline HF nu & Diminuiu & lqual & lqual & lqual & lqual \\
\hline Balanço & Aumentou & lqual & lqual & Diminuiu & lqual \\
\hline Variancia PAS & lqual & Aumentou & Aumentou & Aumentou & lqual \\
\hline LF PAS & Aumentou & lqual & Aumentou & lqual & Aumentou \\
\hline Alfa & Diminuiu & Diminuiu & Diminuiu & lqual & lqual \\
\hline B1 cardíaco & Aumentou & lqual & Aumentou & Aumentou & Aumentou \\
\hline 及2 cardíaco & Aumentou & lqual & Diminuiu & Diminuiu & Diminuiu \\
\hline AT1 medula renal & lqual & Aumentou & Aumentou & Aumentou & lqual \\
\hline IL-6 coração & Diminuiu & Aumentou & Aumentou & Aumentou & lqual \\
\hline NFkB coração & Aumentou & lqual & lqual & Diminuiu & lqual \\
\hline TNF coração & Aumentou & Aumentou & Aumentou & Aumentou & lqual \\
\hline IL-1 coração & lqual & Aumentou & lqual & lqual & lqual \\
\hline IL-10 coração & Aumentou & lqual & lqual & Diminuiu & lqual \\
\hline IL-6 pulmão & Aumentou & Aumentou & Aumentou & Aumentou & Aumentou \\
\hline NFkB pulmão & lqual & Aumentou & Aumentou & Aumentou & lqual \\
\hline IL6-rim & Aumentou & Diminuiu & lqual & Diminuiu & Aumentou \\
\hline BFkB rim & Aumentou & Aumentou & Aumentou & lgual & lgual \\
\hline
\end{tabular}




\section{7) Conclusão}

Quanto à nossa principal hipótese podemos afirmar baseados nos dados obtidos neste estudo que a disautnomia e o aumento da modulação simpática precederam o desenvolvimento da SM no modelo de sobrecarga de frutose em ratos.

Além disso, vimos que a ausência do barorreflexo modificou marcadores metabólicos da SM demonstrando que os aferentes barorreceptores tem um papel na apresentação das alterações temporais. Entretanto, esse papel parece não ser o agravamento do quadro e sim uma atenuação do mesmo, indicando que mais estudos nessa área devem ser desenvolvidos. Essa ideia ganha reforço quando observamos a grupo apenas tratado com frutose, em que o prejuízo da função barorreflexa aparece tardiamente ao estabelecimento da disfunção metabólica. 


\section{8) Referências}

ABBOUD; , F. M. \& M. D. THAMES;. Interaction of Cardiovasvular reflexes in circulatory control. In: (Ed.). HANDBOOK OF PHYSIOLOGY - THE CARDIOVASCULAR SYSTEM III, 1983. Interaction of Cardiovasvular reflexes in circulatory control., p.675-753

ALEXANDER, N., et al. Right-left asymmetry of tyrosine hydroxylase in rat median eminence: influence of arterial baroreflex nerves. Brain Res, v.523, n.2, p.195-8. Jul 23, 1990.

ALEXANDER, N., et al. Indices of sympathetic activity in the sinoaortic-denervated hypertensive rat. Am J Physiol, v.238, n.4, p.H521-6. Apr, 1980.

ALEXOPOULOS, N., et al. Visceral adipose tissue as a source of inflammation and promoter of atherosclerosis. Atherosclerosis, v.233, n.1, p.104-12. Mar, 2014.

ALVAREZ, G. E., et al. Sympathetic neural activation in visceral obesity. Circulation, v.106, n.20, p.2533-6. Nov 12, 2002.

ARAUJO, I. C., et al. Early developmental exposure to high fructose intake in rats with $\mathrm{NaCl}$ stimulation causes cardiac damage. Eur J Nutr. Jan 7, 2015.

BANERJEE, D., et al. Insulin resistance and risk of incident heart failure: cardiovascular health study. Circ Heart Fail, v.6, n.3, p.364-70. May 1, 2013.

BARREIROS, R. C., et al. Frutose em humanos: efeitos metabólicos, utilização clínica e erros inatos associados. Rev Nutri, v.18, n.3, p.377-389, 2005.

BOBULESCU, I. A., et al. Triglycerides in the human kidney cortex: relationship with body size. PLoS One, v.9, n.8, p.e101285, 2014.

BONORA, E., et al. Estimates of in vivo insulin action in man: comparison of insulin tolerance tests with euglycemic and hyperglycemic glucose clamp studies. J Clin Endocrinol Metab, v.68, n.2, p.3748. Feb, 1989.

BRITO, J. O., et al. Parasympathetic dysfunction is associated with insulin resistance in fructose-fed female rats. Braz J Med Biol Res, v.41, n.9, p.804-8. Sep, 2008. 
CAREY, R. M. \& H. M. SIRAGY. The intrarenal renin-angiotensin system and diabetic nephropathy. Trends Endocrinol Metab, v.14, n.6, p.274-81. Aug, 2003.

CERONI, A., et al. Chronic absence of baroreceptor inputs prevents training-induced cardiovascular adjustments in normotensive and spontaneously hypertensive rats. Exp Physiol, v.94, n.6, p.630-40. Jun, 2009.

CHANG, A., et al. Lifestyle-Related Factors, Obesity, and Incident Microalbuminuria: The CARDIA (Coronary Artery Risk Development in Young Adults) Study. Am J Kidney Dis. Apr 10, 2013.

DA SILVA, A. A., et al. The role of the sympathetic nervous system in obesity-related hypertension. Curr Hypertens Rep, v.11, n.3, p.206-11. Jun, 2009.

DAI, S. \& J. H. MCNEILL. Fructose-induced hypertension in rats is concentration- and durationdependent. J Pharmacol Toxicol Methods, v.33, n.2, p.101-7. Apr, 1995.

DALY, P. A. \& L. LANDSBERG. Hypertension in obesity and NIDDM. Role of insulin and sympathetic nervous system. Diabetes Care, v.14, n.3, p.240-8. Mar, 1991.

DAS, U. N. Vagus nerve stimulation as a strategy to prevent and manage metabolic syndrome. Med Hypotheses, v.76, n.3, p.429-33. Mar, 2011.

DE ANGELIS, K., et al. Sympathetic overactivity precedes metabolic dysfunction in a fructose model of glucose intolerance in mice. Am J Physiol Regul Integr Comp Physiol, v.302, n.8, p.R950-7. Apr 15, 2012.

DURVASULA, R. V. \& J. HIMMELFARB. Chronic Kidney Failure and Dialysis. Deker Intellectual Properties, 2011.

DZAU, V. J. Circulating versus local renin-angiotensin system in cardiovascular homeostasis. Circulation, v.77, n.6 Pt 2, p.14-13. Jun, 1988.

ELLIOTT, S. S., et al. Fructose, weight gain, and the insulin resistance syndrome. Am J Clin Nutr, v.76, n.5, p.911-22. Nov, 2002.

FARAH, V., et al. Nocturnal hypertension in mice consuming a high fructose diet. Auton Neurosci, v.130, n.1-2, p.41-50. Dec 30, 2006.

FARAH, V., et al. Stress cardiovascular/autonomic interactions in mice. Physiol Behav, v.89, n.4, p.569-75. Nov 30, 2006. 
FLUES, K., et al. Cardiac and pulmonary arterial remodeling after sinoaortic denervation in normotensive rats. Auton Neurosci, v.166, n.1-2, p.47-53. Jan 26, 2012.

FRANCHINI, K. G. \& E. M. KRIEGER. Carotid chemoreceptors influence arterial pressure in intact and aortic-denervated rats. Am J Physiol, v.262, n.4 Pt 2, p.R677-83. Apr, 1992.

FRATTOLA, A., et al. Prognostic value of 24-hour blood pressure variability. J Hypertens, v.11, n.10, p.1133-7. Oct, 1993.

FRIELER, R. A. \& R. M. MORTENSEN. Immune cell and other noncardiomyocyte regulation of cardiac hypertrophy and remodeling. Circulation, v.131, n.11, p.1019-30. Mar 17, 2015.

GIRMAN, C. J., et al. The metabolic syndrome and risk of major coronary events in the Scandinavian Simvastatin Survival Study (4S) and the Air Force/Texas Coronary Atherosclerosis Prevention Study (AFCAPS/TexCAPS). Am J Cardiol, v.93, n.2, p.136-41. Jan 15, 2004.

GRASSI, G. Sympathetic overdrive and cardiovascular risk in the metabolic syndrome. Hypertens Res, v.29, n.11, p.839-47. Nov, 2006.

GUIMARAES, G. V. \& E. G. CIOLAC. Síndrome metabólica: abordagem do educardor físico. Rev Soc Cardiol Estado de São Paulo, v.4, p.659-670, 2004.

HALL, J. E. The kidney, hypertension, and obesity. Hypertension, v.41, n.3 Pt 2, p.625-33. Mar, 2003.

HALL, J. E., et al. Obesity-induced hypertension: role of sympathetic nervous system, leptin, and melanocortins. J Biol Chem, v.285, n.23, p.17271-6. Jun 4, 2010.

HELLSTROM, H. R. The altered homeostatic theory: A hypothesis proposed to be useful in understanding and preventing ischemic heart disease, hypertension, and diabetes--including reducing the risk of age and atherosclerosis. Med Hypotheses, v.68, n.2, p.415-33, 2007.

HENRY, R. R., et al. Current issues in fructose metabolism. Annu Rev Nutr, v.11, p.21-39, 1991.

HWANG, I. S., et al. Fructose-induced insulin resistance and hypertension in rats. Hypertension, v.10, n.5, p.512-6. Nov, 1987.

ICHIKAWA, I. \& B. M. BRENNER. Importance of efferent arteriolar vascular tone in regulation of proximal tubule fluid reabsorption and glomerulotubular balance in the rat. J Clin Invest, v.65, n.5, p.1192-201. May, 1980. 
IRIGOYEN, M. C., et al. Measurements of renal sympathetic nerve activity in conscious sinoaortic denervated rats. Braz J Med Biol Res, v.21, n.4, p.869-72, 1988.

IRIGOYEN, M. C., et al. The relationship between renal sympathetic nerve activity and arterial pressure after selective denervation of baroreceptors and chemoreceptors. Braz J Med Biol Res, v.24, n.2, p.219-22, 1991.

IRIGOYEN, M. C., et al. Changes of renal sympathetic activity in acute and chronic conscious sinoaortic denervated rats. Hypertension, v.26, n.6 Pt 2, p.1111-6. Dec, 1995.

ISGANAITIS, E. \& R. H. LUSTIG. Fast food, central nervous system insulin resistance, and obesity. Arterioscler Thromb Vasc Biol, v.25, n.12, p.2451-62. Dec, 2005.

ISHIGAKI, N., et al. Involvement of glomerular SREBP-1c in diabetic nephropathy. Biochem Biophys Res Commun, v.364, n.3, p.502-8. Dec 21, 2007.

JULIUS, S., et al. Overweight and hypertension : a 2-way street? Hypertension, v.35, n.3, p.807-13. Mar, 2000.

KALIL, G. Z. \& W. G. HAYNES. Sympathetic nervous system in obesity-related hypertension: mechanisms and clinical implications. Hypertens Res, v.35, n.1, p.4-16. Jan, 2012.

KAMIDE, K., et al. The renin-angiotensin and adrenergic nervous system in cardiac hypertrophy in fructose-fed rats. Am J Hypertens, v.15, n.1 Pt 1, p.66-71. Jan, 2002.

KIBA, T. Relationships between the autonomic nervous system and the pancreas including regulation of regeneration and apoptosis: recent developments. Pancreas, v.29, n.2, p.e51-8. Aug, 2004.

KIKUYA, M., et al. Prognostic significance of blood pressure and heart rate variabilities: the Ohasama study. Hypertension, v.36, n.5, p.901-6. Nov, 2000.

KRIEGER, E. M. Neurogenic Hypertension in the Rat. Circ Res, v.15, p.511-21. Dec, 1964.

. Time course of baroreceptor resetting in acute hypertension. Am J Physiol, v.218, n.2, p.48690. Feb, 1970.

KRIEGER, E. M. Interação Cardiovascular. Fisiologia Cardiovascular. São Paulo: Fundo Editorial BYK Procienx 1976. 
KRIEGER, E. M. \& R. F. MARSEILLAN. Aortic Depressor Fibers in the Rat: An Electrophysiological Study. Am J Physiol, v.205, p.771-4. Oct, 1963.

KUDO, H., et al. Exaggerated blood pressure variability superimposed on hypertension aggravates cardiac remodeling in rats via angiotensin II system-mediated chronic inflammation. Hypertension, v.54, n.4, p.832-8. Oct, 2009.

LAKKA, H. M., et al. The metabolic syndrome and total and cardiovascular disease mortality in middle-aged men. JAMA, v.288, n.21, p.2709-16. Dec 4, 2002.

LANDSBERG, L. Insulin-mediated sympathetic stimulation: role in the pathogenesis of obesity-related hypertension (or, how insulin affects blood pressure, and why). J Hypertens, v.19, n.3 Pt 2, p.523-8. Mar, 2001.

LIVAK, K. J. \& T. D. SCHMITTGEN. Analysis of relative gene expression data using real-time quantitative PCR and the 2(-Delta Delta C(T)) Method. Methods, v.25, n.4, p.402-8. Dec, 2001.

LOPES, H. F. \& B. M. EGAN. Autonomic dysregulation and the metabolic syndrome: pathologic partners in an emerging global pandemic. Arq Bras Cardiol, v.87, n.4, p.538-47. Oct, 2006.

MARCUS, Y., et al. Adipose tissue renin-angiotensin-aldosterone system (RAAS) and progression of insulin resistance. Mol Cell Endocrinol, v.378, n.1-2, p.1-14. Sep 25, 2013.

MARK, A. L., et al. Leptin signaling in the nucleus tractus solitarii increases sympathetic nerve activity to the kidney. Hypertension, v.53, n.2, p.375-80. Feb, 2009.

MCAULEY, P. A., et al. Physical Activity, Measures of Obesity, and Cardiometabolic Risk: The MultiEthnic Study of Atherosclerosis (MESA). J Phys Act Health. May 10, 2013.

MCCUBBIN, J. W., et al. Baroceptor function in chronic renal hypertension. Circ Res, v.4, n.2, p.20510. Mar, 1956.

MIAO, C. Y., et al. Greater hypertrophy in right than left ventricles is associated with pulmonary vasculopathy in sinoaortic-denervated Wistar-Kyoto rats. Clin Exp Pharmacol Physiol, v.31, n.7, p.450-5. Jul, 2004.

MIAO, C. Y., et al. Blood pressure variability is more important than blood pressure level in determination of end-organ damage in rats. J Hypertens, v.24, n.6, p.1125-35. Jun, 2006.

MICHELINI, L. C. Regulação neuro-humoral da pressão arterial. In: (Ed.). Fisiologia, 1999. Regulação neuro-humoral da pressão arterial. 
MILLER, A. W., et al. Impaired vagal reflex activity in insulin-resistant rats. J Cardiovasc Pharmacol, v.33, n.5, p.698-702. May, 1999.

MORAES-SILVA, I., et al. Impaired baroreflex sensitivity is associated with diastolic dysfunction and decreased ventricular capillary density in normotensive and hypertensive rats. Hypertension, v.56, p.80, 2010.

MORAES-SILVA, I. C., et al. Baroreflex deficit blunts exercise training-induced cardiovascular and autonomic adaptations in hypertensive rats. Clin Exp Pharmacol Physiol, v.37, n.3, p.e114-20. Mar, 2010.

MORI, Y., et al. Angiotensin II receptor blockers downsize adipocytes in spontaneously type 2 diabetic rats with visceral fat obesity. Am J Hypertens, v.20, n.4, p.431-6. Apr, 2007.

MORTON, J. J., et al. Persistent hypertension following inhibition of nitric oxide formation in the young Wistar rat: role of renin and vascular hypertrophy. J Hypertens, v.11, n.10, p.1083-8. Oct, 1993.

MOSTARDA, C., et al. Baroreflex sensitivity impairment is associated with cardiac diastolic dysfunction in rats. J Card Fail, v.17, n.6, p.519-25. Jun, 2011.

MUNTZEL, M. S., et al. Mechanisms of insulin action on sympathetic nerve activity. Clin Exp Hypertens, v.17, n.1-2, p.39-50. Jan-Feb, 1995.

NAVAR, L. G., et al. Renal responses to AT1 receptor blockade. Am J Hypertens, v.13, n.1 Pt 2, p.45S54S. Jan, 2000.

OMS. World Health Statistics. Itália: World Health Organization 2013.

OSBORN, J. W. \& S. K. ENGLAND. Normalization of arterial pressure after barodenervation: role of pressure natriuresis. Am J Physiol, v.259, n.6 Pt 2, p.R1172-80. Dec, 1990.

PAGANI, M., et al. Power spectral analysis of heart rate and arterial pressure variabilities as a marker of sympatho-vagal interaction in man and conscious dog. Circ Res, v.59, n.2, p.178-93. Aug, 1986.

PAGANI, M., et al. Spectral analysis of heart rate variability in the assessment of autonomic diabetic neuropathy. J Auton Nerv Syst, v.23, n.2, p.143-53. Aug, 1988.

PARATI, G., et al. Assessment and interpretation of blood pressure variability in a clinical setting. Blood Press. Apr 29, 2013. 
RAO, S. S., et al. Ability of the normal human small intestine to absorb fructose: evaluation by breath testing. Clin Gastroenterol Hepatol, v.5, n.8, p.959-63. Aug, 2007.

RICHELSEN, B. Sugar-sweetened beverages and cardio-metabolic disease risks. Curr Opin Clin Nutr Metab Care. Apr 25, 2013.

ROCCHINI, A. P., et al. Insulin and renal sodium retention in obese adolescents. Hypertension, v.14, n.4, p.367-74. Oct, 1989.

ROCCHINI, A. P., et al. Clonidine prevents insulin resistance and hypertension in obese dogs. Hypertension, v.33, n.1 Pt 2, p.548-53. Jan, 1999.

ROVERE, M. T. L., et al. Baroreflex sensitivity and heart-rate variability in prediction of total cardiac mortality after myocardial infarction. The Lancet, v.351, n.9101, p.478-484, 1998.

SENADOR, D., et al. Effects of restricted fructose access on body weight and blood pressure circadian rhythms. Exp Diabetes Res, v.2012, p.459087, 2012.

SHADE, R. E., et al. Cardiovascular and neuroendocrine responses to baroreceptor denervation in baboons. Am J Physiol, v.258, n.4 Pt 2, p.R930-8. Apr, 1990.

SHINOZAKI, K., et al. Evidence for a causal role of the renin-angiotensin system in vascular dysfunction associated with insulin resistance. Hypertension, v.43, n.2, p.255-62. Feb, 2004.

SILVA, R. J., et al. Simvastatin-induced cardiac autonomic control improvement in fructose-fed female rats. Clinics (Sao Paulo), v.66, n.10, p.1793-6, 2011.

SOARES, P. P., et al. Effects of rat sinoaortic denervation on the vagal responsiveness and expression of muscarinic acetylcholine receptors. J Cardiovasc Pharmacol, v.47, n.3, p.331-6. Mar, 2006.

STANHOPE, K. L., et al. A dose-response study of consuming high-fructose corn syrup-sweetened beverages on lipid/lipoprotein risk factors for cardiovascular disease in young adults. Am J Clin Nutr, v.101, n.6, p.1144-54. Jun, 2015.

SUZUKI, M., et al. Effect of an insulin sensitizer, pioglitazone, on hypertension in fructose-drinking rats. Jpn J Pharmacol, v.74, n.4, p.297-302. Aug, 1997.

TAKAGI, M., et al. Responsiveness of insulin-induced cardiac sympathetic nerve activation associates with blood pressure regulation in diabetics. Am J Physiol Endocrinol Metab, v.284, n.5, p.E1022-6. May, 2003. 
TAPPY, L. \& K. A. LE. Metabolic effects of fructose and the worldwide increase in obesity. Physiol Rev, v.90, n.1, p.23-46. Jan, 2010.

THOREN, P. Efferent renal nerve traffic in the spontaneously hypertensive rat. Clin Exp Hypertens A, v.9 Suppl 1, p.259-79, 1987.

THORP, A. A. \& M. P. SCHLAICH. Relevance of Sympathetic Nervous System Activation in Obesity and Metabolic Syndrome. J Diabetes Res, v.2015, p.341583, 2015.

TRACEY, K. J. Reflex control of immunity. Nat Rev Immunol, v.9, n.6, p.418-28. Jun, 2009.

TRAN, L. T., et al. Selective alpha(1)-adrenoceptor blockade prevents fructose-induced hypertension. Mol Cell Biochem, v.392, n.1-2, p.205-11. Jul, 2014.

TRAN, L. T., et al. The fructose-fed rat: a review on the mechanisms of fructose-induced insulin resistance and hypertension. Mol Cell Biochem, v.332, n.1-2, p.145-59. Dec, 2009.

VANDEN BERGHE, W., et al. Signal transduction by tumor necrosis factor and gene regulation of the inflammatory cytokine interleukin-6. Biochem Pharmacol, v.60, n.8, p.1185-95. Oct 15, 2000.

VASQUEZ, E. C. \& E. M. KRIEGER. Sequence of tachycardia following baroreceptor denervation in the rat. Oxford University Press, p.413-417, 1980.

- Decreased chronotropic responses to adrenergic stimulation following sinoaortic denervation in the rat. Braz J Med Biol Res, v.15, n.6, p.377-87. Dec, 1982.

VERMA, S., et al. Sympathectomy prevents fructose-induced hyperinsulinemia and hypertension. Eur J Pharmacol, v.373, n.2-3, p.R1-4. Jun 4, 1999.

WALLIN, B. G. Human sympathetic nerve activity and blood pressure regulation. Clin Exp Hypertens A, v.11 Suppl 1, p.91-101, 1989.

YOSHIDA, K., et al. Effects of exercise training on glomerular structure in fructose-fed spontaneously hypertensive rats. Hypertens Res, v.26, n.11, p.907-14. Nov, 2003.

ZANESCO, A., et al. Sino-aortic denervation causes right atrial beta adrenoceptor down-regulation. J Pharmacol Exp Ther, v.280, n.2, p.677-85. Feb, 1997. 